Aus der Abteilung Transfusionsmedizin

(PD Dr. med. J. Riggert)

der Medizinischen Fakultät der Universität Göttingen

\title{
UVC als Alternative zur 8-MOP / UVA-Behandlung in der extrakorporalen Photopherese
}

\author{
INAUGURAL-DISSERTATION \\ zur Erlangung des Doktorgrades \\ der Medizinischen Fakultät der \\ Georg-August-Universität zu Göttingen \\ vorgelegt von \\ Carla Barrios-Bussmann \\ aus \\ Mannheim
}

Göttingen 2019 
Dekan:

\section{Betreuungsausschuss}

Betreuer:

Ko-Betreuer:

\section{Prüfungskomission}

Referent:

Ko-Referent/in:

Drittreferent/in:

Datum der mündlichen Prüfung
Prof. Dr. rer. nat. H. K. Kroemer

Prof. Dr. med. T. J. Legler

Prof. Dr. med. I. Bogeski

Prof. Dr. med. T. J. Legler

Prof. Dr. med. I. Bogeski

Prof. Dr. med. M. Oppermann

10.03.2020 
Hiermit erkläre ich, die Dissertation mit dem Titel „UVC als Alternative zur

8-MOP/UVA-Behandlung in der extrakorporalen Photopherese“ eigenständig angefertigt und keine anderen als die von mir angegebenen Quellen und Hilfsmittel verwendet zu haben.

Göttingen, den 14.06.2019 


\section{Inhaltsverzeichnis}

Abbildungsverzeichnis....................................................................

Tabellenverzeichnis...........................................................................

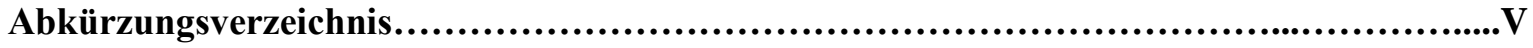

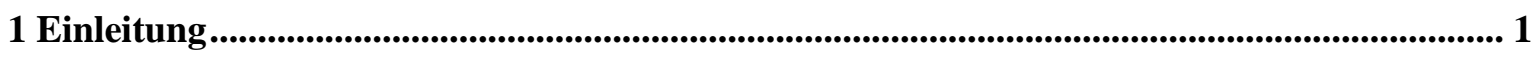

1.1 Hämatopoetische Stammzelltransplantation (HSCT) ....................................................... 1

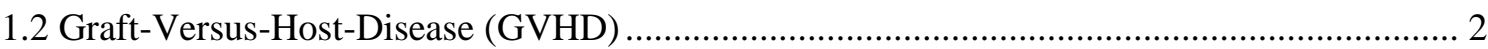

1.2.1 Therapieoptionen der Graft-Versus-Host-Disease ........................................................... 5

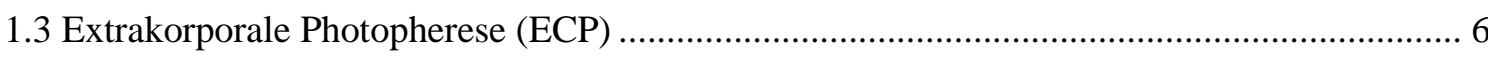

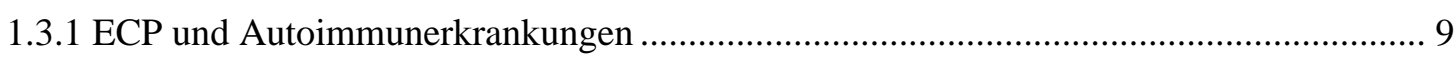

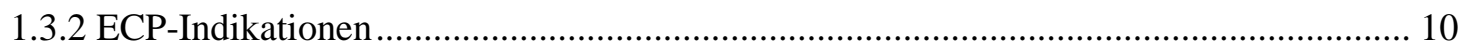

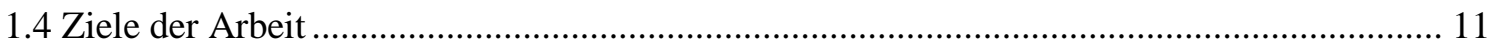

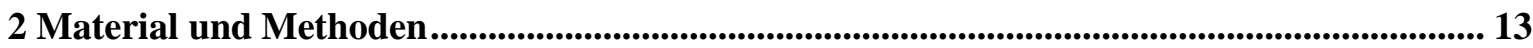

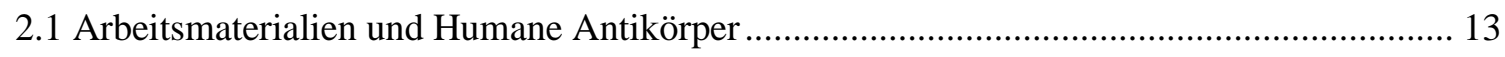

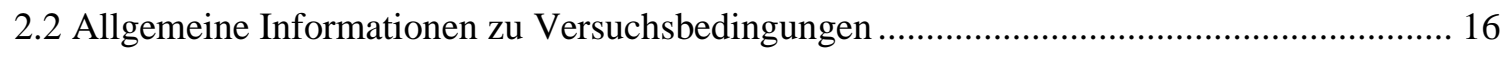

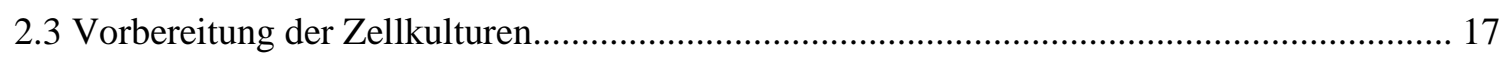

2.3.1 Gewinnung mononukleärer Zellen (MNZ) aus Buffy-Coats ....................................... 17

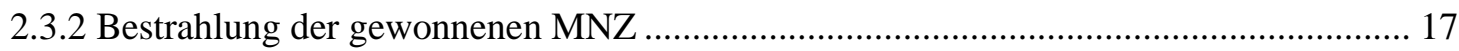

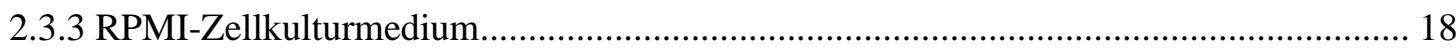

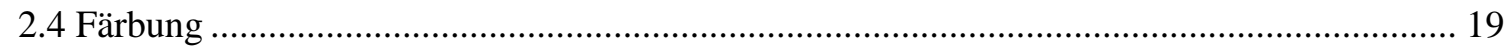

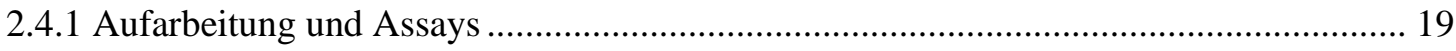

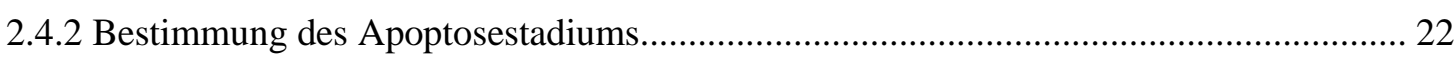

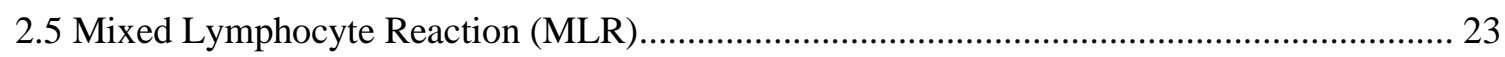

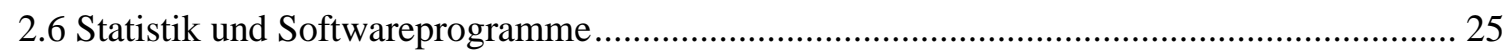

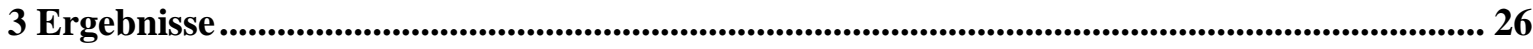

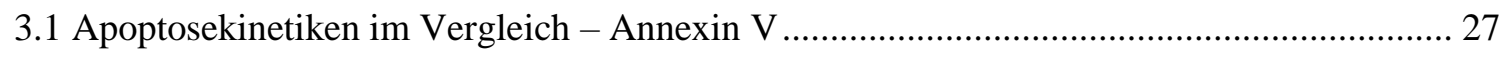

3.1.1 Apoptosekinetik von CD3+ CD4+ Effektorzellen ................................................. 28

3.1.2 Apoptosekinetik von CD3+ CD8+ Effektorzellen ....................................................... 30

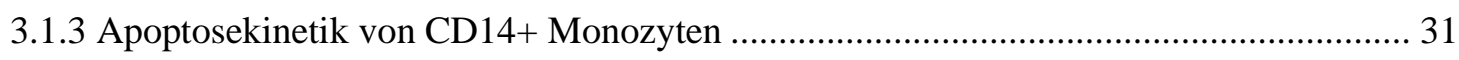

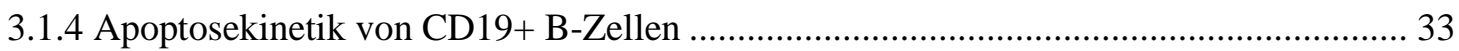

3.1.5 Apoptosekinetik von CD4+ CD39+ regulatorischen T-Zellen ....................................... 34

3.1.6 Apoptosekinetik von CD3+ CD56+ NKT-Zellen ........................................................ 35

3.1.7 Apoptosekinetik von CD3- CD56+ NK-Zellen ............................................................ 37

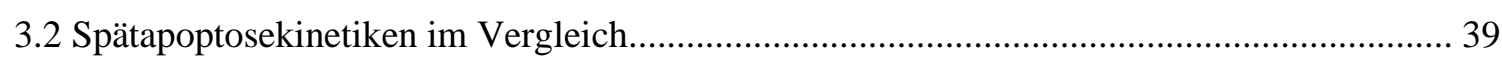

3.2.1 Kinetik der Spätapoptose bei CD3+ CD4+ Effektorzellen ............................................. 39

3.2.2 Kinetik der Spätapoptose bei CD3+ CD8+ Effektorzellen ............................................ 40 
3.2.3 Kinetik der Spätapoptose bei CD14+ Monozyten.......................................................... 41

3.2.4 Kinetik der Spätapoptose bei CD19+ B-Zellen............................................................ 42

3.2.5 Kinetik der Spätapoptose bei CD4+ CD39+ regulatorischen T-Zellen .......................... 43

3.2.6 Kinetik der Spätapoptose bei CD3+ CD56+ NKT-Zellen .............................................. 44

3.2.7 Kinetik der Spätapoptose bei CD3- CD56+ NK-Zellen................................................... 45

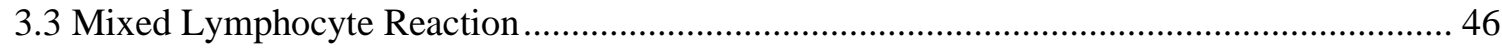

3.3.1 MLR und Aktivitätsmessung bei CD4+ T-Helferzellen ............................................... 47

3.3.2 MLR und Aktivitätsmessung bei CD8+ zytotoxischen T-Zellen..................................... 47

3.3.3 MLR und Aktivitätsmessung bei CD3- CD56+ NK-Zellen............................................ 48

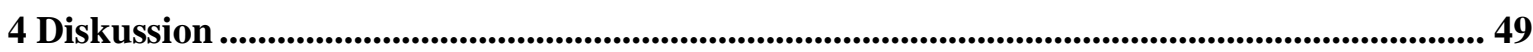

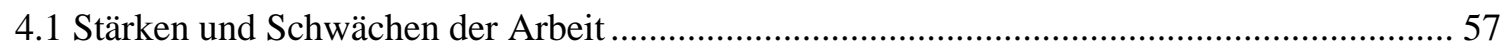

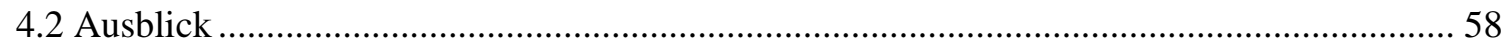

5 Zusammenfassung................................................................................................................................ 59

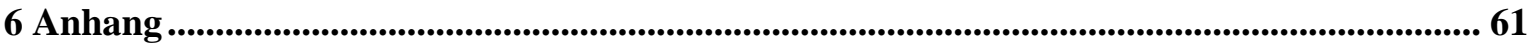

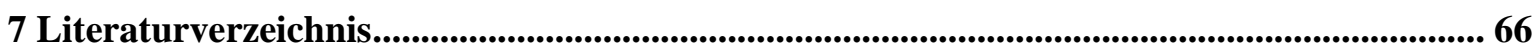




\section{Abbildungsverzeichnis}

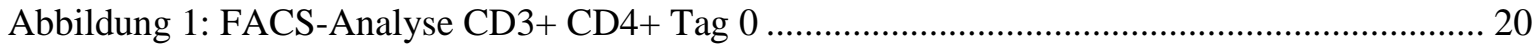

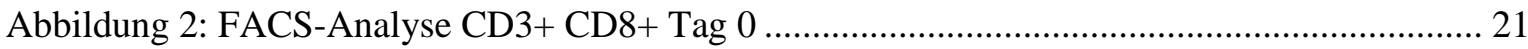

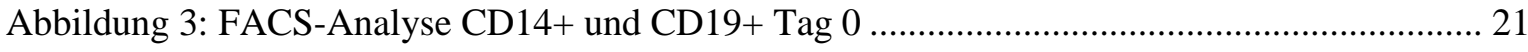

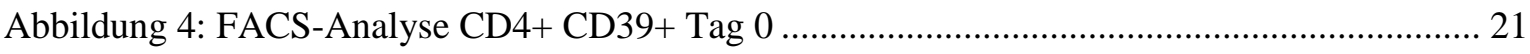

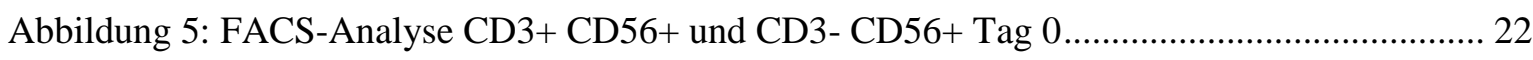

Abbildung 6: Wirkungsverlust durch Plastikoberfläche. UVA und UVC im Vergleich .................. 27

Abbildung 7: CD3+ CD4+ Apoptosekinetiken im Vergleich ............................................................ 29

Abbildung 8: CD3+ CD8+ Apoptosekinetiken im Vergleich ............................................................. 30

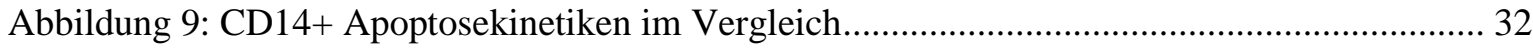

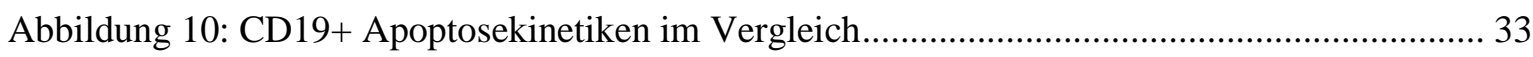

Abbildung 11: CD4+ CD39+ Apoptosekinetiken im Vergleich....................................................... 34

Abbildung 12: CD3+ CD56+ Apoptosekinetiken im Vergleich.......................................................... 36

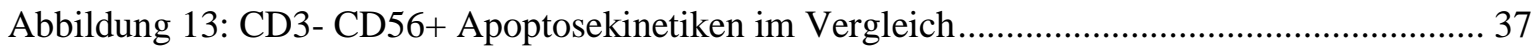

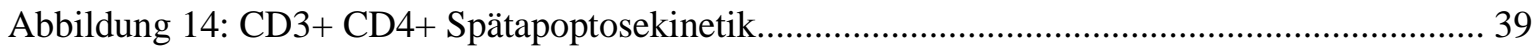

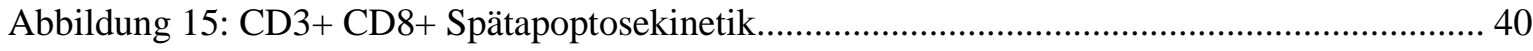

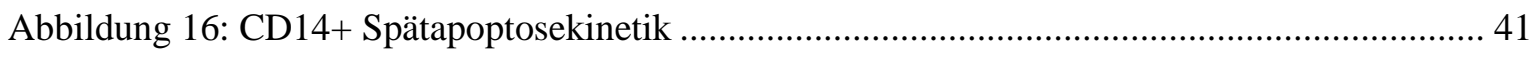

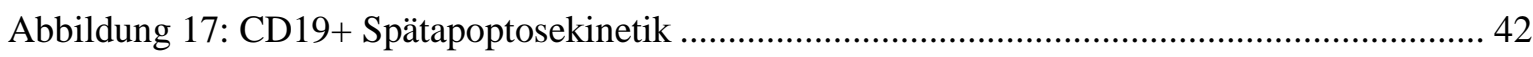

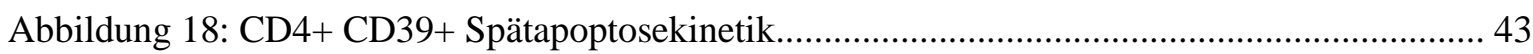

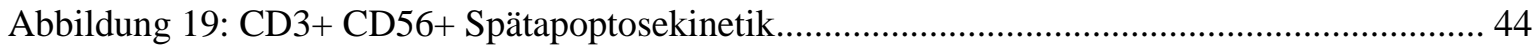

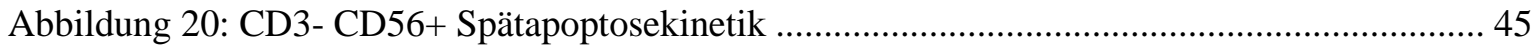

Abbildung 21: MLR: Anteil der CD4 CD69 bzw. CD4 CD154 doppelt-positiven Zellen an allen MNZ der Probe ......................................................................................... 47

Abbildung 22: MLR: Anteil der CD8 CD69 bzw. CD8 CD137 doppelt-positiven Zellen an allen MNZ der Probe ....................................................................................... 47

Abbildung 23: MLR: Anteil CD3- CD56+ CD69+ Zellen an allen MNZ der Probe ....................... 48 


\section{Tabellenverzeichnis}

Tabelle 1: Organstadien der akuten GVHD nach Harris et al. 2016 …........................................... 4

Tabelle 2: Gesamtschweregrade der akuten GVHD, mod. nach Glucksberg (1974)......................... 4

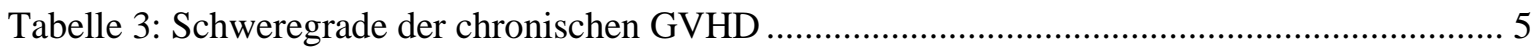

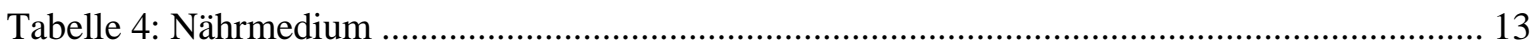

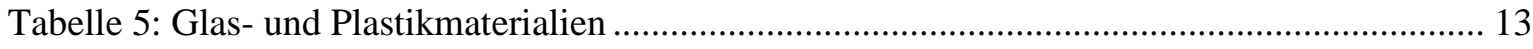

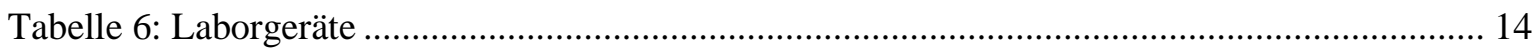

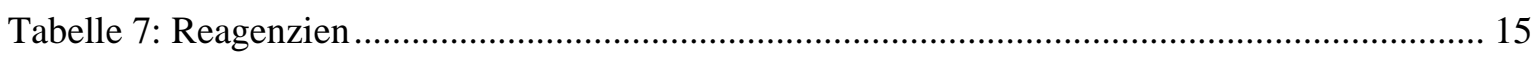

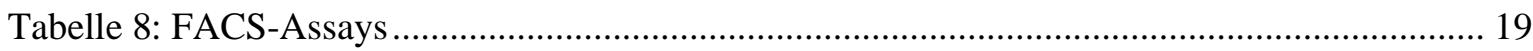

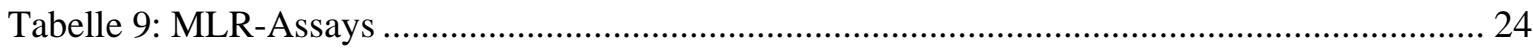

Tabelle 10: UVC $2 \mathrm{~J} / \mathrm{cm}^{2}$ und UVC $6 \mathrm{~J} / \mathrm{cm}^{2}$, Mittelwerte \pm STABW und p-Werte ................ Fehler! Textmarke nicht definiert.

Tabelle 11: UVA $2 \mathrm{~J} / \mathrm{cm}^{2}$ und UVC $6 \mathrm{~J} / \mathrm{cm}^{2}$, Mittelwerte \pm STABW und $\mathrm{p}$-Werte Fehler! Textmarke nicht definiert.

Tabelle 12: Spätapoptose - UVC $2 \mathrm{~J} / \mathrm{cm}^{2}$ und UVC $6 \mathrm{~J} / \mathrm{cm}^{2}$, Mittelwerte \pm STABW und p-Werte Fehler! Textmarke nicht definiert.

Tabelle 13: Spätapoptose - UVA $2 \mathrm{~J} / \mathrm{cm}^{2}$ und UVC $6 \mathrm{~J} / \mathrm{cm}^{2}$, Mittelwerte \pm STABW und p-Werte Fehler! Textmarke nicht definiert. 


\section{Abkürzungsverzeichnis}

8-MOP

aGVHD

aHSCT

AID

ALL

AML

APC

ATG

$\mathrm{BC}$

BAFF

BSA

CD

cGVHD

CLL

CML

CTCL

ECP

FDA

GMP

GVHD

GVL/GVM

HSCT

MHC

MMF

MNZ

$\mathrm{MPh}$

MS

MTX

PBS

RA

SLE

STABW

TRM
8-Methoxypsoralen

acute graft-versus-host disease

allogeneic hematopoietic stem cell transplantation

autoimmune disease

akute lymphatische Leukämie

akute myeloische Leukämie

antigen presenting cells

Antithymozytenglobulin

Buffy Coat

B-cell-activating factor

bovine serum albumin

cluster of differentiation

chronic graft-versus-host disease

chronische lymphatische Leukämie

chronische myeloische Leukämie

cutaneous T-cell lymphoma

extracorporeal photopheresis

Food \& Drug Administration (USA)

good manifacturing practice

graft-versus-host disease

graft-versus-leukemia / graft-versus-malignancy

hematopoietic stem cell transplantation

major histocompatibility complex

Mycophenolat mofetil

mononukleäre Zellen

Makrophagen

Multiple Sklerose

Methotrexat

phosphate-buffered saline

rheumatoide Arthritis

systemischer Lupus Erythematodes

Standardabweichung

transplantationsassoziierte Mortalität 


\section{Einleitung}

\subsection{Hämatopoetische Stammzelltransplantation (HSCT)}

Die Gewebetransplantation zum Ersatz erkrankter Organe stellt im Allgemeinen heutzutage eine wichtige und etablierte Behandlungsmethode dar, wobei die zuerst entwickelte und bis heute noch am häufigsten verwendete Transplantation die Bluttransfusion ist (Murphy und Weaver 2018).

Die hämatopoetische Stammzelltransplantation (HSCT) gehört heute zur Standardbehandlung zahlreicher hämatologischer und genetischer Erkrankungen und kann als eine besondere Art der Bluttransfusion verstanden werden. Seit der ersten erfolgreichen Durchführung einer HSCT im Jahr 1968 durch Dr. Robert A. Good wurden mehr als eine Million HSCT weltweit durchgeführt (Huang und Chao 2017).

Die Transfusion hämatopoetischer Stammzellen ist eine erfolgreich angewendete Therapie, vor allem bei malignen Erkrankungen des hämatopoetischen Systems wie einigen Tumoren, die sich aus Vorläuferzellen im Knochenmark ableiten, zum Beispiel bei bestimmten Leukämieformen (AML, ALL, CML, CLL) und einigen Lymphomen. Sie findet meist dann Verwendung, wenn andere Therapieansätze refraktär verlaufen.

Grundprinzip der Transfusion gesunder hämatopoetischer Stammzellen ist das Ersetzen eines erkrankten, entarteten blutbildenden Systems durch Spenderstammzellen, die sowohl die Wiederbesiedlung des Empfängerknochenmarks mit den drei myeloischen Zelllinien (Erythrozyten, Granulozyten / Makrophagen, Thrombozyten) gewährleisten als auch den Aufbau eines funktionierenden Immunsystems ermöglichen (Thomas et al. 1975). Je nach Erkrankung und äußeren Umständen stehen unterschiedliche Transplantationsvorgänge zur Verfügung.

Bei der autologen HSCT werden den Patienten eigene, möglichst in kompletter Remission gewonnene Stammzellen entnommen und zu einem späteren Zeitpunkt retransfundiert. Die syngene HSCT beschreibt die Transplantation hämatopoetischer Stammzellen zwischen genetisch identischen Individuen (eineiige Zwillinge), wobei dies genetisch der autologen SCT entspricht. 
Die in der Praxis am häufigsten angewandte Form ist jedoch die allogene HSCT. Hierbei entstammen die zu transplantierenden Zellen einem gesunden Fremdspender und können somit die erkrankte Hämatopoese der Patienten ersetzen.

Um die Chancen auf ein erfolgreiches Engraftment der Spenderzellen und die Regeneration des neuen Blut- und Immunsystems auf ein Maximum zu erhöhen, wird das Empfängerknochenmark vor der eigentlichen Transplantation konditioniert. Dies wird entweder durch alleinige Hochdosis-Chemotherapie, alleinige Strahlentherapie oder durch kombinierte Radio-Chemotherapie erreicht. Ziele der Konditionierung sind die Immunsuppression, die Myeloablation und die Eradikation verbleibender Tumorzellen im Empfängerknochenmark.

Adaptive Immunreaktionen gegen Proteine des Empfängergewebes und vice versa sind allerdings in den meisten Fällen das größte Hindernis für eine erfolgreiche Übertragung.

\subsection{Graft-Versus-Host Disease (GVHD)}

Die Graft-versus-Host Erkrankung (GVHD) gehört zu den Hauptkomplikationen der allogenen Stammzelltransplantation (aHSCT) (Ferrara et al. 2009; Martínez-Laperche et al. 2018) und tritt in ihrer akuten Form bei ca. $70 \%$ (Kitko und Levine 2015) und in ihrer chronischen Form bei ca. 40-60 \% der Patienten auf (Sung und Chao 2013).

Sie stellt eine protrahiert einsetzende Abstoßungsreaktion dar und ist in ihrer chronischen Form, auch wenn Tendenzen rückläufig sind, die Haupttodesursache bei zunächst Überlebenden der aHSCT mit einer Gesamtmortalität von 40-60 \% (Huang und Chao 2017; Martínez-Laperche et al. 2018). Todesursache sind hauptsächlich opportunistische Infektionen, die aus der therapiebedingten immunsuppressiven Situation resultieren. Die GVHD kann als ein Syndrom verstanden werden, das u. a. aus einer Inkompatibilität der Minor- und Majorhistokompatibilitätskomplexe zwischen Donor und Empfänger resultiert (Coghill et al. 2011; Martínez-Laperche et al. 2018). Auf pathophysiologischer Ebene im Entstehungsprozess der GVHD erkennen reife T-Zellen des Spenders, die das allogene Knochenmark kontaminieren und durch aktivierte Empfänger-APCs induziert werden, Gewebe des Empfängers als fremd an und rufen Entzündungsreaktionen hervor (MartínezLaperche et al. 2018). 
Das klinische Bild der GVHD, ausgelöst durch die oben beschriebenen, im Transplantat enthaltenen T-Zellen, führt zur Reduktion der Lebensqualität und erhöht die Morbidität und Mortalitätswahrscheinlichkeit der Patienten. Eine Depletion der T-Zellen im Spenderknochenmark vor der Transplantation wäre demnach eine denkbare Präventionsmaßnahme, würde allerdings außer Acht lassen, dass ein großer Teil der therapeutischen Wirkung der HSCT bei einer Leukämie auf einem graft-versus-malignancy-Effekt (GVM) beruht, der maßgeblich durch jene T-Zellen vermittelt wird (Huang und Chao 2017; Ferrara et al. 2009; Choi und Reddy 2010). T-Zellen aus dem Spenderblut erkennen hierbei Nebenhistokompatibilitätsantigene oder tumorspezifische Antigene des Empfängers, die von übrig gebliebenen Leukämiezellen exprimiert werden, und können diese abtöten.

Die Unterteilung der Erkrankung in eine akute (aGVHD) und eine chronische GVHD (cGVHD) wurde ursprünglich anhand des Zeitpunktes der Krankheitsentwicklung festgemacht, wobei sich die Klassifikation an der zeitlichen Grenze von 100 Tagen orientiert. Treten Symptome innerhalb der ersten 100 Tage nach aHSCT auf, wird die Abstoßungsreaktion als ,akut“ beschrieben, wohingegen die Entwicklung von Symptomen nach 100 Tagen nach der Transplantation als ,chronisch“ bewertet wird. Diese strikte Aufteilung wurde zunehmend verlassen, da gezeigt werden konnte, dass sowohl klinische Äußerungen der cGVHD auch in den ersten 100 Tagen auftreten, als auch solche der aGVHD noch nach 100 Tagen in Kombination mit typischen Symptomen der chronischen Abstoßungsreaktion auftreten können. Dies führte $\mathrm{zu}$ einer Neuentwicklung von Definitionen, die sich mehr an klinischen Symptomen orientieren (Garnett et al. 2013). Besonders gravierend tritt die Erkrankung auf, wenn Hauptantigene der MHC-Klasse I oder II nicht zusammenpassen. Darüber hinaus korreliert das Auftreten einer aGVHD in besonderem Maß mit einer niedrigen Anzahl an regulatorischen T-Zellen bei allogen transplantierten Patienten (Rezvani et al. 2006). Weitere Risikofaktoren für die Entwicklung der Abstoßungsreaktion bestehen im steigenden Alter der Empfänger, in vorangegangenen Donor-Alloimmunisationen (oder vorangegangenen aGVHD) und der Art der GVHDProphylaxe. Die am häufigsten betroffenen Organe sind die Haut, der Darm und die Leber. Die Einteilung der Organstadien und die sich daraus ergebenden Gesamtschweregrade der aGVHD sind aus Tabelle eins und zwei ersichtlich. 
Tabelle 1: Organstadien der akuten GVHD nach Harris et al. (2016)

\begin{tabular}{|c|c|c|c|}
\hline & Haut & Leber & Darm \\
\hline Schweregrad & Klinisches Bild & Bilirubin mg/dl & Diarrhoe ml/Tag (d) \\
\hline 0 & Kein Erythem / Exanthem & Bilirubin $<2 \mathrm{mg} / \mathrm{dl}$ & $\begin{array}{l}\text { Diarrhoe }<500 \mathrm{ml} / \mathrm{d} \\
\text { Kinder: }<10 \mathrm{ml} / \mathrm{kg} / \mathrm{d} \\
\text { oder }<4 \mathrm{x} / \mathrm{d}\end{array}$ \\
\hline 1 & $\begin{array}{l}\text { Makulopapulöses } \\
\text { Exanthem } \\
<25 \% \text { der } \mathrm{KO}^{1}\end{array}$ & Bilirubin $2-3 \mathrm{mg} / \mathrm{dl}$ & $\begin{array}{l}\text { Diarrhoe } 500-1000 \mathrm{ml} / \mathrm{d}^{2} \\
\text { Oder 3-6 Stühle/d oder } \\
\text { Übelkeit }^{3} \\
\text { Kinder: } 10-19,9 \mathrm{ml} / \mathrm{kg} / \mathrm{d} \\
\text { oder < 4-6x/ d }\end{array}$ \\
\hline 2 & $\begin{array}{l}\text { Makulopapulöses } \\
\text { Exanthem } \\
25-50 \% \text { der } \mathrm{KO}\end{array}$ & Bilirubin $3-6 \mathrm{mg} / \mathrm{dl}$ & $\begin{array}{l}\text { Diarrhoe } 1000-1500 \mathrm{ml} / \mathrm{d} \\
\text { oder }>6 \text { Stühle } / \mathrm{d} \\
\text { Kinder: } 20-30 \mathrm{ml} / \mathrm{kg} / \mathrm{d} \\
\text { oder } 7-10 \mathrm{x} / \mathrm{d}\end{array}$ \\
\hline 3 & Generalisiertes Exanthem & Bilirubin 6-15 mg/dl & $\begin{array}{l}\text { Diarrhoe }>1500 \mathrm{ml} / \mathrm{d} \\
\text { Kinder: }>30 \mathrm{ml} / \mathrm{kg} / \mathrm{d} \\
\text { oder }>10 \mathrm{x} / \mathrm{d}\end{array}$ \\
\hline 4 & $\begin{array}{l}\text { Generalisiertes Exanthem } \\
\text { mit Blasenbildung und } \\
\text { Desquamation } \\
>5 \% \mathrm{KO}\end{array}$ & Bilirubin $>15 \mathrm{mg} / \mathrm{dl}$ & $\begin{array}{l}\text { „akuter Bauch“ mit oder ohne } \\
\text { paralytischem Ileus } \\
\text { blutige Diarrhoe }\end{array}$ \\
\hline
\end{tabular}

${ }^{1}$ Berechnung der Körperoberfläche (KO) nach 9er-Regelung

${ }^{2}$ Stuhlmenge pro Stuhlgang min. 100-200 ml

${ }^{3}$ anhaltende Übelkeit mit histologischen Zeichen einer GVHD in Magen- oder Duodenalbiopsie

Tabelle 2: Gesamtschweregrade der akuten GVHD, mod. nach Glucksberg et al. (1974)

\begin{tabular}{|c|c|c|c|c|}
\hline Grad & Haut & Leber & Darm & Karnofsky (\%) \\
\hline 0 & 0 & 0 & 0 & 100 \\
\hline \multirow[t]{2}{*}{ I (leicht) } & $1-2$ & 0 & 0 & \multirow[t]{2}{*}{80} \\
\hline & 0 & $0-1$ & $0-1$ & \\
\hline \multirow[t]{3}{*}{ II (moderat) } & 0 & 1 & 1 & \multirow[t]{3}{*}{70} \\
\hline & $1-3$ & $0-1$ & $0-1$ & \\
\hline & 3 & 0 & 0 & \\
\hline III (schwer) & $2-3$ & $2-3$ & $2-3$ & 60 \\
\hline IV (lebensbedrohlich) & $2-4$ & $2-4$ & $2-4$ & $40-50$ \\
\hline
\end{tabular}

Es wird angenommen, dass die Gradeinteilung nach Glucksberg et al. mit der transplantationsassoziierten Mortalität (TRM) korreliert. Bei Grad 0 beträgt die TRM bis zu $28 \%$, bei Grad IV bis zu $92 \%$ (Garnett et al. 2013).

Die Klinik der cGVHD zeigt demgegenüber mehr Ähnlichkeiten mit einer systemischen Autoimmunerkrankung. Sklerotische Haut- und Schleimhautveränderungen, Lungenbeteiligung, chronische Enteritiden oder chronische Leberdysfunktionen, die auf lange Sicht zur Fibrosierung der Organe führen, sind beschriebene Symptommanifestationen. Auch die 
Beteiligung von Muskeln, Faszien und Gelenken ist nicht selten. Die Beurteilung des Schweregrades der cGVHD, s. Tabelle drei, erfolgt im Gegensatz zur Einteilung der aGVHD nach den NIH-Konsensuskriterien aus dem Jahr 2005 sowie der Nachfolgekonferenz 2014 (Filipovich et al. 2005; Jagasia et al. 2015).

Tabelle 3: Schweregrade der chronischen GVHD nach NIH-Konsensus-Kriterien (2005, 2014)

\begin{tabular}{|l|l|l|l|}
\hline $\begin{array}{l}\text { Gesamt- } \\
\text { Schweregrad }\end{array}$ & mild & moderat & schwer \\
\hline $\begin{array}{l}\text { Zahl der betroffenen } \\
\text { Organe }\end{array}$ & $1-2$ & $>2$ & $>2$ \\
\hline $\begin{array}{l}\text { Schweregrad der } \\
\text { Organmanifestation }\end{array}$ & $\begin{array}{l}\text { mild } \\
\text { (außer Lunge) }\end{array}$ & $\begin{array}{l}\text { mild-moderat } \\
\text { (Lunge: nur mild) }\end{array}$ & $\begin{array}{l}\text { schwer } \\
\text { (Lunge: moderat-schwer) }\end{array}$ \\
\hline
\end{tabular}

Wie bei soliden Organtransplantationen kann auch eine GVHD im Zusammenhang mit Nebenhistokompatibilitätsantigenen auftreten. Eine begleitende Immunsuppression ist präventiv bei jeder Stammzelltransplantation obligatorisch.

\subsubsection{Therapieoptionen der Graft-Versus-Host-Disease}

Der Forschungsschwerpunkt des Transplantationsmanagements liegt in der Prävention der GVHD-Entwicklung. Prophylaktische Therapieregime haben die Funktionsuntüchtigkeit der Donor-T-Zellen zum Ziel. Einerseits kann dies immunmodulatorisch (z. B. mit Ciclosporin, MTX, Tacrolimus, MMF) versucht werden; eine andere präventive Maßnahme besteht darin, die reifen T-Zellen aus dem Transplantat des Spenders vor der Transplantation in vitro zu depletieren und im Zuge dessen auch die alloreaktiven T-Zellen zu entfernen. Dies kann mit monoklonalen (z. B. Alemtuzumab, anti CD-52) oder polyklonalen Antikörpern wie dem Antithymozytenglobulin (ATG) gelingen. Das Verhindern einer GVHD hat Vorteile für die Patienten, gleichzeitig steigt jedoch das Risiko für ein Leukämierezidiv, da durch die Depletion der Spender-T-Zellen auch der erwünschte GVMEffekt vermindert wird oder ausbleibt.

Treten Symptome einer Abstoßungsreaktion auf, stellt die systemische Immunsuppression mit Glukokortikoiden bei akuter oder chronischer GVHD die Basis der First-Line-Therapie. Bekannte Nebenwirkungen wie Osteoporose, Hyperglykämien und die Entstehung von Diabetes Mellitus oder das Risiko für die Entwicklung eines Magenulkus erfordern eine wachsame Balance zwischen Gesundheitsgewinn und Erkrankungs- bzw. Komplikations- 
risiko, was oft in einer Dosisreduktion resultiert. Pilz- und Virusinfektionen sind häufige Therapiekomplikationen, eine antiinfektiöse Begleitmedikation ist dementsprechend empfohlen.

Bleibt eine Verbesserung der Symptome aus oder verschlechtert sich die Klinik der Patienten unter der Therapie, kommt in solchen steroidrefraktären Situationen die Second-LineTherapie zur Anwendung. Dies ist bei bis zu 40 \% der Fälle einer aGVHD notwendig (Kitko und Levine 2015).

Neben weiteren chemischen Pharmaka ist bei beiden Formen der GVHD die extrakorporale Photopherese (ECP) als mögliche Zweitlinientherapie aufgeführt, für die es aktuell allerdings noch keine Arzneimittelzulassung in dieser Indikation gibt. Der Einsatz erfolgt deswegen noch fast ausschließlich im Off-Label-Bereich (Taverna et al. 2015). Dennoch wird die ECP-Bestrahlungstherapie in der Behandlung von Patienten mit GVHD bereits seit Jahren weltweit in den renommiertesten Zentren routinemäßig mit bezeichnendem Erfolg durchgeführt. Sie wird von zahlreichen hochrangigen, wissenschaftlichen Institutionen als eine effiziente Behandlung der GVHD empfohlen, und es gibt erste Stimmen, die die Meinung vertreten, die ECP-Therapie könnte aufgrund der effektiven Wirkung, die sie besonders bei kutanen Ausprägungen hat, zunehmend die immunsuppressiven Behandlungsregime ablösen (Richet et al. 2018).

\subsection{Extrakorporale Photopherese (ECP)}

Das therapeutische Verfahren der extrakorporalen Photopherese (ECP) ist, so wie es heute verwendet wird, ein vergleichsweise junges Therapieverfahren, das 1988 (Marshall 2006) erstmalig in den USA für die Therapie des kutanen T-Zell-Lymphoms zugelassen wurde (US Food and Drug Administration, FDA). Heute wird es für diese Indikation weltweit in mehr als 350 Zentren durchgeführt (Ventura et al. 2018). Die generelle Idee der Verwendung ultravioletter Strahlung zur Behandlung von Erkrankungen ist jedoch in keiner Weise eine Erfindung aus jüngster Zeit.

Mitte des 19. Jahrhunderts war unter dem Begriff „Heliotherapie“ eine Sonnenlichttherapie bekannt, die auch zur Behandlung der tuberkulösen Arthritis empfohlen wurde (Wu et al. 2016). Im Jahr 1877 beschrieben Downes et.al (Wu et al. 2016), dass Sonnenlicht bakterizide Wirkung zu haben schien und das Immunsystem stimuliere, und in den 1940er-1950er Jahren wurde UV-Strahlung bereits therapeutisch bei zahlreichen unterschiedlichen 
Erkrankungen eingesetzt, wie beispielsweise zur Behandlung der Sepsis, der Pneumonie oder der Tuberkulose (Wu et al. 2016). Im Zuge der Entdeckung und Weiterentwicklung der Antibiotika geriet diese Art der minimal-invasiven Therapie in der zweiten Hälfte des zwanzigsten Jahrhunderts jedoch ins Abseits der Aufmerksamkeit und war schnell nicht mehr Gegenstand damaliger Forschung (Wu et al. 2016).

Durch vermehrtes Auftreten multiresistenter Keime in den vergangenen Jahren, die inzwischen nicht mehr hinreichend durch gängige Antibiotika behandelt werden können, ist es heute von enormer Wichtigkeit, erneut verstärkt in die Forschung ultravioletter Strahlung und deren immunmodulatorische Effekte als eine mögliche, alternative Behandlungsmethode von Infektionen zu investieren. Andernfalls könnte sich die Menschheit in naher Zukunft erneut mit einem seit rund einem Jahrhundert behoben geglaubten Problem tödlich verlaufender Wund- und postoperativer Infektionen konfrontiert sehen (Bush et al. 2011). Die Abtötung auch antibiotikaresistenter Keime und die vermutete Abwesenheit von Resistenzentwicklungen gegen UV-Radiation macht die Lichttherapie und insbesondere die UVC-Strahlung mit ihrem bekannten keimtötenden Potenzial zu einem attraktiven Forschungsgegenstand (Yin et al. 2013).

Während reine ultraviolette Strahlung in den oben beschriebenen Beispielen und Anwendungsgebieten immunstimulierend wirkt, weist das Therapieprinzip der ECP einen immunmodulatorischen Effekt auf, wobei Immunmodulation im Sinne einer erforderlichen Anpassung an die entsprechend vorliegende Immunsituation verstanden wird. Im GVHDSetting bewirkt die ECP eine Immuntoleranz, um das Engraftment der Donorstammzellen zu unterstützen. Im Rahmen der CTCL-Behandlung hingegen, wirkt die ECP-Therapie immunstimulierend.

Obwohl die ECP-Behandlung seit mehr als dreißig Jahren im klinischen Einsatz ist, sind die molekularen Wirkmechanismen noch nicht gänzlich verstanden. Grundhypothese der ECPWirkung ist jedoch die Induktion von Apoptose in Leukozyten, deren Reinfusion mit nachfolgender Phagozytose durch APCs und der Switch der APC-Aktivität in Richtung Immunmodulation (Chen et al. 2015). Außerdem werden sowohl ein Anstieg antiinflammatorischer und eine Abnahme proinflammatorischer Zytokine als auch eine Produktion antigen-spezifischer Tregs als weitere Schlüsselmechanismen beschrieben (Ward 2011).

Die Praxis der ECP-Prozedur lässt sich in drei Schritte unterteilen: Leukapherese, Photoaktivierung und Reinfusion. Die Dauer einer ECP-Behandlung beträgt, abhängig vom 
eingesetzten Apheresegerät, zwischen drei und sechs Stunden, wobei die Behandlung meist an zwei aufeinanderfolgenden Tagen erfolgt. Vollblut der Patienten wird hierfür durch einen meist peripher liegenden, großlumigen venösen Zugang gewonnen. Im deutschsprachigen Raum werden bevorzugt das Inline-Aphereseverfahren UVAR XTS System (Therakos ${ }^{\mathrm{TM}}$, Europe, Ascot, UK) und das Offline-Verfahren von Macopharma verwendet. Beim InlineVerfahren erfolgt die Photoaktivierung während der Leukapherese im Zellseparator, der zuvor mit einem DNA-Interkalator bestückt wurde. Beim Offline-Verfahren wird das Leukapheresat in einen Bestrahlungsbeutel überführt, ein DNA-Interkalator zugesetzt und anschließend mit UVA bestrahlt.

Sowohl beim Inline-Verfahren als auch beim Offline-Verfahren wird der heute chemisch hergestellte DNA-Interkalator 8-Methoxypsoralen (8-MOP) als sterile Lösung zugegeben, z. B. Uvadex® [Methoxsalen], $20 \mu \mathrm{g} / \mathrm{ml}$, Therakos Europe, Ascot, UK (Schiller et al. 2011). Ursprünglich ist 8-MOP ein natürliches Extrakt von Pflanzen der Gruppe der Psoralene und fand in der Behandlung der Hautkrankheit Vitiligo bereits im alten Ägypten Verwendung (Marshall 2006). Im Rahmen der ECP-Behandlung wird die 8-MOP-Lösung nicht unter sterilen Bedingungen in den Behandlungsbeutel injiziert. 8-MOP hat photosensibilisierende Eigenschaften, bewirkt nach Aktivierung durch UVA-Strahlung (315-380 nm) Zellmembranschäden, DNA-Doppelstrangbrüche und führt durch eine erfolgreiche Photoaktivierung der Zellen und der Bindung zahlreicher zytosolischer Proteine anschließend zur Apoptose. 8-MOP entfaltet seine toxische Wirkung ausschließlich unter dem Einfluss von UVA-Strahlung (Marshall 2006). Nach Beendigung der Bestrahlungszeit treten keine weiteren DNA-Strangbrüche mehr auf (Heshmati 2003). Die Bestrahlung erfolgt in einer Photoaktivierungskammer, die von oben und unten mit UVA-Lampen ausgestattet ist.

Nach dem Konzept der Hormesis ist die Bestrahlung von ca. 5-15\% der peripheren Leukozyten für ein erfolgreiches Therapieergebnis ausreichend (Gorgun et al. 2002). Weltweit beträgt die Standarddosis $2 \mathrm{~J} / \mathrm{cm}^{2}$ und bewirkt durch das photosensibilisierende 8MOP die Entstehung von DNA-Doppelstrangbrüchen durch DNA-crosslinking, die nach Versagen zellinterner Reparaturmechanismen zum therapeutisch erwünschten programmierten Zelltod führen. Am Ende der Photoaktivierungszeit - nach Induktion der Apoptose - werden die behandelten Blutbestandteile den Patienten zurückinfundiert.

Nach Reinfusion werden die apoptotischen Leukozyten zeitnah von Antigenpräsentierenden-Zellen (APCs) phagozytiert und somit aus der peripheren Blutbahn entfernt. 
Dieser Vorgang der Phagozytose von apoptotischen Lymphozyten durch unreife dendritische Zellen mit anschließendem Reifungsprozess und Präsentation von antigenen Peptiden wird von Edelson et al. als Transimmunisierung bezeichnet (Schiller et al. 2011; Girardi et al. 2006). Transimmunisierung, d. h. der Transfers von Tumorantigenen / Autoantigenen $\mathrm{zu}$ neuen, differenzierenden dendritischen Zellen, induziert u. a. durch entsprechende Zytokinproduktionen, beispielsweise IL-10, die Entwicklung regulatorischer T-Zellen (Tregs) (Schiller et al. 2011). Tregs sind wahrscheinlich in der Lage, autoimmun reagierende T-Zellen bei einer GVHD oder die CD4+ Tumorzellen des Sézary-Syndroms zu supprimieren. Die Modulation der regulatorischen T-Zellen, die Veränderung des Zytokinprofils mit der Wiederherstellung eines Th1/Th2-Gleichgewichts und der Normalisierung des CD4/CD8-Quotienten scheinen eine Schlüsselrolle im therapeutischen Wirkmechanismus der ECP zu spielen (Kuzmina et al. 2015).

Ein Vorteil der ECP gegenüber der alternativen, herkömmlichen Glucocorticoidtherapie ist die Möglichkeit der Reduktion medikamentöser Immunsuppression durch das Wirkprinzip der Immunmodulation bzw. durch die spezifische Induktion von Immuntoleranz (Chen et al. 2015).

Es gibt keine Berichte zu signifikanten therapiebedingten Infektionsanstiegen oder sekundären Folgeerkrankungen. Der Graft-versus-Leukemia-Effekt bleibt unbeeinträchtigt (Chen et al. 2015) und auch Komplikationen wie dem Tumorlyse-Syndrom wird durch behutsame, sukzessive Apoptoseinduktion begegnet (Edelson 2014).

Die gute Verträglichkeit bei wenig Nebenwirkungen führt zu großer Patientenzufriedenheit und seltenen Therapieabbrüchen (Edelson 1989; Christensen and Heald 1991; Oliven und Shechter 2001).

\subsubsection{ECP und Autoimmunerkrankungen}

In einer wissenschaftlichen Metaanalyse über 65 Publikationen, die sich mit ECPErfahrungsberichten in der Anwendung bei Autoimmunerkrankungen (AID) befassen, beschreiben Kuzmina et al. (Kuzmina et al. 2015) drei Erklärungshypothesen für einen eventuellen Therapieerfolg.

Als Autoimmunität wird eine Immunreaktion gegen körpereigenes Gewebe bezeichnet, die aus dem Verlust immunologischer Toleranz resultiert. Versagen Selektionsmechanismen im 
Knochenmark, in der Milz, in Lymphknoten oder im Thymus über autoreaktive B- und/ oder T-Zellen, kann Fremdes von Körpereigenem nicht mehr differenziert werden und eigene Gewebe werden vom Immunsystem angegriffen.

Es besteht der beschriebene Verdacht (Kuzmina et al. 2015), dass auch eine unzureichende Beseitigung von apoptotischem Material möglicherweise einen Beitrag zur Entwicklung von Autoimmunerkrankungen leistet. Da festzustehen scheint, dass es unter dem Einfluss der ECP zu einer Differenzierung der Monozyten hin zu dendritischen Zellen kommt, die, charakterisiert durch das Oberflächenmolekül CD36, zur Phagozytose befähigt sind, beschreiben Kuzmina et al (Kuzmina et al. 2015) dieses Phänomen als eine Arbeitshypothese für eine mögliche klinische Anwendbarkeit der ECP bei AIDs.

Außerdem seien B-Zellen unter anderem durch die Produktion von autoreaktiven Antikörpern bekannte Mediatoren der Autoimmunität, der wiederum durch den supprimierenden bzw. normalisierenden Effekt der ECP auf B-Zellen und den B-SurvivalFactor (BAFF) begegnet werden könne.

Als weitere Möglichkeit für die Wirkungsweise der ECP-Therapie auf AID führt die oben genannte Berichtanalyse den therapiebedingten Anstieg der Tregs auf, denn laut diversen Berichten (Kuzmina et al. 2015) sei ein niedriger Spiegel an letzteren in mehreren AID, wie beispielsweise DM1, SLE und RA festgestellt worden. Forschungsgegenstand der zusammengefassten Publikationen waren AID wie die atopische Dermatitis, die systemische Sklerose, SLE, MS, RA und andere.

\subsubsection{ECP-Indikationen}

Seit der Erstzulassung der ECP-Therapie durch die FDA im Jahr 1988 (Marshall 2006), damals für das fortgeschrittene CTCL, hat sich das Indikationsspektrum auf andere Krankheitsbilder, auch außerhalb des dermatologischen Anwendungsbereichs, erweitert. Hauptsächlich betrifft das in Deutschland die steroidrefraktäre akute und chronische GVHD (Lorenz et al. 2015; Gorgun et al. 2002), aber auch die systemische Sklerodermie und die Behandlung von Abstoßungsreaktionen nach soliden Organtransplantationen, vor allem von Herz und Lunge (Lorenz et al. 2015). 


\subsection{Ziele der Arbeit}

Die GVHD zählt zu den häufigsten Komplikationen nach einer aHSCT, insbesondere innerhalb der ersten sechs Monate nach Therapie. In dieser Arbeit wird sie als Beispielindikation für eine ECP-Therapie aufgeführt, da sie deutschlandweit die dafür häufigste Indikation darstellt. Die GVHD ist ein signifikanter Grund für den Mortalitätsanstieg nach aHSCT. Sie führt dazu, dass der Versuch einer allogenen Stammzelltransplantation, welche in den meisten Fällen aufgrund therapierefraktärer Chemo- oder Radiotherapieansätze die letzte potenziell kurative Therapiemöglichkeit darstellt, nicht erfolgreich verläuft, sondern Patienten versterben.

Standardmäßig wird die GVHD mit einer Hochdosis-Steroidtherapie behandelt, wobei eine starke Immunsuppression mit dem hohen Risiko für opportunistische Infektionen wissend in Kauf genommen wird. Verläuft die medikamentöse First-Line-Therapie jedoch steroidrefraktär - oder abhängig, wird inzwischen weltweit die ECP als Second-LineTherapie eingesetzt (Schiller et al. 2011). Diese wird nach internationalen Standards mit UVA-Strahlung bei einer Dosis von $2 \mathrm{~J} / \mathrm{cm}^{2}$ und mit dem DNA-Interkalator 8-MOP durchgeführt. Die Wellenlänge der UVA-Strahlung (315 nm-380 nm) erlaubt ein Durchdringen bis auf Dermisniveau, ist jedoch energetisch nicht ausreichend stark, um die therapeutisch notwenige Apoptose in den bestrahlten MNZ zu induzieren. Aus diesem Grund ist die etablierte ECP-Therapie unter UVA-Strahlung auf das heute chemisch hergestellte 8-Methoxypsoralen angewiesen. Das manuelle Injizieren des DNA-Interkalators in den geschlossenen Behandlungsbeutel birgt jedoch ein potenzielles Kontaminationsrisiko. Ein bis dahin in sich geschlossenes, steriles System wird erforderlicherweise aufgebrochen und gerät in unmittelbaren Kontakt mit der direkten Umgebung.

Dementsprechend stellte sich die Frage, ob es durch die Verwendung einer energetisch stärkeren Strahlung wie UVC (100 nm-280 nm), die ohne zusätzliches Medikament zu den therapeutisch erforderlichen DNA-Strangbrüchen führt, möglich ist, die Öffnung des Systems durch eine manuelle Injektion in den Behandlungsbeutel zu vermeiden und somit das Risiko für Kontaminationen mit Bakterien und Pilzen zu minimieren.

Anhand vergleichender Experimente wurden in der vorliegenden Arbeit die jeweiligen Wirkungen von UVA und UVC auf die Kinetik und die absoluten Werte des Zelltods unterschiedlicher Leukozytensubpopulationen einander gegenübergestellt. 
Ziel der Arbeit war es, die Intensität und Zeitdauer der UVC-Bestrahlung so einzustellen, dass das Apoptosemuster und die Apoptosekinetik der konventionellen 8-MOP / UVABestrahlungstherapie entspricht und diese so im besten Fall austauschbar wäre. 


\section{Material und Methoden}

\subsection{Arbeitsmaterialien und Humane Antikörper}

Die nachfolgenden tabellarischen Aufstellungen geben eine Übersicht über alle in der vorliegenden Arbeit verwendeten Arbeitsmaterialien und humanen Antikörper. Die in diesem Projekt verwendeten Buffy-Coats wurden aus Vollblutspenden der Abteilung Transfusionsmedizin der Universitätsmedizin Göttingen nach Einwilligung der Spender gewonnen. Sie stellten Restmaterial dar, das für eine Thrombozytenproduktion nicht benötigt wurde. Vor Durchführung der Versuche wurde ein Ethikantrag gestellt und ein positives Votum eingeholt.

(Ethik-Komission der Universitätsmedizin Göttingen, Antragsnummer 26/9/17)

Tabelle 4: Nährmedium

\begin{tabular}{|l|l|l|}
\hline Bezeichnung & Material & Hersteller \\
\hline RPMI-Medium & RPMI-Medium 1640 (1X) & Gibco, Thermo Fischer \\
& + GlutaMAX ${ }^{\mathrm{TM}}$-I mit 10\% & Scientific \\
& Fetal Bovine Serum (FBS) & \\
& und 1\% & \\
& Pencillin/Streptomycin & \\
& (PenStrep) & \\
\hline
\end{tabular}

Tabelle 5: Glas- und Plastikmaterialien

\begin{tabular}{|l|l|l|}
\hline Bezeichnung & Material & Hersteller \\
\hline FACS-Röhrchen & $\begin{array}{l}\text { FACS-Röhrchen 5 ml } \\
\text { Polystyrene } \\
\text { Round-Bottom-Tube }\end{array}$ & Falcon, Durham (USA) \\
\hline Zählkammer & $\begin{array}{l}\text { Neubauer-improved } \\
\text { Zählkammer Assistent }{ }^{\circledR}\end{array}$ & $\begin{array}{l}\text { Glaswarenfabrik Karl } \\
\text { Hecht, Sondheim v.d. Rhön }\end{array}$ \\
\hline Eppendorfgefäß & $\begin{array}{l}\text { Eppendorf Safe-Lock-Tubes } \\
1,5 \mathrm{ml}, 2 \mathrm{ml}\end{array}$ & $\begin{array}{l}\text { Eppendorf, Wesseling- } \\
\text { Berzdorf }\end{array}$ \\
\hline Pipettenspitzen & Pipettenspitzen 10/20 $\mu 1$, & Starlab International \\
& $100 \mu 1,1000 \mu 1$ TipOne & GmbH, Hamburg \\
& Filter Tip $($ sterile) & \\
\hline Pipettenspitzen & Pipettenspitzen 2,5 $\mu \mathrm{l}$ & Biozym, Hessisch \\
& SafeSeal-Tips ${ }^{\circledR}$ Premium & Oldendorf \\
\hline 50ml-Reaktionsgefäß & Falcon Tube, konischer & Greiner Bio-One GmbH, \\
& Boden, Cellstar ${ }^{\circledR}$, steril & Frickenhausen \\
\hline
\end{tabular}




\begin{tabular}{|l|l|l|}
\hline Zellkulturflaschen & $\begin{array}{l}\text { Zellkulturflasche, 250 ml, } \\
75 \mathrm{~cm}^{2}, \text { Cellstar®, steril }\end{array}$ & $\begin{array}{l}\text { Greiner Bio-One GmbH, } \\
\text { Frickenhausen }\end{array}$ \\
\hline Zellkulturflaschen & $\begin{array}{l}\text { Zellkulturflasche, } 25 \mathrm{~cm}^{2}, \\
\text { Cellstar®, CytoOne, steril }\end{array}$ & $\begin{array}{l}\text { Starlab International } \\
\text { GmbH, Hamburg }\end{array}$ \\
\hline Pasteurpipetten aus Glas & $\begin{array}{l}\text { Pasteurpipetten approx. } \\
150 \mathrm{~mm}\end{array}$ & $\begin{array}{l}\text { Brand GmbH\&Co. KG, } \\
\text { Wertheim }\end{array}$ \\
\hline Pipettierhilfe & Serologische Pipette $10 \mathrm{ml}$ & $\begin{array}{l}\text { Sarstedt AG\&Co, } \\
\text { Nümbrecht }\end{array}$ \\
\hline Pipettierhilfe & Serologische Pipette $25 \mathrm{ml}$ & $\begin{array}{l}\text { Sarstedt AG\&Co, } \\
\text { Nümbrecht }\end{array}$ \\
\hline
\end{tabular}

Tabelle 6: Laborgeräte

\begin{tabular}{|l|l|l|}
\hline Bezeichnung & Gerät & Hersteller \\
\hline Zentrifuge & Rotanta 46 RS & Hettich, Tuttingen \\
\hline Sterilbank & $\begin{array}{l}\text { Microflow biological saftey } \\
\text { cabinet } \text { MDH 51426 }\end{array}$ & $\begin{array}{l}\text { Nalge Nunc International, } \\
\text { (USA/Dänemark) }\end{array}$ \\
\hline Vakuumpumpe & LABOPORT® N86 KN.18 & $\begin{array}{l}\text { KNF, Village-Neuf } \\
\text { (Frankreich) }\end{array}$ \\
\hline Durchlichtmikroskop & Lichtmikroskop Axiostar & Zeiss, Jena \\
\hline Inverses Auflichtmikroskop & $\begin{array}{l}\text { Lichtmikroskop } \\
\text { Axiovert 25 }\end{array}$ & Zeiss, Jena \\
\hline Elektrisches Pipettiergerät & pipetus ${ }^{\circledR}$ & $\begin{array}{l}\text { Hirschmann Laborgeräte, } \\
\text { Eberstadt }\end{array}$ \\
\hline Vortexer & Vortexer Typ VF2 & $\begin{array}{l}\text { IKA®-WerkeGmbH\&Co. } \\
\text { KG, Staufen }\end{array}$ \\
\hline Durchflusszytometer & $\begin{array}{l}\text { BD FACSCanto } \\
\text { Cytometer } \text { II Flow }\end{array}$ & $\begin{array}{l}\text { BD Biosciences, Frankling } \\
\text { Lakes (USA) }\end{array}$ \\
\hline Computer & $\begin{array}{l}\text { PC mit folgeneder } \\
\text { Software: BD FACSDiva }\end{array}$ & $\begin{array}{l}\text { BD Biosciences, Franklin } \\
\text { Lakes (USA) }\end{array}$ \\
\hline Inkubator & Inkubator HERA cell @ & Heraeus, Hanau \\
\hline UVA-Bestrahlungsgerät & $\begin{array}{l}\text { Crosslinker } \\
\text { Cat.No.3100300 }\end{array}$ & $\begin{array}{l}\text { Herolab GmbH, } \\
\text { Wiesloch }\end{array}$ \\
\hline UVC-Bestrahlungsgerät & $\begin{array}{l}\text { Crosslinker } \\
\text { Cat.No.3100100 }\end{array}$ & $\begin{array}{l}\text { Herolab GmbH, } \\
\text { Wiesloch }\end{array}$ \\
\hline Gammastrahler & Gamma Bestrahlungsanlage & $\begin{array}{l}\text { STS Steuerungstechnik \& } \\
\text { Strahlenschutz GmbH } \\
\text { Braunschweig }\end{array}$ \\
\hline & & \\
\hline
\end{tabular}


Tabelle 7: Reagenzien

\begin{tabular}{|c|c|c|}
\hline Bezeichnung & Substanz & Hersteller \\
\hline 7-AAD-Lösung & $\begin{array}{l}\text { 7-AAD Viability Staining } \\
\text { Solution }\end{array}$ & $\begin{array}{l}\text { BioLegend, San Diego } \\
\text { (USA) }\end{array}$ \\
\hline Annexin V-Puffer & Annexin V Binding Buffer & $\begin{array}{l}\text { BioLegend, San Diego } \\
\text { (USA) }\end{array}$ \\
\hline Annexin V-Antikörper & $\begin{array}{l}\text { Anti-human Annexin V } \\
\text { Pacific Blue }\end{array}$ & $\begin{array}{l}\text { BioLegend, San Diego } \\
\text { (USA) }\end{array}$ \\
\hline CD3-Antikörper & $\begin{array}{l}\text { Pacific Blue }{ }^{\mathrm{TM}} \text { anti-human } \\
\text { CD3 } \\
\text { Clone: OKT3 }\end{array}$ & $\begin{array}{l}\text { BioLegend, San Diego } \\
\text { (USA) }\end{array}$ \\
\hline CD4-Antikörper & $\begin{array}{l}\text { PE anti-human CD4 } \\
\text { Clone: RPA-T4 }\end{array}$ & $\begin{array}{l}\text { BioLegend, San Diego } \\
\text { (USA) }\end{array}$ \\
\hline CD4-Antikörper & $\begin{array}{l}\text { Pacific Blue }{ }^{\mathrm{TM}} \text { anti-human } \\
\text { CD4 } \\
\text { Clone: RPA-T4 }\end{array}$ & $\begin{array}{l}\text { BioLegend, San Diego } \\
\text { (USA) }\end{array}$ \\
\hline CD4-Antikörper & $\begin{array}{l}\text { Alexa Fluor@488 } \\
\text { anti-human CD4 } \\
\text { Clone: RPA-T4 }\end{array}$ & $\begin{array}{l}\text { BioLegend, San Diego } \\
\text { (USA) }\end{array}$ \\
\hline CD8-Antikörper & $\begin{array}{l}\text { PE anti-human CD8 } \\
\text { Clone: SK1 }\end{array}$ & $\begin{array}{l}\text { BioLegend, San Diego } \\
\text { (USA) }\end{array}$ \\
\hline CD8-Antikörper & $\begin{array}{l}\text { Alexa Fluor®488 } \\
\text { anti-human CD8 } \\
\text { Clone: SK1 }\end{array}$ & BioLegend, San Diego \\
\hline CD14-Antikörper & $\begin{array}{l}\text { Pacific Blue }{ }^{\mathrm{TM}} \text { anti-human } \\
\text { CD14 } \\
\text { Clone: M5E2 }\end{array}$ & $\begin{array}{l}\text { BioLegend, San Diego } \\
\text { (USA) }\end{array}$ \\
\hline CD-19-Antikörper & $\begin{array}{l}\text { PE anti-human CD19 } \\
\text { Clone: HIB19 }\end{array}$ & $\begin{array}{l}\text { BioLegend, San Diego } \\
\text { (USA) }\end{array}$ \\
\hline CD56-Antikörper & $\begin{array}{l}\text { PE anti-human CD56 } \\
\text { (NCAM) } \\
\text { Clone: HCD56 }\end{array}$ & $\begin{array}{l}\text { BioLegend, San Diego } \\
\text { (USA) }\end{array}$ \\
\hline CD39-Antikörper & $\begin{array}{l}\text { PE anti-human CD39 } \\
\text { Clone: A1 }\end{array}$ & $\begin{array}{l}\text { BioLegend, San Diego } \\
\text { (USA) }\end{array}$ \\
\hline CD154-Antikörper & $\begin{array}{l}\text { PE anti-human CD154 } \\
\text { Clone: } 24-31\end{array}$ & $\begin{array}{l}\text { BioLegend, San Diego } \\
\text { (USA) }\end{array}$ \\
\hline CD69-Antikörper & $\begin{array}{l}\text { APC anti-human CD69 } \\
\text { Clone: FN50 }\end{array}$ & $\begin{array}{l}\text { BioLegend, San Diego } \\
\text { (USA) }\end{array}$ \\
\hline CD137-Antikörper & $\begin{array}{l}\text { PE anti-human CD137 } \\
\text { (4-1BB) } \\
\text { Clone: 4B4-1 }\end{array}$ & $\begin{array}{l}\text { BioLegend, San Diego } \\
\text { (USA) }\end{array}$ \\
\hline DNA-Interkalator & $\begin{array}{l}\text { Methoxypsoralen-Lösung } \\
0,02 \mathrm{mg} / \mathrm{ml}\end{array}$ & $\begin{array}{l}\text { Universitätsmedizin } \\
\text { Göttingen (Apotheke) } \\
\text { Deutschland }\end{array}$ \\
\hline
\end{tabular}




\begin{tabular}{|c|c|c|}
\hline Destilliertes Wasser & $\begin{array}{l}\text { Ampuwa® Spüllösung } \\
1000 \text { ml Plastipur® }\end{array}$ & Fresenius Kabi, Frankreich \\
\hline $\begin{array}{l}\text { Natriumcitrat- } \\
\text { Stammlösung }\end{array}$ & $\begin{array}{l}\text { 73,525 g Tri-Natriumcitrat- } \\
\text { Dihydrat in } 1 \text { Liter } \\
\text { destilliertem Wasser }\end{array}$ & Merck, KGaA, Darmstadt \\
\hline Antibiotikum & Penicillin / Streptomycin & Thermo-Fischer, Gibco \\
\hline MACS-Puffer & $\begin{array}{l}\text { autoMACS }{ }^{\circledR} \text { Running } \\
\text { Buffer, MACS Separation } \\
\text { Buffer }\end{array}$ & Miltenyi Biotec \\
\hline PBS & $\begin{array}{l}\text { PBS pH 7,4 (1X) } \\
\text { Phosphate Buffered Saline } \\
{[-] \mathrm{Cacl}_{2}} \\
{[-] \mathrm{MgCl}_{2}}\end{array}$ & $\begin{array}{l}\text { gibco®by life } \\
\text { technologies }^{\mathrm{TM}}\end{array}$ \\
\hline Trenn-Lösung & $\begin{array}{l}\text { Ficoll-Paque }{ }^{\mathrm{TM}} \text { PLUS } \\
\text { endotoxin tested } \\
(<0,12 \mathrm{EU} / \mathrm{ml})\end{array}$ & $\begin{array}{l}\text { GE Healthcare Bio- } \\
\text { Sciences AB, } \\
\text { Schweden }\end{array}$ \\
\hline Zytokinstimulation & Ionomycin $-2 \mu \mathrm{M}$ & $\begin{array}{l}\text { Sigma, Aldrich, St.Louis, } \\
\text { USA }\end{array}$ \\
\hline Zellaktivierung & $\begin{array}{l}\text { Phorbol Myristat Acetat } \\
\text { (PMA) }-40 \mathrm{ng} / \mathrm{ml}\end{array}$ & $\begin{array}{l}\text { Sigma, Aldrich, St.Louis, } \\
\text { USA }\end{array}$ \\
\hline
\end{tabular}

\subsection{Allgemeine Informationen zu Versuchsbedingungen}

Wenn im Folgenden nicht anders angegeben, wurden die beschriebenen Zentrifugationsschritte bei $20^{\circ} \mathrm{C}$ und einer Beschleunigung und Bremse von $\mathrm{R}=9$ durchgeführt. Die Inkubation der Zellen erfolgte bei $37^{\circ} \mathrm{C}$ und $5 \% \mathrm{CO}_{2}$ im Inkubator. Vor Einbringen von Materialien unter die Sterilbank wurden diese stets mit Ethanol desinfiziert. Das Absaugen von Überständen erfolgte mittels Vakuumpumpe und Glaspasteurpipette. Werden nachfolgend Zellzahlen angegeben oder diese als Bestandteil der Probenvorbereitung ermittelt, erfolgte dieser Schritt mit einem Durchlichtmikroskop unter Verwendung einer Neubauer-Zählkammer, wobei die Zelldichte stets mit dem inversen Auflichtmikroskop kontrolliert wurde. 


\subsection{Vorbereitung der Zellkulturen}

\subsubsection{Gewinnung mononukleärer Zellen (MNZ) aus Buffy-Coats}

Um die Auswirkung der UVC-Strahlung auf humane Leukozyten mit der bewährten Wirkung von 8-MOP / UVA-Strahlung in in vitro Experimenten vergleichend untersuchen zu können, wurden mononukleäre Zellen (MNZ) aus Buffy-Coats verwendet. Buffy-Coats entstehen durch die Auftrennung einer Vollblutspende und enthalten neben Leukozyten und Thrombozyten, die den Großteil ausmachen, eine Mischung verschiedener Zellarten. Für die nachfolgenden Versuche mussten die benötigten MNZ aus den Buffy-Coats isoliert werden.

Für die Isolierung der Leukozytenschicht wurde das Blut der einzelnen Buffy-Coats homogen vermengt und anschließend $25 \mathrm{ml}$ davon in ein $50 \mathrm{ml}$-Reaktionsgefäß gegeben. Des Weiteren wurde die Natriumcitrat-Stammlösung im Verhältnis 1:1 mit PBS gemischt, wodurch eine Natriumcitrat-PBS-Lösung entstand. Anschließend wurden $25 \mathrm{ml}$ dieser Natriumcitrat-PBS-Lösung zu dem Vollblut des Buffy-Coats in das $50 \mathrm{ml}$-Reaktionsgefäß hinzugegeben. Die erhaltene Lösung wird als Zellsuspension bezeichnet. Gleichzeitig wurden in ein weiteres $50 \mathrm{ml}$-Reaktionsgefäß $20 \mathrm{ml}$ Ficoll-Trennlösung gegeben und vorsichtig mit $30 \mathrm{ml}$ Zellsuspension überschichtet. Nach einer Zentrifugation bei Raumtemperatur $\left(20^{\circ} \mathrm{C}\right)$ mit 600 g für 30 min und einer Bremse $\mathrm{R}=0$ wurde zunächst die oben aufliegende Plasmaschicht mittels Glaspasteurpipette und Vakuumpumpe zu einem Großteil abgesaugt und 3-5 ml der darunterliegenden Leukozytenschicht in ein weiteres 50 ml-Reaktionsgefäß überführt. Anschließend wurden die extrahierten MNZ in einem dreifachen Volumen der hergestellten Natriumcitrat-PBS-Lösung resuspendiert und mit $200 \mathrm{~g}$ für zehn Minuten zentrifugiert. Der erhaltene Überstand wurde nach dem Zentrifugieren erneut abgesaugt. Das verbliebene Zellpellet wurde in $8 \mathrm{ml}$ NatriumcitratPBS-Lösung erneut resuspendiert und auch wieder mit $200 \mathrm{~g}$ für zehn Minuten zentrifugiert. Nach dem Absaugen des Überstandes wurde wiederum das erhaltene Zellpellet in $5 \mathrm{ml}$ PBS+BSA resuspendiert und in $25 \mathrm{~cm}^{2}$ große Zellkulturflaschen pipettiert.

\subsubsection{Bestrahlung der gewonnenen MNZ}

Im ersten Teil der Arbeit wurden die Zellen in den Kulturflaschen nach Zugabe von jeweils $50 \mu 1$ 8-Methoxypsoralen (8-MOP) mit UVA-Licht bestrahlt. Die Bestrahlungsdosis betrug entsprechend der international anerkannten Standardtherapie $2 \mathrm{~J} / \mathrm{cm}^{2}$. 
Im zweiten Teil der Arbeit wurden die Zellen ohne Zugabe von 8-MOP mit UVC-Licht bestrahlt. Hier betrug die Dosis zunächst in Anlehnung an die bewährte UVAStandardtherapie ebenfalls $2 \mathrm{~J} / \mathrm{cm}^{2}$. UVC-Licht wird jedoch durch die Plastikoberfläche der Kulturflaschen stärker absorbiert, weshalb höhere Dosen notwendig sind, um eine vergleichbare Dosisleistung an der Zelloberfläche zu erreichen. Mittels Messsonde wurde in repetitiven Versuchen der Verlust der beiden unterschiedlichen Strahlungen, UVA und UVC, durch die Plastikoberfläche ermittelt. Während UVA-Strahlung bei der Standardstrahlendosis von $2 \mathrm{~J} / \mathrm{cm}^{2}$ durch die Plastikoberfläche einen Verlust von $10 \%$ aufwies, wurde bei UVC-Strahlung und gleicher Strahlendosis ein Verlust von $70 \%$ gemessen. Im weiteren Verlauf des Projektes wurden die UVC-Bestrahlungsdosen infolgedessen auf $6 \mathrm{~J} / \mathrm{cm}^{2}$ erhöht, um die vergleichbare Dosisleistung bei UVA-Strahlung von $1,8 \mathrm{~J} / \mathrm{cm}^{2} \mathrm{zu}$ erreichen. Die Berechnungsgrundlage der Bestrahlungsdosis von UVC $6 \mathrm{~J} / \mathrm{cm}^{2}$ ist ersichtlich aus der Abbildung 6 in Kapitel 3.

Nach der Bestrahlung wurden die $5 \mathrm{ml}$-Zellen aus den Kulturflaschen zurück in ein $50 \mathrm{ml}-$ Reaktionsgefäß pipettiert und mit zehn Milliliter PBS+BSA aufgefüllt. Daraufhin erfolgte eine Zellzählung in einer Verdünnung von 1:10 in PBS+BSA-Lösung.

Nach Berechnung der Zellzahl wurde die entsprechende Millilitermenge mit $350 \mathrm{~g}$ für zehn Minuten abzentrifugiert, der entstandene Überstand erneut abgesaugt und wiederum das erhaltene Zellpellet unter der Sterilbank in $4 \mathrm{ml}$ auf Raumtemperatur erwärmtes RPMIMedium resuspendiert.

Für eine Zeitreihe wurden jeweils 4 Zellkulturen à $10 \times 10^{6}$ Zellen angelegt, die an vier aufeinanderfolgenden Tagen verwendet wurden.

\subsubsection{RPMI-Zellkulturmedium}

Das Zellkulturmedium wurde stets unter sterilen Bedingungen und maximal für die Verwendung von drei Wochen hergestellt. Es setzt sich zusammen aus 450 ml RPMI 1640, $50 \mathrm{ml}$ Fetal Bovine Serum und $5 \mathrm{ml}$ Penicillin / Streptomycin. 


\subsection{Färbung}

\subsubsection{Aufarbeitung und Assays}

An vier aufeinanderfolgenden Tagen wurden die Lymphozytensubpopulationen gefärbt und gemessen. Mengenangaben sind aus der nachfolgenden Tabelle 8 ersichtlich. Ziel war es, die Apoptosekinetik im Verlauf von 96 Stunden zu untersuchen.

Zunächst wurden die Zellen aus den Zellkulturflaschen, die bei $37{ }^{\circ} \mathrm{C}$ und $5 \% \mathrm{CO}_{2} \mathrm{im}$ Inkubator aufbewahrt wurden, entnommen und in jeweils 50-ml-Reaktionsgefäße pipettiert. Im Anschluss daran wurden die Zellen in den Reaktionsgefäßen mit $350 \mathrm{~g}$ für zehn Minuten abzentrifugiert. Der entstandene Überstand wurde verworfen, die Zellpellets in je $800 \mu \mathrm{l}$ MACS-Puffer resuspendiert und dann à $100 \mu \mathrm{l}$ auf die FACS-Röhrchen verteilt, wobei in das Kontrollröhrchen $300 \mu$ l gegeben wurden.

Anschließend erfolgte die Zugabe der humanen Antikörper. Nach 15-minütiger Inkubation unter Lichtausschluss wurden die Proben in jedem Röhrchen mit je 2 ml MACS-Puffer aufgefüllt und erneut mit $350 \mathrm{~g}$ für 5 Minuten zentrifugiert. Daraufhin wurde jedes Zellpellet in $100 \mu \mathrm{l}$ Annexin V-Puffer resuspendiert und sowohl mit 2,5 $\mu \mathrm{l}$ Annexin V-Antikörper als auch mit $5 \mu 1$ 7-AAD-Antikörper ergänzt. Nach erneuter 15-minütiger Inkubationszeit unter Lichtausschluss wurden abschließend $400 \mu$ Annexin V-Puffer hinzugefügt.

Die hergestellten Proben konnten im darauffolgenden Schritt im Durchflusszytometer analysiert werden. Hier konnten sowohl der gesamte Apoptosegrad mittels Annexin V positiver Zellen ermittelt werden, als auch der Prozentanteil an Zellen davon, die sich bereits in Spätapoptose befanden und zusätzlich auch 7-AAD-positiv waren.

Tabelle 8: FACS-Assays

\begin{tabular}{|l|l|l|l|}
\hline Assay & Antikörper & Menge & Fluoreszenz \\
\hline & & & \\
\hline 1. & CD3 & $1,0 \mu \mathrm{l}$ & Pacific Blue \\
\hline CD4 T-Helper cells & CD4 & $0,75 \mu \mathrm{l}$ & PE \\
\hline & Annexin V & $2,5 \mu \mathrm{l}$ & FITC \\
\hline & $7-A A D$ & $5,0 \mu \mathrm{l}$ & \\
\hline & & & Pacific Blue \\
\hline 2. & CD3 & $1,0 \mu \mathrm{l}$ & PE \\
\hline CD8 Cytotoxic T cells & CD8 & $2,5 \mu \mathrm{l}$ & FITC \\
\hline & Annexin V & $2,5 \mu \mathrm{l}$ & \\
\hline & $7-A A D$ & $5,0 \mu \mathrm{l}$ & \\
\hline & & & \\
\hline
\end{tabular}




\begin{tabular}{|c|c|c|c|}
\hline 3. & CD14 & $5,0 \mu \mathrm{l}$ & Pacific Blue \\
\hline CD19 B cells & CD19 & $1,0 \mu \mathrm{l}$ & $\mathrm{PE}$ \\
\hline \multirow[t]{2}{*}{ CD14 Monocytes } & Annexin V & $2,5 \mu \mathrm{l}$ & FITC \\
\hline & 7-AAD & $5,0 \mu \mathrm{l}$ & \\
\hline 4. & CD3 & $1,0 \mu \mathrm{l}$ & Pacific Blue \\
\hline CD3- CD56+ NK cells & CD56 & $5,0 \mu \mathrm{l}$ & PE \\
\hline \multirow{2}{*}{$\begin{array}{l}\text { CD3+ CD56+ NKT } \\
\text { cells }\end{array}$} & Annexin V & $2,5 \mu \mathrm{l}$ & FITC \\
\hline & 7-AAD & $5,0 \mu \mathrm{l}$ & \\
\hline 5. & CD4 & $1,5 \mu \mathrm{l}$ & Pacific Blue \\
\hline Tregs & CD39 & $5,0 \mu \mathrm{l}$ & $\mathrm{PE}$ \\
\hline \multirow[t]{2}{*}{ TH17 cells } & Annexin V & $2,5 \mu \mathrm{l}$ & FITC \\
\hline & 7-AAD & $5,0 \mu \mathrm{l}$ & \\
\hline 6. & Unstained & & \\
\hline Control & & & \\
\hline
\end{tabular}

Die folgenden Abbildungen eins bis fünf zeigen repräsentative Beispielauszüge der FACSAnalyse zu jeder untersuchten Zellpopulation, jeweils an Tag null.

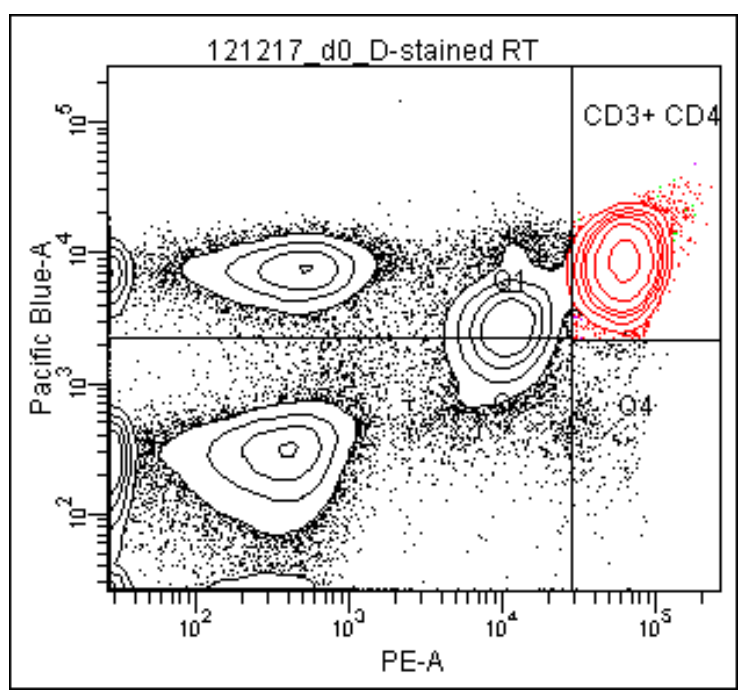

Abbildung 1: FACS-Analyse CD3+CD4+Tag 0 


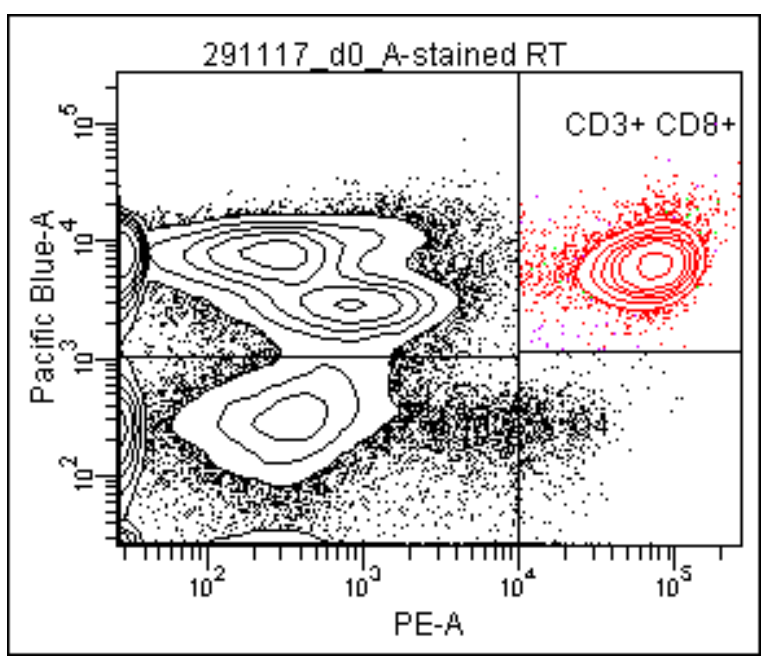

Abbildung 2: FACS-Analyse CD3+CD8+Tag 0

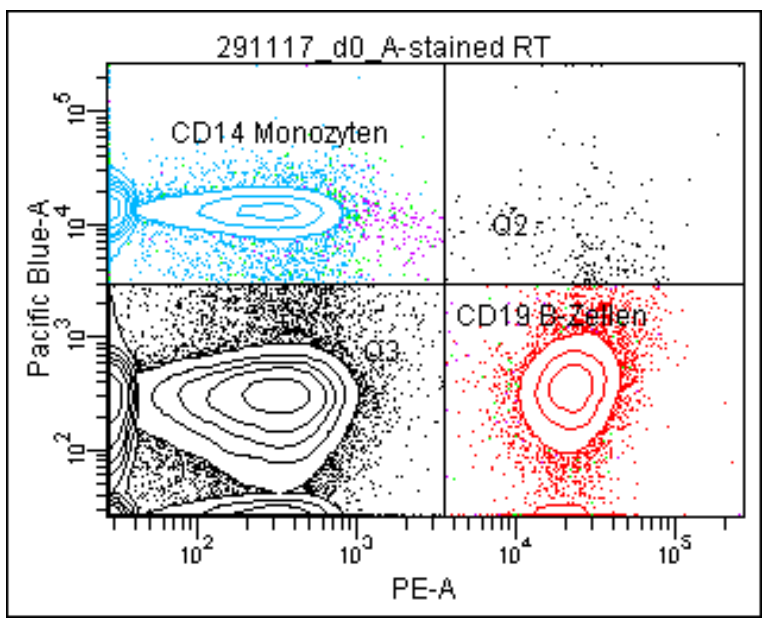

Abbildung 3: FACS-Analyse CD14+ und CD19+ Tag 0

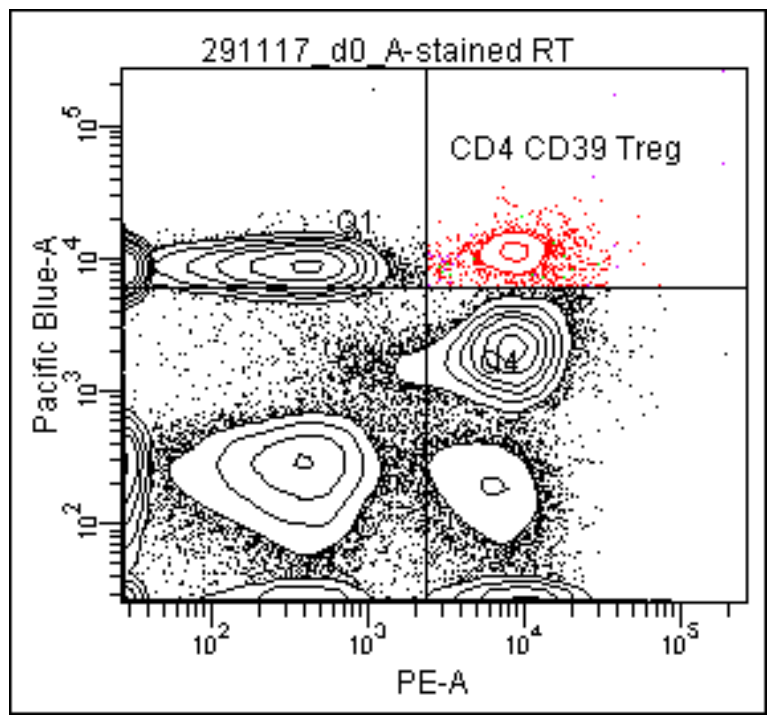

Abbildung 4: FACS-Analyse CD4+CD39+ Tag 0 


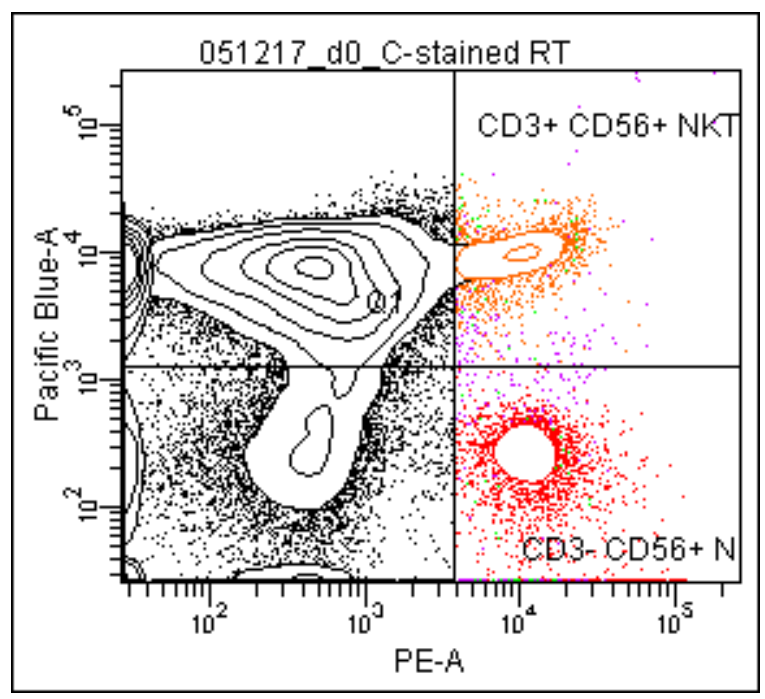

Abbildung 5: FACS-Analyse CD3+CD56+ und CD3-CD56+ Tag 0

\subsubsection{Bestimmung des Apoptosestadiums}

Die Farbstoffmarkierung zur Bestimmung der Apoptoserate der untersuchten MNZ wurde stets in einer Doppelfärbung unter Verwendung von Annexin V und 7-AAD durchgeführt. Intakte, physiologisch gesunde Zellen reagieren auf beide Färbungen negativ, frühapoptotische Zellen werden durch Annexin V detektiert, jedoch nicht durch 7-AAD. Spätapoptotische Zellen reagieren hingegen auf beide Färbungen positiv. Auch nekrotische Zellen reagieren positiv auf die Färbung mit Annexin V und 7-AAD.

\subsubsection{Annexin $V$}

Bei der Färbung mit einem Annexin V-Antikörper bindet dieser selektiv an negative Phospholipide (bzw. Phosphatidylserin), welche in vitalen Zellen in der inneren Schicht der Zellmembran zu finden sind. Im Rahmen der Apoptose geht die Asymmetrie der Zellmembran verloren. Phosphatidylserin ist dann auch verstärkt in der äußeren Schicht der Zellmembran exprimiert und kann somit mit Fluorochrom-markierten Annexin VAntikörpern sichtbar gemacht werden. Dadurch kann nach der Zellfärbung zwischen apoptotischen und vitalen Leukozyten unterschieden werden. 


\subsubsection{7-Aminoactinomycin}

Der Apoptosemarker 7-Aminoactinomycin (7-AAD) gehört zur Stoffklasse der Peptide und wird als Zellfarbstoff verwendet. Es färbt spezifisch avitale Zellen, die im Zuge des Zelltodes ihren asymmetrischen Zellmembranaufbau verlieren. Durch den Verlust der intakten Zellmembran kann 7-AAD in das Zellinnere gelangen, spezifisch zwischen Cytosin und Guanin die DNA interkalieren und deren Fluoreszenzeigenschaft verändern.

\subsection{Mixed Lymphocyte Reaction (MLR)}

Bei der GVHD erkennen Spender-T-Lymphozyten HLA-Antigene der antigenpräsentierenden Empfängerzellen, wodurch T-Zellen aktiviert werden und unter Sekretion proinflammatorischer Zytokine proliferieren. Diese Situation lässt sich in vitro mithilfe der Mixed Lymphocyte Reaction (MLR) konstruieren und wird als Nachweisverfahren von alloreaktiven T-Zellen verwendet, wenn z. B. bei der Auswahl von Knochenmarkspendern eine möglichst niedrige Alloreaktivität essenziell ist. Technisch gesehen handelt es sich bei der MLR um ein zelluläres ex vivo Immunoassay aus zwei genetisch unterschiedlichen Lymphozytenpopulationen, welches die T-Zell-Reaktionen auf äußere Stimuli einschätzt und im Fall dieser Arbeit ein in vitro-Modell der Gewebeabstoßung darstellt. Hierbei wurden im Rahmen des Projektes bestrahlte Zellen, wie z. B. reife dendritische Zellen (DC), als Stimulatoren zusammen mit allogenen T-Lymphozyten eines potenziellen Spenders als Effektorzellen ko-kultiviert, um im Anschluss die Spender-T-Zell-Reaktion quantifizieren zu können. Die Bestrahlung mit 20 Gy imitierte hierbei die erforderliche HochdosisChemotherapie, die Patienten vor einer aHSCT erhalten, und sollte die im Versuch erwünschte unidirektionale Immunantwort erreichen. T-Lymphozyten werden hierbei als Responder/ Efferktorzellen durch die zuvor mittels Bestrahlung inaktivierten DCs (Stimulatorzellen) zur Proliferation angeregt (one-way-reaction) und anschließend in ihrer Reaktivität gemessen (Mangi und Kantor 1975) (Harrison und Paul 1973).

Durch Färbung von Aktivitätsmarkern können mittels FACS-Analyse Schlüsse über die Proliferationsrate gezogen werden. Proliferieren Zellen bzw. steigt ihre Aktivität durch Wachstum und Teilung, sind sie reaktiv und das Transplantat würde im Umkehrschluss in vivo mit großer Wahrscheinlichkeit abgestoßen werden. 
Für die Isolierung der Leukozytenschicht wurde das Blut der einzelnen Buffy-Coats, wie oben unter „Gewinnung MNZ aus Buffy-Coats“ beschrieben, mittels Ficoll-Dichtegradienten gewaschen, zentrifugiert und separiert.

Nach dem letzten Zentrifugationsschritt wurde das Zellpellet nach Absaugen der oben aufliegenden Plasmaschicht in $15 \mathrm{ml}$ RPMI-Medium resuspendiert und die erhaltenen MNZ mit einer Neubauer-Zählkammer gezählt. Eine der beiden in Zellkulturmedium resuspendierten Zellpopulationen wurde im Anschluss daran mit 20 Gy $\gamma$-Strahlung bestrahlt und im Folgenden mit der unbestrahlten Zellpopulation in zweifacher Ausführung kokultiviert. Es wurden je Population $10 \times 10^{6}$ Zellen in $20 \mathrm{ml}$ Medium in Kultur gebracht.

Nach 24 Stunden wurde unter sterilen Bedingungen unter der Sterilbank eine der beiden inkubierten Zellkulturen der standardisierten ECP-Therapie unterzogen. Dazu wurden der Zellkultur zunächst $2 \mathrm{ml}$ bzw. $10 \%$ der Zellen entnommen, in eine $25 \mathrm{~cm}^{2}$-Zellkulturflasche umpipettiert und $20 \mu 1$ 8-MOP zugegeben. Im Anschluss wurden die Zellen mit der Standard-UVA-Dosis von $2 \mathrm{~J} / \mathrm{cm}^{2}$ bestrahlt, daraufhin zurück in ihre ursprüngliche Zellkulturflasche gegeben und weiter bei $37{ }^{\circ} \mathrm{C}$ inkubiert. Nach 72 Stunden im Anschluss an die ECP-Therapie wurde die mit 8-MOP / UVA therapierte Zellpopulation mit der unbehandelten Kontrollpopulation mittels Durchflusszytometrie anhand der Färbung in ihrer Aktivitätsausprägung verglichen. Tabelle neun zeigt die verwendeten Mengenangaben.

Tabelle 9: MLR-Assays

\begin{tabular}{|l|l|l|l|}
\hline Assay & Antikörper & Menge & Fluoreszenz \\
\hline & & & \\
\hline 1. & CD4 & $5 \mu 1$ & Alexa 488 \\
\hline $\begin{array}{l}\text { Aktivierte } \\
\text { CD4 T-helper-cells }\end{array}$ & CD154 & $5 \mu 1$ & PE \\
\hline & CD69 & $5 \mu 1$ & APC \\
\hline & & & Alexa 488 \\
\hline 2. & CD8 & $5 \mu 1$ & APC \\
\hline $\begin{array}{l}\text { Aktivierte } \\
\text { CD8 Cytotoxic T cells }\end{array}$ & CD69 & $5 \mu 1$ & PE \\
\hline & CD137 & $5 \mu 1$ & \\
\hline & & & Pacific Blue \\
\hline 3. & CD3 & $2,5 \mu 1$ & PE \\
\hline Aktivierte NK-Zellen & CD56 & $5 \mu 1$ & APC \\
\hline & CD69 & $5 \mu 1$ & \\
\hline & & & \\
\hline 4. & Unstained & & \\
\hline Control & & & \\
\hline
\end{tabular}




\subsection{Statistik und Softwareprogramme}

Um die zwei Strahlenarten UVA und UVC auf ihre apoptoseinduzierende Wirkung in den untersuchten Leukozytensubpopulationen vergleichen und analysieren zu können, wurden die erhobenen Ergebnisse mit dem statistischen Softwareprogramm Graph Pad Prism in Säulendiagrammen objektiviert dargestellt. Der Globalvergleich ANOVA wurde ebenfalls mit Graph Pad Prism ermittelt. Anschließend wurden mithilfe von TIBCO Statistica ${ }^{\mathrm{TM}}$ aussagekräftige p-Werte zu signifikanten Unterschieden in der apoptoseinduzierenden Wirkung von 8-MOP / UVA und UVC errechnet. Als signifikanter Unterschied wurde $\mathrm{p}<0,05$ definiert. Ziel der Arbeit war es, die Nicht-Unterlegenheit der UVC-Wirkung durch p-Werte $>0,05 \mathrm{zu}$ zeigen. Falls nicht anders angegeben, werden Daten als Mittelwert \pm Standardabweichung (STABW) angegeben. 


\section{Ergebnisse}

Die extrakorporale Photopherese mit 8-MOP und UVA ist seit Jahren eine bewährte Therapieoption bei zahlreichen Erkrankungen.

In der vorliegenden Arbeit wurde die Kombination aus UVA-Strahlung und 8-MOP im Sinne der etablierten ECP-Therapie mit der Wirkung von UVC-Strahlung in einem in vitro Modell mit der Wirkung von UVC-Strahlung verglichen. Gegenstand der Untersuchung war der Vergleich der jeweils induzierten Apoptosekinetik in den bestrahlten mononukleären Zellen, da die Induktion des programmierten Zelltods mit nachfolgender Immunmodulation im Organismus des Patienten als der grundlegende Wirkmechanismus in der ECPBehandlung verstanden wird, auch wenn die exakte Wirkungsweise der Photochemotherapie bis dato noch nicht gänzlich begriffen ist.

Für einen erfolgreichen Therapieverlauf ist allerdings nicht nur eine möglichst hohe Apoptoserate von 5-10 \% der bestrahlten Leukozyten, sondern auch die Kinetik, also der stufenweise Anstieg der Apoptose von Bedeutung, um u. a. auch proinflammatorischen Prozessen vorzubeugen.

Für einen vollständigen Überblick und einen grundlegenden Vergleich wurde zunächst die bereits bekannte apoptoseinduzierende Wirkung von 8-MOP/ UVA $2 \mathrm{~J} / \mathrm{cm}^{2}(\mathrm{n}=9)$ in mehreren in vitro Versuchen reproduziert und mit einer unbehandelten Zellgruppe $(\mathrm{n}=11)$ verglichen. Daraufhin wurde in zwei weiteren Versuchsabschnitten die Apoptoseinduktion durch UVC-Strahlung getestet. Im ersten Schritt, angelehnt an die ECP-Therapiedosis mit UVA, mit einer Dosisleistung von $2 \mathrm{~J} / \mathrm{cm}^{2}(\mathrm{n}=9)$ und im zweiten Schritt, nach Berücksichtigung der Strahlenabsorption durch das Plastik der Kulturflasche, in dreifacher Dosierung mit $6 \mathrm{~J} / \mathrm{cm}^{2}(\mathrm{n}=12)$. Die Dosissteigerung ist hier lediglich ein Ausgleich des Verlusts an Strahlungsleistung durch die Plastikoberfläche der Kulturflaschen. Die Dosis, die die Zelloberfläche erreichte, war bei 8-MOP/ UVA $2 \mathrm{~J} / \mathrm{cm}^{2}$ und UVC $6 \mathrm{~J} / \mathrm{cm}^{2}$ rechnerisch identisch und betrug $1,8 \mathrm{~J} / \mathrm{cm}^{2}$. Die Berechnungsgrundlage der UV-Dosis ist aus der folgenden Grafik ersichtlich. 


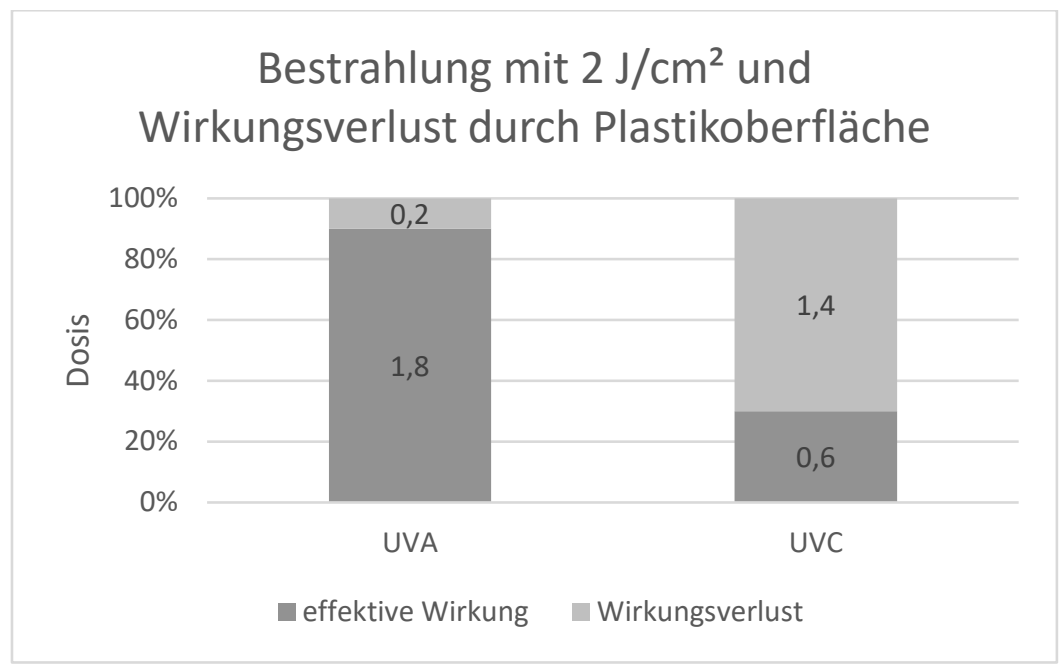

Abbildung 6: Wirkungsverlust durch Plastikoberfläche. UVA und UVC im Vergleich

Abschließend wurden die Messergebnisse der beiden UVC-Versuche mit den Ergebnissen von 8-MOP / UVA $2 \mathrm{~J} / \mathrm{cm}^{2}$ und der Kontrollgruppe statistisch verglichen. Als Apoptosemarker wurden Annexin V und 7-AAD verwendet, die in vier aufeinanderfolgenden Tagen mittels Durchflusszytometrie in ihrem Anstieg gemessen wurden.

\subsection{Apoptosekinetiken im Vergleich - Annexin V}

Im Folgenden werden die Reaktionen der untersuchten Zellgruppen auf die konventionelle Bestrahlung mit UVA in der Standarddosis von $2 \mathrm{~J} / \mathrm{cm}^{2}$ unter Zugabe von 8-MOP beschrieben und im Anschluss mit den Apoptosekinetiken unter dem Einfluss von UVCStrahlung verglichen. Aus den Grafiken geht jeweils ebenfalls die Apoptosekinetik einer unbehandelten Kontrollgruppe hervor, die an Tag drei jeweils signifikant geringere Apoptoseraten aufweist und so die apoptoseinduzierende Wirkung der ECP-Therapie und die der UVC-Strahlung bestätigt.

Der Vollständigkeit halber und um der Möglichkeit einer rein zufällig steigenden Apoptosekinetik nach UVC-Bestrahlung zu begegnen, wurden in drei Versuchen $(n=3)$ aus drei unterschiedlichen BCs je zwei parallele Versuchsreihen gestartet. Dabei blieb eine Versuchsreihe als Kontrollgruppe unbehandelt, während die andere mit UVC-Licht in der Dosis $2 \mathrm{~J} / \mathrm{cm}^{2}$ bestrahlt wurde. Aus den Ergebnissen konnte auf eine eindeutige und unabhängige apoptoseinduzierende Wirkung von UVC-Strahlung geschlossen werden, die sich in darauffolgenden Versuchsdurchgängen stets wiederholte. 
Der Globalvergleich ANOVA der drei Parallelversuche war für alle untersuchten Subpopulationen an Tag eins, zwei und drei signifikant. Für CD3+CD4+ T-Helferzellen mit $\mathrm{p}<0,01$, für CD3+CD8+ zytotoxische T-Zellen und CD14+ Monozyten mit $\mathrm{p}<0,05$. Für CD19+ B-Zellen war ANOVA signifikant mit $\mathrm{p}<0,05$, für CD3+ CD56+ NKT-Zellen mit $\mathrm{p}<0,01$ und für CD3-CD56+ NK-Zellen mit $\mathrm{p}<0,05$. Lediglich zu den regulatorischen TZellen ließ sich keine Aussage treffen, da durch Probenausfall der Versuch nicht auswertbar war. Die drei parallel durchgeführten Versuchsreihen wurden mit ihren Ergebnissen in die unbehandelte Kontrollgruppe und in die mit UVC $2 \mathrm{~J} / \mathrm{cm}^{2}$ bestrahlte Kohorte statistisch aufgenommen und finden im Folgenden in der Gesamtauswertung ihren Ausdruck.

Im Folgenden werden die einzelnen Reaktionen der untersuchten Leukozytensubpopulationen beschrieben. Die Grafiken beziehen sich hier auf den Apoptoseindikator Annexin V.

\subsubsection{Apoptosekinetik von CD3+ CD4+ Effektorzellen}

CD3+ CD4+ Zellen repräsentieren eine Subgruppe der T-Lymphozyten, auch T-Helferzellen genannt. T-Helferzellen haben die Aufgabe, ihnen an MHCII-Rezeptoren präsentierte Antigene $\mathrm{zu}$ erkennen, Zytokine $\mathrm{zu}$ synthetisieren, auszuschütten und somit weitere Komponenten des Immunsystems wie Makrophagen oder zytotoxische T-Zellen zu mobilisieren. Im zirkulierenden Blut eines gesunden Erwachsenen machen sie 27-57 \% der Lymphozyten aus und lassen sich in TH1, TH2-Zellen und TH17-Zellen unterteilen. Auf UVA-Bestrahlung reagierten T-Helferzellen vulnerabel und gingen drei Tage nach Behandlung beinahe vollständig in Apoptose. Unter dem Einfluss von UVC-Strahlung war ebenfalls ein stetiger Anstieg der Apoptoserate zu erkennen, die Kinetik verlief jedoch insgesamt etwas langsamer. 


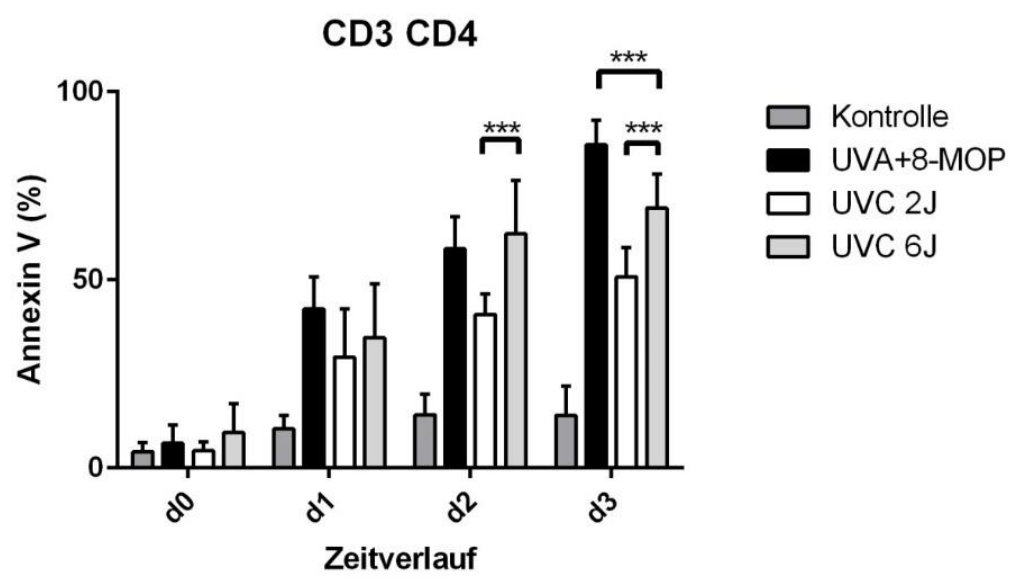

Abbildung 7: CD3+CD4+ Apoptosekinetiken im Vergleich: 8-MOP / UVA 2 J, UVC 2 J, UVC 6 J, unbehandelte Kontrolle $* p<0,05 \quad * * p<0,01 \quad * * * p<0,001$

Kontrolle $n=11 \quad$ UVA $+8-M O P n=9 \quad$ UVC $2 J n=9 \quad$ UVC $6 \mathrm{~J} n=12$

An Tag null, ca. eine Stunde nach der etablierten ECP-Therapie mit UVA $2 \mathrm{~J} / \mathrm{cm}^{2}$, wurde eine Apoptoserate von 6,5\% gemessen. Nach Ablauf von 24 Stunden, an Tag eins, war die Apoptoserate bereits auf 42,2\% angestiegen und am darauffolgenden Tag zwei waren es 58,2 \%. Am dritten Tag, ca. 72 Stunden nach ECP-Therapie, konnte eine Zelltodrate von $86 \%$ festgestellt werden. Die Standardabweichung (STABW) am dritten Tag betrug 6,5\%. Die unbehandelte Kontrollgruppe zeigte über den Zeitraum der 72 Stunden ebenfalls einen stetigen Anstieg der Apoptoserate und erreichte an Tag drei einen Mittelwert von 13,9\% mit einer STABW von $7,8 \%$.

Auf alleinige UVC-Strahlung reagierten CD3+CD4+ Zellen über den gemessenen Zeitraum von 72 Stunden mit einem konstanten Apoptoseanstieg. Im ersten Versuchsdurchgang mit $2 \mathrm{~J} / \mathrm{cm}^{2}$ wurden an Tag null 4,5\% der Zellen in Apoptose gemessen, an Tag eins 29,4\% und an Tag zwei 40,8 \%. An Tag drei betrug die Apoptoserate 50,8 \%. Nach Verdreifachung der Strahlendosis auf $6 \mathrm{~J} / \mathrm{cm}^{2}$ betrugen die durchschnittlich gemessenen Apoptosewerte an Tag null 9,4\%, an Tag eins 34,7\% und an Tag zwei 62,2\%. An Tag drei wurde ein Durchschnittswert von $69,1 \%$ erhoben.

Der Globalvergleich ANOVA war an Tag eins, zwei und drei signifikant, mit $\mathrm{p}<0,0001$. Insgesamt gingen CD3+ CD4+ T-Helferzellen vergleichsweise zögerlich in Apoptose. Während an Tag drei 8-MOP / UVA eine Apoptoserate von 85,8 \% erreichte, waren es unter dem Einfluss der angepassten UVC-Bestrahlung auf $6 \mathrm{~J} / \mathrm{cm}^{2} 69,1 \%$. Bis einschließlich Tag zwei zeigten die Ergebnisse keine signifikanten Unterschiede zwischen den beiden 
untersuchten Strahlenarten, lediglich an Tag drei wurde ein signifikanter Unterschied mit $\mathrm{p}<0,001$ festgestellt.

Nach Dosissteigerung der UVC-Strahlung von $2 \mathrm{~J} / \mathrm{cm}^{2}$ auf $6 \mathrm{~J} / \mathrm{cm}^{2}$ zeigten sich signifikante Apoptosewertsteigerungen an Tag zwei und drei, jeweils mit $\mathrm{p}<0,001$.

\subsubsection{Apoptosekinetik von CD3+ CD8+ Effektorzellen}

CD3+ CD8+ Zellen repräsentieren eine Subgruppe der T-Lymphozyten, auch zytotoxische T-Zellen genannt. Wie T-Helferzellen sind auch sie Teil des spezifischen Immunsystems und haben die Aufgabe, Antigene an MHC I-Rezeptoren zu erkennen und im Fall einer Virusinfektion oder einer Entartung der Zelle diese durch zytotoxische Substanzen oder durch Aktivierung eines Fas-Rezeptors abzutöten.

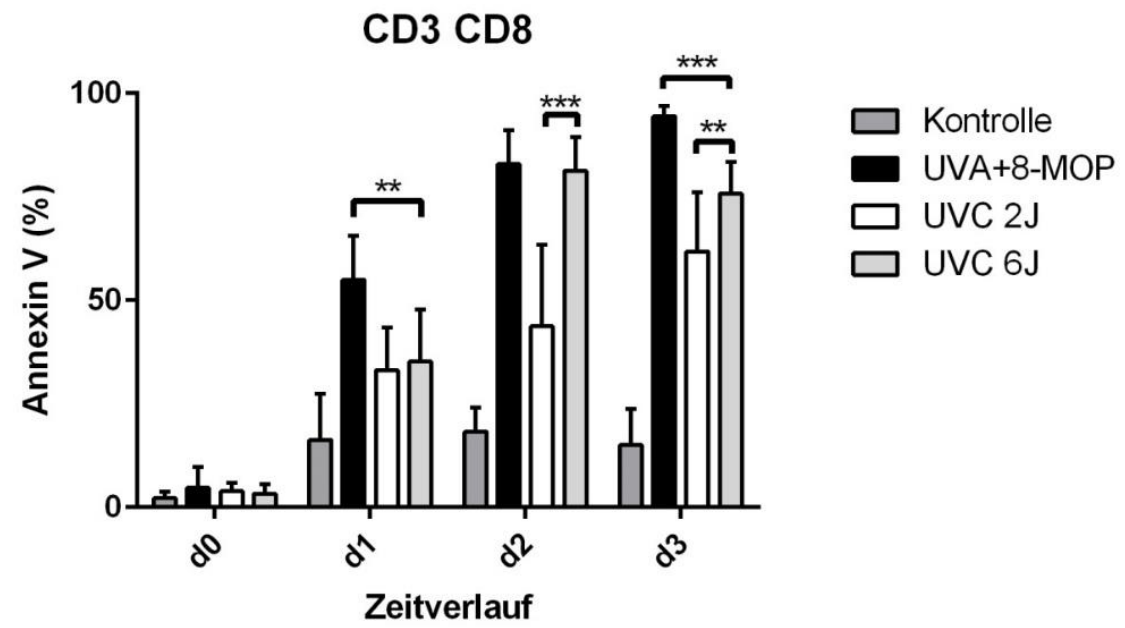

Abbildung 8: CD3+CD8+ Apoptosekinetiken im Vergleich: 8-MOP / UVA 2 J, UVC 2 J, UVC 6 J, unbehandelte Kontrolle $* p<0,05 \quad * * p<0,01 \quad * * * p<0,001$

Kontrolle $n=11 \quad$ UVA $+8-M O P n=9 \quad$ UVC $2 J n=9 \quad$ UVC $6 J n=12$

CD3+ CD8+ Zellen waren für die Wirkungen der ECP-Therapie mit 8-MOP / UVA stark anfällig und gingen nahezu vollständig in Apoptose. Während an Tag null die Apoptoserate noch bei 4,7\% lag, stieg sie an Tag eins bereits auf 55\%. An Tag zwei wurden 82,9\% gemessen und ca. 72 Stunden nach Wirkung der ECP-Therapie lag eine Apoptoserate von rund $95 \%$ vor. Die STABW an Tag drei betrug 2,4\%. Die unbehandelte Kontrollgruppe erreichte an Tag drei eine Apoptoserate von $15 \%$. 
Unter UVC-Strahlung zeigten CD8-Effektorzellen ebenfalls eine starke Apoptoseinduktion. Im ersten Versuchsdurchlauf mit einer Bestrahlungsdosis von $2 \mathrm{~J} / \mathrm{cm}^{2}$ verlief die Apoptosekinetik konstant steigend, die Apoptoserate betrug an Tag null 3,8 \%, an Tag eins 33,1\%, an Tag zwei 43,7 \% und an Tag drei 61,8\%. Die STABW an Tag drei betrug 14,2 \%. Nach Verdreifachung der Dosisleistung auf $6 \mathrm{~J} / \mathrm{cm}^{2}$ stiegen die Apoptosewerte im Mittel an. An Tag null wurden zunächst 3,3 \% gemessen, an Tag eins 35,2 \% und an Tag zwei Werte von 81,3\%. An Tag drei betrugen die durchschnittlichen Apoptosewerte 75,8 \%.

Der Globalvergleich ANOVA war an Tag eins, zwei und drei signifikant, mit $p<0,0001$.

CD3+ CD8+ Effektorzellen reagierten sowohl unter 8-MOP / UVA als auch und unter der Alternativstrahlung UVC mit einem starken Apoptoseanstieg. An Tag drei wurden unter UVC $6 \mathrm{~J} / \mathrm{cm}^{2}$ im Mittel Werte von 75,8 \% gemessen. Die Apoptoserate unter 8-MOP / UVA betrug an Tag drei 94,5\%, rund zehn Prozentpunkte mehr als unter dem Einfluss reiner UVC-Strahlung. Signifikante Unterschiede zwischen den zwei Strahlenarten zeigten sich an Tag eins mit $\mathrm{p}<0,01$ und an Tag drei mit $\mathrm{p}<0,001$.

Nach Dosissteigerung der UVC-Strahlung von $2 \mathrm{~J} / \mathrm{cm}^{2}$ auf $6 \mathrm{~J} / \mathrm{cm}^{2}$ zeigten sich signifikante Apoptosewertsteigerungen an Tag zwei mit $\mathrm{p}<0,001$ und an Tag drei mit $\mathrm{p}<0,01$.

\subsubsection{Apoptosekinetik von CD14+ Zellen}

CD14 ist das charakteristische Oberflächenmolekül (cluster of differentiation) der Monozyten. Monozyten zirkulieren bis zu 48 Stunden im Blut, machen 2-8\% der Leukozyten aus und besitzen die Fähigkeit zur aktiven Migration in umliegendes Gewebe, wo sie zu Makrophagen ausdifferenzieren. Sie sind Teil des angeborenen unspezifischen Immunsystems und haben die Aufgabe der Phagozytose fremder Partikel mit anschließender Antigenpräsentation auf MHC II-Rezeptoren. 


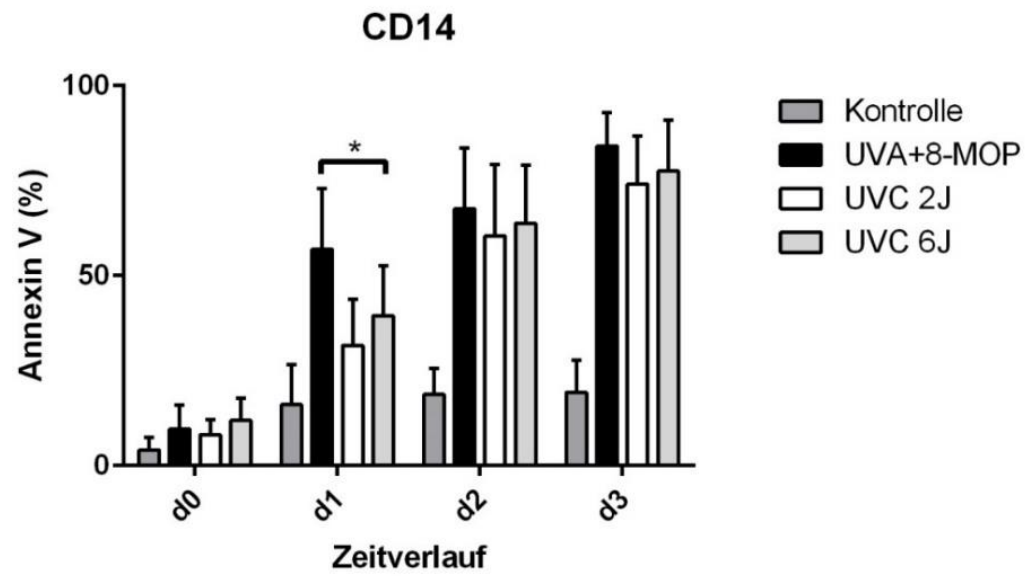

Abbildung 9: CD14+ Apoptosekinetiken im Vergleich: 8-MOP / UVA 2 J, UVC 2 J, UVC 6 J, unbehandelte Kontrolle $* p<0,05 \quad * * p<0,01 \quad * * * p<0,001$

Kontrolle $n=11 \quad$ UVA $+8-M O P n=9 \quad$ UVC $2 J n=9 \quad$ UVC $6 J n=12$

In der vorliegenden Arbeit reagierten CD14+ Zellen im Rahmen der ECP-Therapie mit einem konstanten Apoptoseanstieg auf UVA-Bestrahlung. An Tag null wurde eine Zelltodrate von 9,6\% gemessen, an Tag eins waren es bereits 56,9\%. Tag zwei ergab Apoptoseraten von durchschnittlich $67,7 \%$, die sich zum dritten Tag hin auf 84,2 \% steigerten. Die STABW an Tag drei betrug 8,8 \%. Die unbehandelte Kontrollgruppe zeigte eine ähnliche Apoptosekinetik mit stetigem Anstieg, allerdings mit einer maximalen Apoptoserate an Tag drei von 19,3\%.

Auf die alleinige Bestrahlung mit UVC reagierten Monozyten mit einem linearen Apoptoseanstieg. Bei einer Dosis von $2 \mathrm{~J} / \mathrm{cm}^{2}$ betrug die Apoptoserate an Tag null 8,0 \%, an Tag eins 31,9\%, an Tag zwei 60,5\% und an Tag drei 74,9\%. Die STABW am dritten Tag betrug 12,0\%. Nach Verdreifachung der UV-Dosisleistung stieg die Apoptoserate an und betrug an Tag null 11,9\%, an Tag eins 39,4 \%, an Tag zwei 63,8 \% und an Tag drei 77,5 \%.

Der Globalvergleich ANOVA war an Tag eins, zwei und drei signifikant, mit $\mathrm{p}<0,0001$

CD14+ Monozyten zeigten somit insgesamt sowohl unter 8-MOP / UVA als auch unter UVC-Einfluss einen kontinuierlichen Apoptoseanstieg über den beschriebenen zeitlichen Verlauf von 72 Stunden. Während 8-MOP / UVA an Tag drei Werte von 84,2 \% erreichte, führte reine UVC-Strahlung mit einer Dosis von $6 \mathrm{~J} / \mathrm{cm}^{2}$ dagegen zu einer Apoptoserate von 77,5\%. Abgesehen von einem Unterschied zwischen der Bestrahlung mit 8-MOP / UVA und UVC $6 \mathrm{~J} / \mathrm{cm}^{2}$ an Tag eins, mit $\mathrm{p}<0,05$, gab es hier keine weiteren statistisch signifikanten Differenzen. 


\subsubsection{Apoptosekinetik von CD19+ Zellen}

CD19 ist das charakteristische Oberflächenmolekül der B-Lymphozyten. Nach Aktivierung in sekundären Lymphorganen durch einen Antigenkontakt nehmen sie als reife Plasmazellen die Antikörperproduktion auf. B-Lymphozyten sind Teil des spezifischen Immunsystems.

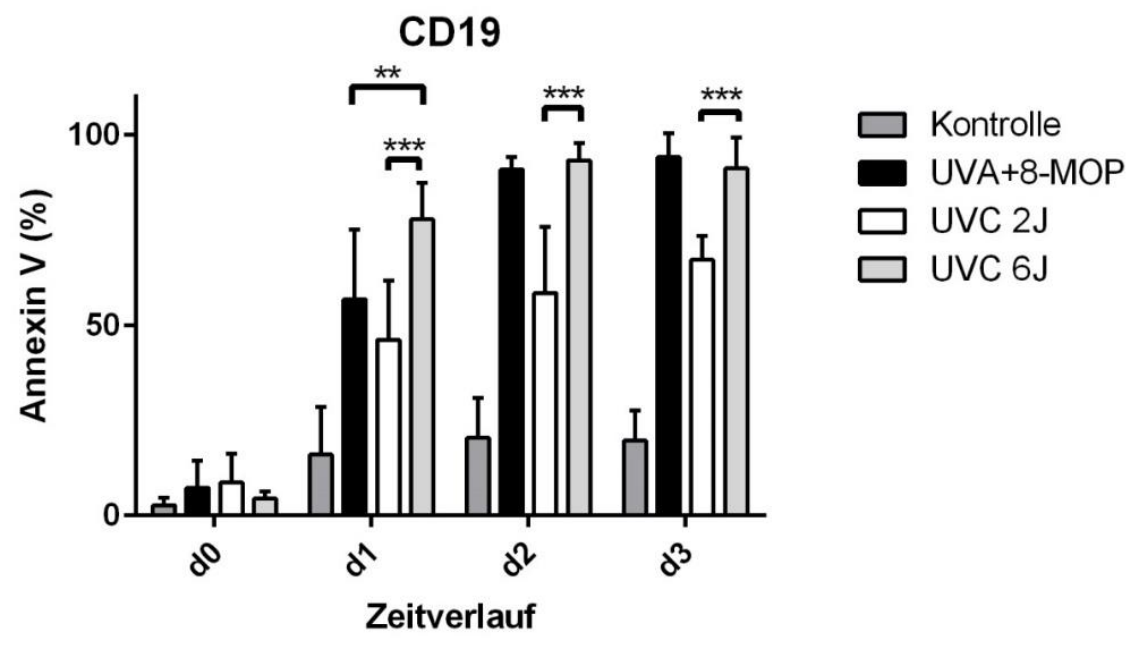

Abbildung 10: CD19+ Apoptosekinetiken im Vergleich: 8-MOP / UVA 2 J, UVC 2 J, UVC 6 J, unbehandelte Kontrolle $* p<0,05 \quad * * p<0,01 \quad * * * p<0,001$

Kontrolle $n=11 \quad$ UVA+8 $-M O P n=9 \quad$ UVC $2 J n=9 \quad$ UVC $6 J n=12$

B-Lymphozyten reagierten mit nahezu vollständiger Apoptose auf die UVA-Strahlung im Rahmen der ECP-Behandlung. An Tag null betrug die Apoptoserate 7,3 \%, an Tag eins stieg sie auf 58,2 \% an. An Tag zwei wurden 91,5\% gemessen und an Tag drei erreichte die Apoptoserate Werte von 94,5\%. Die STABW an Tag drei betrug 5,9\%. Auch in der unbehandelten Kontrollgruppe war ein stetiger Anstieg der Apoptoserate zu verzeichnen, das Maximum an Tag drei lag hier jedoch bei 19,7 \%.

Unter dem Einfluss von alleiniger UVC-Bestrahlung gingen B-Lymphozyten ebenfalls stark in Apoptose. Im ersten Versuchsdurchgang mit einer Strahlendosis von $2 \mathrm{~J} / \mathrm{cm}^{2}$ wurden an Tag null durchschnittliche Apoptoseraten von 8,8 \%, an Tag eins von 48,2 \%, an Tag zwei von 58,4 \% und an Tag drei von 68,1 \% erhoben. Die STABW an Tag drei betrug hier 6,6 \%. Im zweiten Versuchsdurchgang, nach Anpassung der Dosisleistung auf $6 \mathrm{~J} / \mathrm{cm}^{2}$, stiegen die Apoptosewerte im Mittel an. An Tag null betrugen sie noch 4,4\%, an Tag eins bereits 77,7 \%, an Tag zwei im Durchschnitt 93,2 \% und an Tag drei 91,1\%.

Der Globalvergleich ANOVA war an Tag eins, zwei und drei signifikant, mit $\mathrm{p}<0,0001$. 
CD19+ B-Lymphozyten reagierten somit insgesamt besonders vulnerabel auf die Strahlenversuche. Sowohl unter der Kombination aus 8-MOP / UVA $2 \mathrm{~J} / \mathrm{cm}^{2}$ als auch nach UVCBestrahlung mit $6 \mathrm{~J} / \mathrm{cm}^{2}$ betrug die Apoptoserate bereits an Tag zwei mehr als $90 \%$. An Tag drei belief sich die Apoptoserate unter UVA-Strahlung auf 94,5\%, unter dem Einfluss von UVC-Strahlung wurden am dritten Tag Mittelwerte von 91,1 \% erhoben. Lediglich an Tag eins zeigte sich ein signifikanter Unterschied der beiden Strahlenarten mit $\mathrm{p}<0,01$.

Nach Dosissteigerung der UVC-Strahlung von $2 \mathrm{~J} / \mathrm{cm}^{2}$ auf $6 \mathrm{~J} / \mathrm{cm}^{2}$ zeigten sich signifikante Apoptosewertsteigerungen an Tag eins, zwei und drei, jeweils mit $p<0,001$.

\subsubsection{Apoptosekinetik von CD4+ CD39+ regulatorischen T-Zellen}

Regulatorische T-Zellen sind eine spezialisierte Untergruppe der T-Lymphozyten, die die Selbsttoleranz des Immunsystems regulieren und so das Risiko für die Entstehung von Autoimmunerkrankungen senken können.

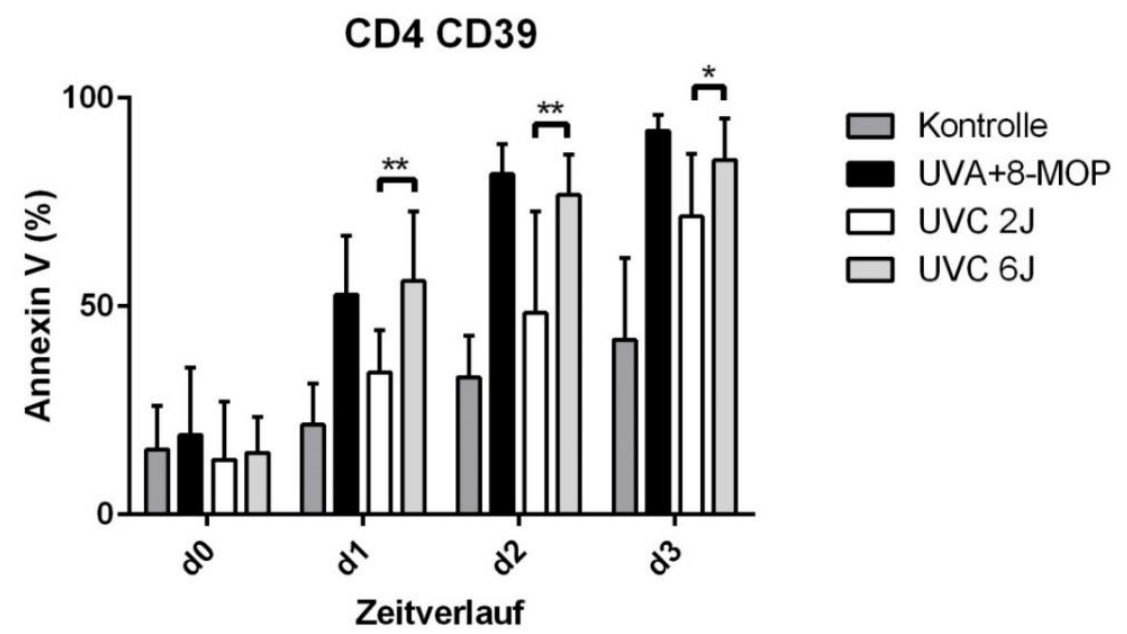

Abbildung 11: CD4+ CD39+ Apoptosekinetiken im Vergleich: 8-MOP / UVA $2 \mathrm{~J}$, UVC $2 \mathrm{~J}$, UVC 6 J, unbehandelte Kontrolle

$* p<0,05 \quad * * p<0,01 \quad * * * p<0,001$

Kontrolle $n=11 \quad$ UVA+8-MOP $n=9 \quad$ UVC $2 J n=9 \quad$ UVC $6 J n=12$

Regulatorische T-Zellen präsentierten sich bzgl. Apoptosekinetik als vulnerable Zellgruppe. An Tag null nach ECP-Behandlung mit UVA $2 \mathrm{~J} / \mathrm{cm}^{2}$ betrug die Apoptoserate bereits 19,1\%, die am darauffolgenden Tag eins auf 52,8 \% anstieg. An Tag zwei waren 81,7 \% der bestrahlten Zellen in Apoptose, an Tag drei waren es schlussendlich 92,1\%. Die STABW an Tag drei betrug 3,8\%. Die unbehandelte Kontrollgruppe wies eine 
vergleichsweise hohe Apoptosekinetik auf, jedoch mit einer maximalen Apoptoserate von $44,6 \%$ an Tag drei und einer STABW von $20,7 \%$.

Auf UVC-Strahlung antworteten regulatorische T-Zellen mit einer stetig ansteigenden Apoptoserate. Unter dem Einfluss einer UVC-Strahlendosis von $2 \mathrm{~J} / \mathrm{cm}^{2}$ wurden an Tag null im Durchschnitt Apoptoseraten von 13,1 \% gemessen, an Tag eins, Raten von 36,0 \%, an Tag zwei von 52,5\% und an Tag drei von 72,6 \%. Nach Verdreifachung der Dosisleistung auf $6 \mathrm{~J} / \mathrm{cm}^{2}$ stieg die Apoptoserate an. An Tag null lag der durchschnittliche Wert bei 14,8 \%, an Tag eins bei $56,1 \%$, an Tag zwei bei $76,7 \%$ und an Tag drei bei $85,1 \%$. Die STABW am dritten Tag betrug 9,9\%.

Der Globalvergleich ANOVA war an Tag eins, zwei und drei signifikant, mit $\mathrm{p}<0,0001$. CD4+ CD39+ regulatorische T-Zellen reagierten sowohl auf 8-MOP/UVA als auch auf UVC-Strahlung in der Dosis $6 \mathrm{~J} / \mathrm{cm}^{2}$ insgesamt mit ähnlicher Apoptosekinetik. Beide Strahlenarten bewirkten einen kontinuierlichen Apoptoseanstieg, wobei an Tag drei die Apoptoserate unter UVA-Strahlung mit 92,1 \% rund sieben Prozentpunkte höher lag als die unter alleiniger UVC-Einwirkung. An keiner Stelle konnten signifikante Unterschiede zwischen der apoptoseinduzierenden Wirkung der beiden Strahlenarten festgestellt werden. Die $\mathrm{p}$-Werte betrugen durchgehend an allen vier Tagen $>0,05$.

Nach Dosissteigerung der UVC-Strahlung von $2 \mathrm{~J} / \mathrm{cm}^{2}$ auf $6 \mathrm{~J} / \mathrm{cm}^{2}$ zeigten sich signifikante Apoptosewertsteigerungen an Tag eins und zwei mit $p<0,01$ und an Tag drei mit $p<0,05$.

\subsubsection{Apoptosekinetik von CD3+ CD56+ NKT-Zellen}

Natürliche Killer-T-Lymphozyten sind den NK-Zellen ähnlich, gehören jedoch zur Gruppe der T-Zellen und können so u. a. durch T-Zell-Rezeptoren fremde Lipide erkennen und virusinfizierte Zellen auch mittels zytotoxischer Effektormoleküle wie Perforin und Granzymen vernichten. 


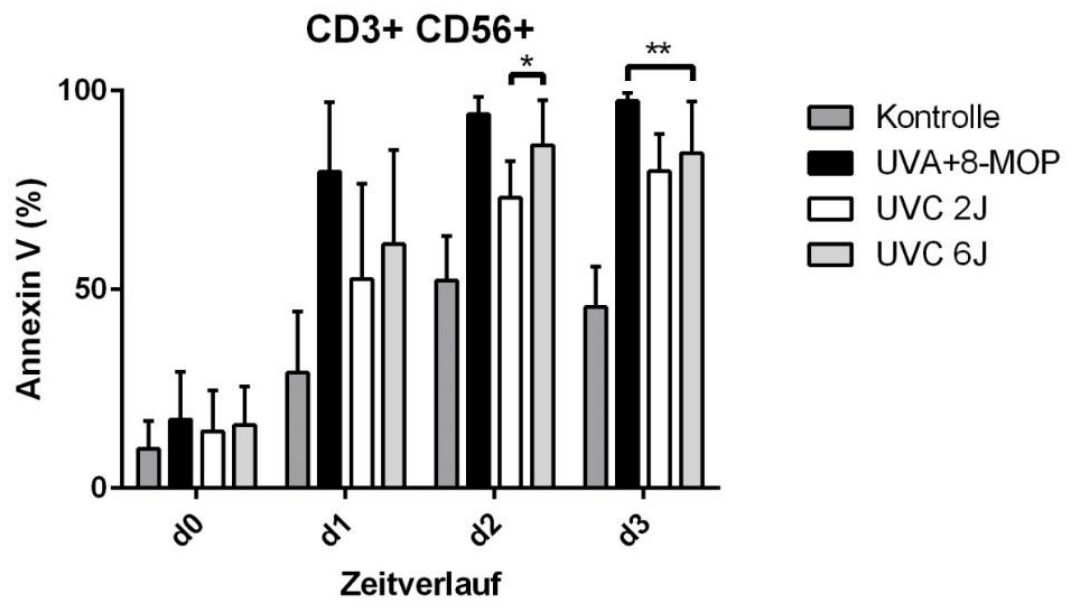

Abbildung 12: CD3+ CD56+ Apoptosekinetiken im Vergleich: 8-MOP / UVA $2 \mathrm{~J}$, UVC $2 \mathrm{~J}$, UVC $6 \mathrm{~J}$, unbehandelte Kontrolle

$* p<0,05 * * *<<0,01 \quad * * * p<0,001$

Kontrolle $n=11 \quad U V A+8-M O P n=9 \quad$ UVC $2 J n=9 \quad$ UVC $6 J n=12$

NKT-Zellen wiesen in den beschriebenen Versuchen ein vulnerables Apoptoseprofil auf. Nach der Behandlung mit 8-MOP und UVA-Strahlung in Standarddosis wurde an Tag null eine Apoptoserate von 17,3\% gemessen. An Tag eins waren es bereits 79,6\% und an Tag zwei $94 \%$. Rund 72 Stunden nach Behandlung, an Tag drei, betrug die Apoptoserate im Durchschnitt 97,4\%. Die STABW am dritten Tag betrug $2 \%$. Die unbehandelte Kontrollgruppe wies ebenfalls eine starke Apoptoseinduktion auf. An Tag drei wurden Apoptosewerte von 45,5\% und eine STABW von 10,3\% gemessen.

UVC-Bestrahlung bewirkte in natürlichen Killer-T-Zellen im Verlauf von 96 Stunden ebenfalls zunehmende Apoptoseraten. Unter einer Dosis von $2 \mathrm{~J} / \mathrm{cm}^{2}$ betrug die Apoptoserate an Tag null 13,2 \%, an Tag eins 53,2 \%, an Tag zwei 73,0 \% und an Tag drei $76,5 \%$. Unter der dreifachen Bestrahlungsdosis von $6 \mathrm{~J} / \mathrm{cm}^{2}$ stiegen die Apoptoseraten der NKT-Zellen an. An Tag null wurden 15,8 \%, an Tag eins 61,4 \%, an Tag zwei 86,3\% und an Tag drei 84,3\% gemessen. Die STABW betrug hier am dritten Tag 12,9\%.

Der Globalvergleich ANOVA war an Tag eins, zwei und drei signifikant, mit p < 0,0001. Auch CD3+ CD56+ NKT-Zellen reagierten auf beide Strahlenarten mit einer ähnlichen Apoptosekinetik. Unter UVC-Einwirkung wurde mit der angepassten Dosis von $6 \mathrm{~J} / \mathrm{cm}^{2}$ an Tag drei eine Apoptoserate von 84,3\% gemessen, unter UVA-Strahlung wurden Apoptosewerte von 97,4\% erreicht. Bis einschließlich Tag zwei konnten zwischen den beiden Strahlenarten und unter angepasster Dosisleistung keine signifikanten Unterschiede festgestellt werden. Lediglich an Tag drei wurde ein $\mathrm{p}$-Wert von $<0,01$ gemessen. 
Nach Dosissteigerung der UVC-Strahlung von $2 \mathrm{~J} / \mathrm{cm}^{2}$ auf $6 \mathrm{~J} / \mathrm{cm}^{2}$ zeigten sich eine signifikante Apoptosewertsteigerung an Tag zwei mit $\mathrm{p}<0,05$.

\subsubsection{Apoptosekinetik von CD3- CD56+ NK-Zellen}

Natürliche Killerzellen gehören zum unspezifischen Immunsystem und weisen antigenunabhängig eine sofortige Reaktionsbereitschaft gegen virusinfizierte Zellen und Tumorzellen auf.

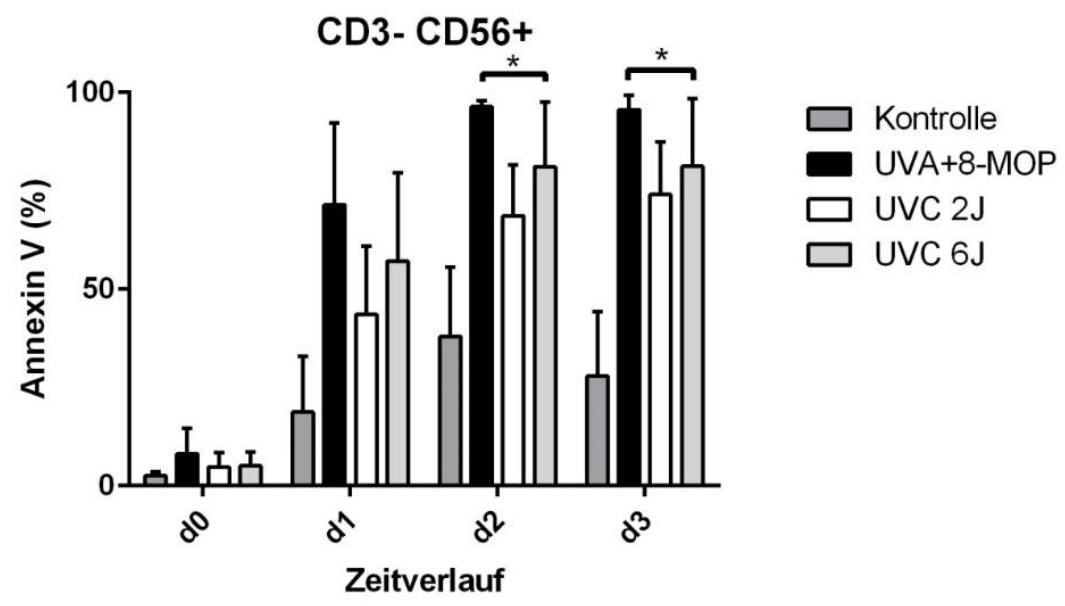

Abbildung 13: CD3-CD56+ Apoptosekinetiken im Vergleich: 8-MOP / UVA $2 \mathrm{~J}$, UVC $2 \mathrm{~J}$, UVC $6 \mathrm{~J}$, unbehandelte Kontrolle

$* p<0,05 \quad * * p<0,01 \quad * * * p<0,001$

Kontrolle $n=11 \quad$ UVA $+8-M O P n=9 \quad$ UVC $2 J n=9 \quad$ UVC $6 J n=12$

NK-Zellen reagierten, wie andere Zellgruppen auch, mit einem starken und schnellen Apoptoseanstieg auf die ECP-Behandlung. An Tag null wurden Apoptosewerte von 8,1\% gemessen, an Tag eins waren es 71,5\% und an Tag zwei bereits 96,4\%. Die durchschnittliche Apoptoserate an Tag drei betrug 95,6 \% mit einer STABW von 3,6 \%. Die gemessenen Apoptoseraten der unbehandelten Kontrollgruppe betrugen an Tag drei im Mittel 27,9\%. Die STABW betrug hier an Tag drei $16,3 \%$.

Natürliche Killerzellen reagierten auf die alleinige Wirkung von UVC-Strahlen mit einem konstanten Apoptoseanstieg über den gemessenen Zeitraum von 72 Stunden. Im ersten Versuchsdurchgang mit einer Dosis von $2 \mathrm{~J} / \mathrm{cm}^{2}$ betrug die Apoptoserate an Tag null 4,5\%, an Tag eins 45,0 \%, an Tag zwei 68,6 \% und an Tag drei 72,0 \%. Die dreifache Dosisleistung ließ die Apoptoseraten steigen, was der zweite Versuchsdurchgang mit einer Dosis von 
$6 \mathrm{~J} / \mathrm{cm}^{2}$ zeigte. Hier betrug die Apoptoserate an Tag null 5,1\%, an Tag eins 57,2\%, an Tag zwei $81,1 \%$ und an Tag drei 81,2 \%. Die STABW an Tag drei betrug 17,2 \%.

Der Globalvergleich ANOVA war an Tag eins, zwei und drei signifikant, mit $\mathrm{p}<0,0001$. CD3- CD56+ NK-Zellen reagierten mit einem stetigen Apoptoseanstieg auf die Bestrahlung mit UVC-Licht und erreichten unter der Dosis $6 \mathrm{~J} / \mathrm{cm}^{2}$ am dritten Messtag durchschnittliche Apoptosewerte von 81,2\%. Im Vergleich wurden unter dem Einfluss von UVA-Strahlung Werte von 95,6\% erreicht. Signifikante Unterschiede zwischen den beiden Strahlenarten zeigten sich an Tag zwei und an Tag drei, jeweils mit $\mathrm{p}<0,05$.

In der vorliegenden Arbeit konnte experimentell einerseits die bereits bekannte Wirkung von 8-MOP / UVA-Strahlung im Rahmen der ECP-Therapie reproduziert und andererseits erstmalig eine signifikante apoptoseinduzierende Wirkung von UVC-Strahlung gezeigt werden.

Obwohl eine eindeutige Apoptoseinduktion durch UVC-Strahlung in den oben beschriebenen Versuchen für alle sieben untersuchten Zellgruppen im Verlauf von 72 Stunden gezeigt werden konnte, wurden trotz Dosisanpassung und Berücksichtigung der Strahlenabsorption an der Plastikoberfläche der Kulturflaschen im zweiten Versuchsdurchgang noch nicht exakt äquivalent hohe Werte wie unter der konventionellen und etablierten Therapie mit 8-MOP / UVA $2 \mathrm{~J} / \mathrm{cm}^{2}$ erreicht.

Im Anhang sind aus Übersichtstabellen Mittelwerte \pm STABW und p-Werte zu oben beschriebenen Vergleichen ersichtlich.

Tabelle 10 beinhaltet Daten zum Vergleich von UVC $2 \mathrm{~J} / \mathrm{cm}^{2}$ und UVC $6 \mathrm{~J} / \mathrm{cm}^{2}$.

Tabelle 11 beinhaltet Daten zum Vergleich von 8-MOP / UVA $2 \mathrm{~J} / \mathrm{cm}^{2}$ und UVC $6 \mathrm{~J} / \mathrm{cm}^{2}$. 


\subsection{Spätapoptosekinetiken im Vergleich}

Werden apoptotische Zellen sowohl durch Annexin V FITC als auch durch 7-AAD markiert, kann von einer spätapoptotischen Situation der Zelle ausgegangen werden. In der vorliegenden Arbeit wurden Apoptoseraten und -kinetiken während des gesamten Projektzeitraums stets sowohl mit Annexin V FITC als auch mit 7-AAD parallel bestimmt. Für eine vollständige Darlegung der Versuchsergebnisse folgt die graphische Darstellung der Kinetikdynamiken der Spätapoptose im zeitlichen Verlauf der vier gemessenen Tage. Spätapoptose bezeichnet hier jeweils den prozentualen Anteil der 7-AAD und Annexin V positiven Zellen an allen MNZ. Jede untersuchte Zellgruppe wird aus Gründen der Übersicht in einem eigenen Graph aufgezeigt. Es werden jeweils die Spät-Apoptosewerte der unbehandelten Kontrollgruppe, die der mit 8-MOP / UVA $2 \mathrm{~J} / \mathrm{cm}^{2}$ behandelten Gruppe und die der zwei Versuchsdurchgänge mit UVC à $2 \mathrm{~J} / \mathrm{cm}^{2}$ und UVC à $6 \mathrm{~J} / \mathrm{cm}^{2}$ dargestellt.

7-AAD ist als „Avitalfarbstoff“ ein etablierter Zelltodmarker. In den aufgeführten Versuchen wurden kaum unterschiedliche Merkmale zwischen den vier Untersuchungskonditionen hinsichtlich der 7-AAD Ausprägung gefunden. Als eine Auffälligkeit ist jedoch die vergleichsweise geringe Ausprägung spätapoptotischer Werte bei CD14+ Monozyten zu nennen.

\subsubsection{Kinetik der Spätapoptose bei CD3+ CD4+ T-Helferzellen}

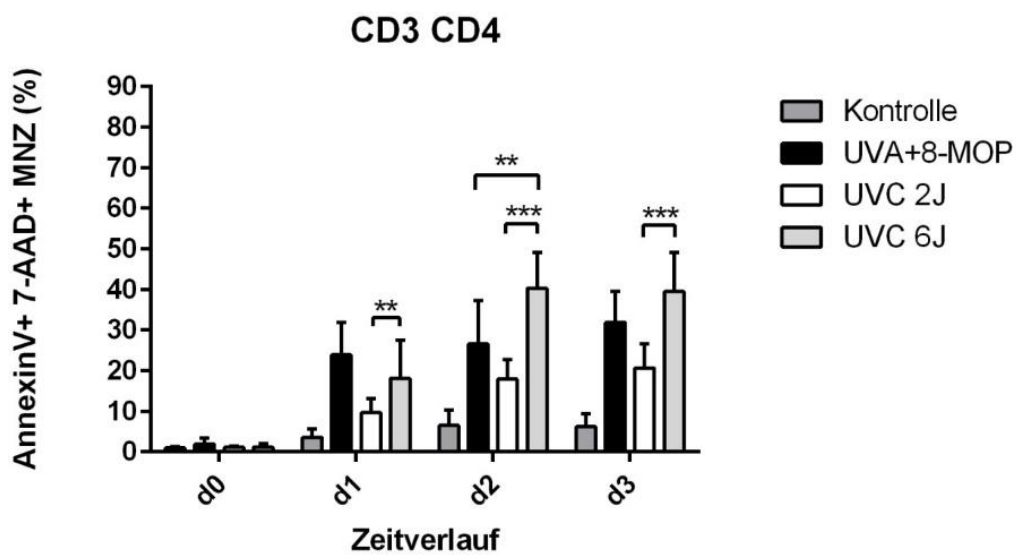

Abbildung 14: CD3+CD4+ Spätapoptosekinetik

$* p<0,05 \quad * * p<0,01 \quad * * * p<0,001$

Kontrolle $n=11 \quad$ UVA $+8-M O P n=9 \quad$ UVC $2 J n=9 \quad$ UVC $6 J n=12$ 
Während 8-MOP / UVA $2 \mathrm{~J} / \mathrm{cm}^{2}$ am dritten Messtag bei CD4+ T-Helferzellen spätapoptotische Werte von 31,9\% mit einer STABW von 7,7\% hervorbrachte, waren es unter dem Einfluss von alleiniger UVC-Strahlung mit $2 \mathrm{~J} / \mathrm{cm}^{2}$ zunächst $20,6 \%$ mit einer STABW von $6 \%$. Nach Verdreifachung der UVC-Strahlendosis auf $6 \mathrm{~J} / \mathrm{cm}^{2}$ wurde an Tag drei ein mittlerer Spätapoptosewert von 39,5\% mit einer STABW von 9,6. \% gemessen. Die unbehandelte Kontrollgruppe führte an Tag drei lediglich zu einer spätapoptotischen Rate von $6,2 \%$. Beide untersuchte Strahlenarten, UVA und UVC, bewirkten einen stetigen Anstieg der Spätapoptosewerte.

Der Globalvergleich ANOVA war an Tag eins, zwei und drei signifikant mit $\mathrm{p}<0,0001$. Nach Verdreifachung der UVC-Strahlendosis zeigte sich zwischen den Strahlendosen $2 \mathrm{~J}$ und $6 \mathrm{~J}$ an Tag eins ein signifikanter Unterschied in der induzierten Apoptoserate mit $\mathrm{p}<0,01$. An Tag zwei und drei wurde ein signifikanter Unterschied mit $\mathrm{p}<0,001$ gemessen.

\subsubsection{Kinetik der Spätapoptose bei CD3+ CD8+ zytotoxischen T-Zellen}

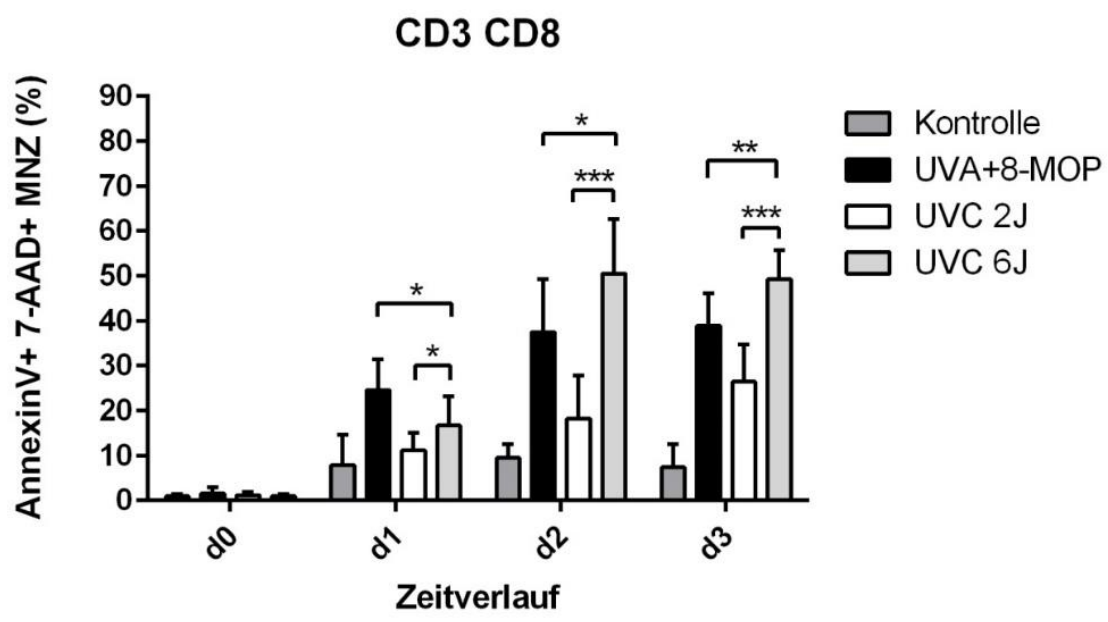

Abbildung 15: CD3+CD8+ Spätapoptosekinetik

$* p<0,05 \quad * * p<0,01 \quad * * * p<0,001$

Kontrolle $n=11 \quad$ UVA+8-MOP $n=9 \quad$ UVC $2 J n=9 \quad$ UVC $6 J n=12$

Zytotoxische CD8+ T-Zellen zeigten unter dem Einfluss von 8-MOP/ UVA $2 \mathrm{~J} / \mathrm{cm}^{2}$ ebenfalls einen konstanten Anstieg der Spätapoptose und wiesen am dritten Tag Werte von $38,9 \%$ auf. Die STABW betrug hier 7,2 \%. Nach Einwirkung alleiniger UVC-Strahlung und einer Dosis von $2 \mathrm{~J} / \mathrm{cm}^{2}$ wurden am dritten Messtag Werte von 26,4 \% mit einer STABW von $8,3 \%$ gemessen. Nach Steigerung der UVC-Strahlendosis auf $6 \mathrm{~J} / \mathrm{cm}^{2}$ betrugen die Werte an Tag drei bereits 49,2\% und ergaben eine STABW von 6,4\%. Die unbehandelte 
Kontrollgruppe zeigte mit einer durchschnittlichen spätapoptotischen Rate von 7,4\% deutlich niedrigere Werte.

Der Globalvergleich ANOVA war an Tag eins, zwei und drei signifikant mit $\mathrm{p}<0,0001$. Nach Steigerung der UVC-Strahlendosis auf $6 \mathrm{~J} / \mathrm{cm}^{2}$ zeigten sich zwischen den beiden Strahlendosen $2 \mathrm{~J} / \mathrm{cm}^{2}$ und $6 \mathrm{~J} / \mathrm{cm}^{2}$ ab Tag eins, signifikante Unterschiede in der induzierten Apoptoserate. An Tag eins mit $\mathrm{p}<0,05$ und an Tag zwei und drei mit $\mathrm{p}<0,001$.

\subsubsection{Kinetik der Spätapoptose bei CD14+ Monozyten}

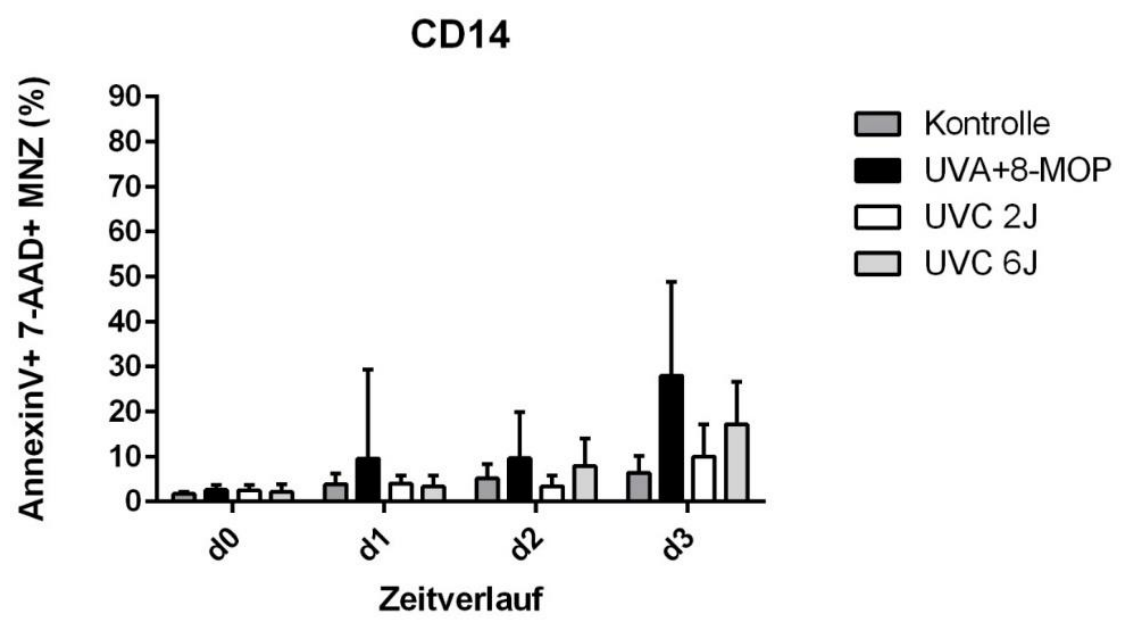

Abbildung 16: CD14+ Spätapoptosekinetik

$* p<0,05 \quad * * p<0,01 \quad * * * p<0,001$

Kontrolle $n=11 \quad$ UVA+8-MOP $n=9 \quad$ UVC $2 J n=9 \quad$ UVC $6 J n=12$

Im Durchschnitt zeigten CD14+ Monozyten vergleichsweise geringe spätapoptotische Werte. Unter 8-MOP / UVA $2 \mathrm{~J} / \mathrm{cm}^{2}$ betrugen die Werte an Tag drei $28 \%$ mit einer STABW von $20,9 \%$. Unter dem Einfluss von alleiniger UVC-Strahlung waren die Werte etwas geringer. Nach Behandlung mit UVC $2 \mathrm{~J} / \mathrm{cm}^{2}$ wurden am dritten Tag spätapoptotische Werte von $10 \%$ mit einer STABW von 7,2\% gemessen, nach Verdreifachung der Dosisleistung auf $6 \mathrm{~J} / \mathrm{cm}^{2}$ wurde an Tag drei ein Mittelwert von 17,2\% mit einer STABW von 9,4\% erreicht. Die unbehandelte Kontrollgruppe wies an Tag drei eine Spätapoptoserate von lediglich $6,4 \%$ auf.

Der Globalvergleich ANOVA war an Tag eins, zwei und drei signifikant mit $\mathrm{p}=0,0004$. Zwischen den beiden untersuchten Strahlenarten konnten keine signifikanten Unterschiede hinsichtlich induzierter Apoptoseraten festgestellt werden. Auch die Verdreifachung der 
Dosisleistung der UVC-Strahlung brachte keine signifikant höheren spätapoptotischen Werte hervor.

\subsubsection{Kinetik der Spätapoptose bei CD19+ B-Zellen}

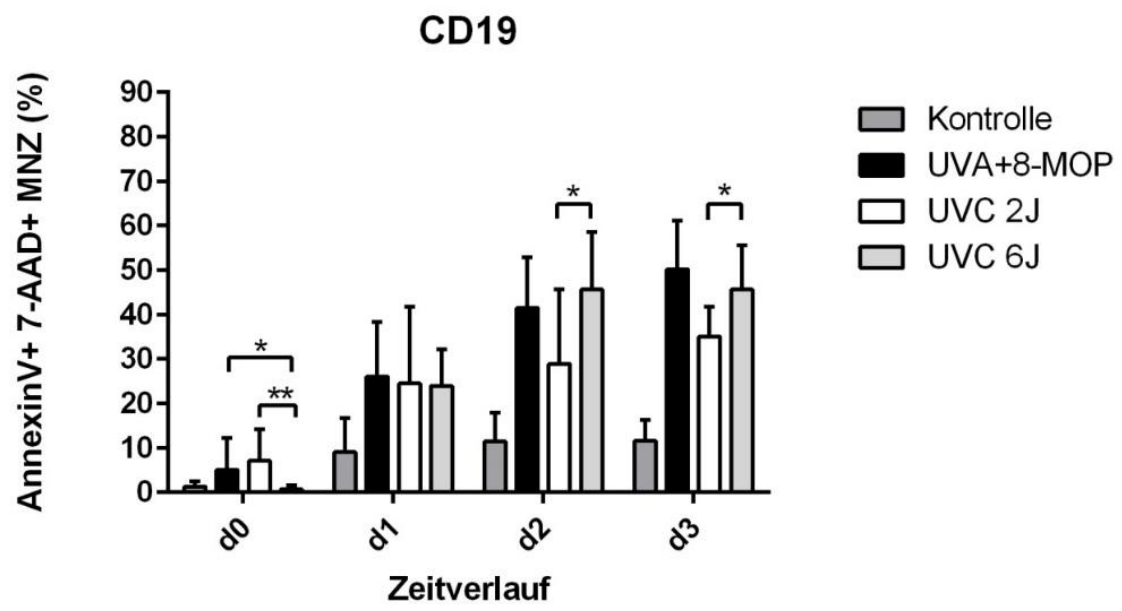

Abbildung 17: CD19+ Spätapoptosekinetik

$* p<0,05 \quad * * p<0,01 \quad * * * p<0,001$

Kontrolle $n=11 \quad$ UVA $+8-M O P n=9 \quad$ UVC $2 J n=9 \quad$ UVC $6 J n=12$

CD19+ B-Zellen zeigten an Tag drei nach Behandlung mit 8-MOP/ UVA $2 \mathrm{~J} / \mathrm{cm}^{2}$ spätapoptotische Werte von 50,2 \% mit einer STABW von 10,9\%. Unter dem Einfluss von UVC-Strahlung und einer Dosis von $2 \mathrm{~J} / \mathrm{cm}^{2}$ wurde ein spätapoptotischer Mittelwert von $35 \%$ mit einer STABW von 6,7 \% gemessen. Nach Verdreifachung der UVC-Strahlendosis auf $6 \mathrm{~J} / \mathrm{cm}^{2}$ waren es an Tag drei 45,6\% mit einer STABW von $10 \%$. Beide untersuchten Strahlenarten konnten im Verlauf der beobachteten 72 Stunden ansteigende Spätapoptosewerte erzeugen. Die unbehandelte Kontrollgruppe wies eindeutig geringere Werte auf und erreichte an Tag drei einen Mittelwert von lediglich 11,6\%.

Der Globalvergleich ANOVA war an Tag eins, zwei und drei signifikant mit $p<0,0001$. CD19+ B-Zellen reagierten auf die Einwirkung von 8-MOP/UV A $2 \mathrm{~J} / \mathrm{cm}^{2}$ und UVC $6 \mathrm{~J} / \mathrm{cm}^{2}$ mit einem ähnlichen Apoptoseprofil. Die Steigerung der UVC-Strahlendosis auf $6 \mathrm{~J} / \mathrm{cm}^{2}$ zeigte an Tag zwei und drei im Vergleich zur Dosis $2 \mathrm{~J} / \mathrm{cm}^{2}$ signifikante Unterschiede mit $\mathrm{p}<0,05$. 


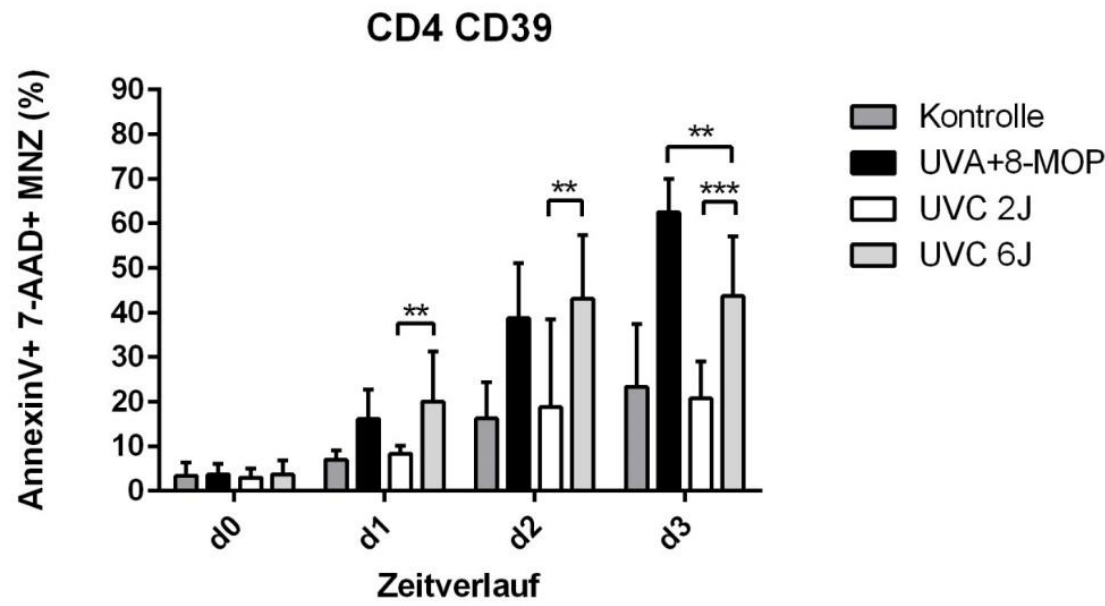

Abbildung 18: CD4+ CD39+ Spätapoptosekinetik

$* p<0,05 \quad * * p<0,01 \quad * * * p<0,001$

Kontrolle $n=11 \quad$ UVA $+8-M O P n=9 \quad$ UVC $2 J n=9 \quad$ UVC $6 J n=12$

CD4+ CD39+ regulatorische T-Zellen zeigten unter ECP-Therapie mit 8-MOP / UVA $2 \mathrm{~J} / \mathrm{cm}^{2}$ am dritten Tag spätapoptotische Werte von $62,5 \%$ mit einer STABW von 7,4 \%. Unter dem Einfluss von UVC-Strahlung wurden an Tag drei zunächst mit einer Dosis von $2 \mathrm{~J} / \mathrm{cm}^{2}$ spätapoptotische Werte von $20,7 \%$ mit einer STABW von 8,3\% gemessen. Nach Dosissteigerung auf $6 \mathrm{~J} / \mathrm{cm}^{2}$ wurden am dritten Tag Werte von 43,7\% gemessen. Die STABW betrug hier $13,5 \%$. Beide untersuchten Strahlenarten führten im Verlauf der 72 Stunden zu einem konstanten Anstieg der Spätapoptose. Die unbehandelte Kontrollgruppe wies an Tag drei einen Wert von 23,3\% auf.

Der Globalvergleich ANOVA war an Tag eins, zwei und drei signifikant mit $p<0,0001$. Lediglich an Tag drei zeigte sich ein signifikanter Unterschied zwischen der apoptoseinduzierenden Wirkung von 8-MOP / UVA $2 \mathrm{~J} / \mathrm{cm}^{2}$ und UVC $6 \mathrm{~J} / \mathrm{cm}^{2}$ mit $\mathrm{p}<0,01$. Die Steigerung der UVC-Strahlendosis von $2 \mathrm{~J} / \mathrm{cm}^{2}$ auf $6 \mathrm{~J} / \mathrm{cm}^{2}$ führte zu signifikanten Anstiegen der spätapoptotischen Werte, an Tag eins und zwei mit $p<0,01$ und an Tag drei mit $\mathrm{p}<0,001$. 


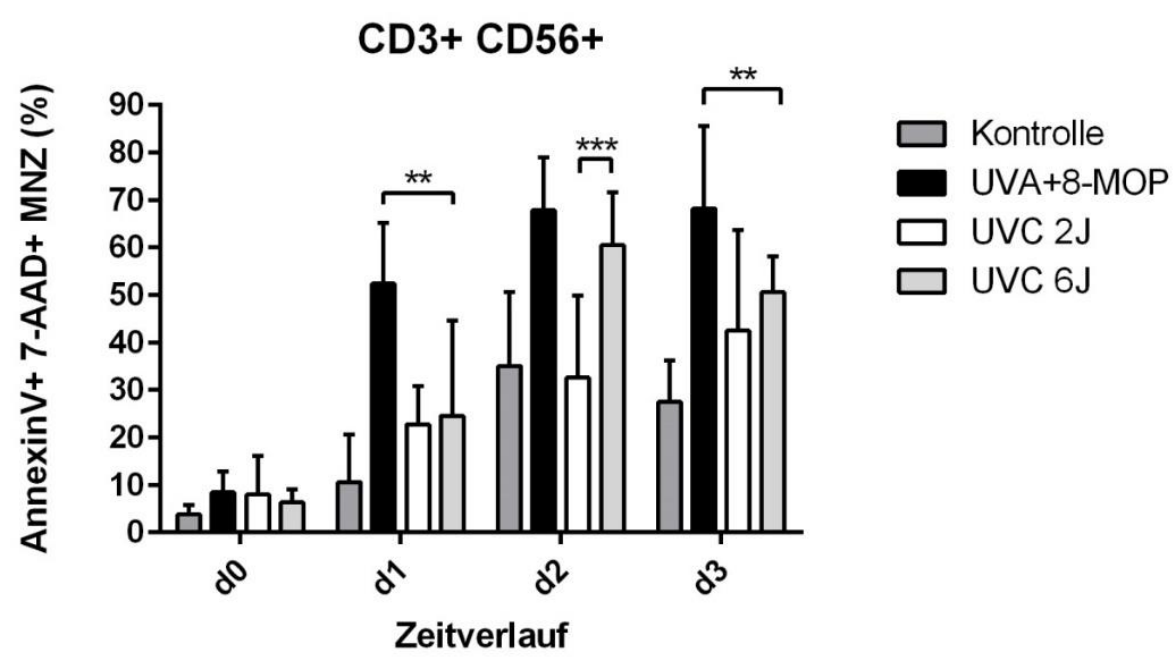

Abbildung 19: CD3+ CD56+ Spätapoptosekinetik

$* p<0,05 \quad * * p<0,01 \quad * * * p<0,001$

Kontrolle $n=11 \quad$ UVA $+8-M O P n=9 \quad$ UVC $2 J n=9 \quad$ UVC $6 J n=12$

Natürliche Killer-T-Zellen zeigten ein vergleichsweise vulnerables Apoptoseprofil auf. Unter 8-MOP / UVA $2 \mathrm{~J} / \mathrm{cm}^{2}$ zeigten sich am dritten Tag spätapoptotische Werte von $68,2 \%$ mit einer STABW von 17,3\%. Unter dem Einfluss von alleiniger UVC-Strahlung konnte ein ähnliches Apoptoseprofil festgestellt werden. Zunächst wurden nach Einwirken einer Dosis von $2 \mathrm{~J} / \mathrm{cm}^{2}$ am dritten Tag Werte von 42,5\% mit einer STABW von 21,2 \% gemessen. Nach Dosissteigerung auf $6 \mathrm{~J} / \mathrm{cm}^{2}$ waren es an Tag drei 50,5\% mit einer STABW von 7,6\%. Die unbehandelte Kontrollgruppe wies bei den NKT-Zellen ebenfalls vergleichsweise hohe spätapoptotische Werte auf. An Tag drei wurden hier 27,5 \% gemessen.

Der Globalverleich ANOVA war an Tag eins, zwei und drei signifikant mit $p<0,0001$. Trotz Verdreifachung der UVC-Dosis wurden an Tag eins und drei noch signifikante Unterschiede im Vergleich zur apoptoseinduzierenden Wirkung von 8-MOP / UVA $2 \mathrm{~J} / \mathrm{cm}^{2}$ festgestellt, jeweils mit $\mathrm{p}<0,01$. 


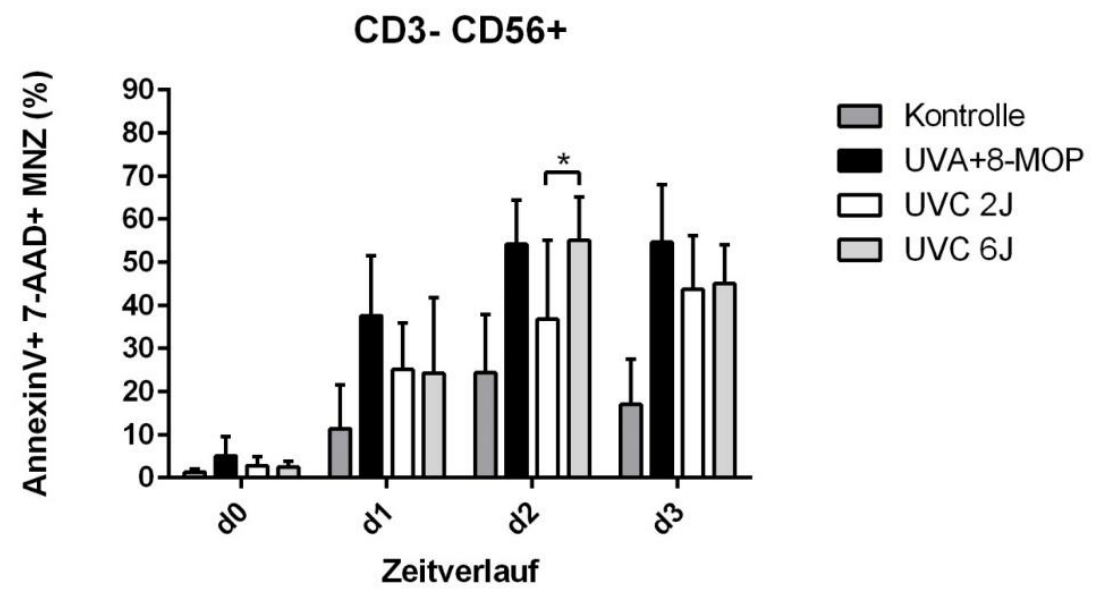

Abbildung 20: CD3-CD56+ Spätapoptosekinetik

$* p<0,05 \quad * * p<0,01 \quad * * * p<0,001$

Kontrolle $n=11 \quad$ UVA+8-MOP $n=9 \quad$ UVC $2 J n=9 \quad$ UVC $6 J n=12$

Auch NK-Zellen zeigten über den gemessenen Zeitraum von vier Tagen eine durchschnittlich konstant ansteigende Spätapoptosekinetik. Am dritten Tag wurden unter 8-MOP / UVA $2 \mathrm{~J} / \mathrm{cm}^{2}$ Werte von $54,7 \%$ mit einer STABW von $13,4 \%$ erreicht. Unter alleiniger Einwirkung von UVC-Strahlung wurden am dritten Tag zunächst nach einer Dosis von $2 \mathrm{~J} / \mathrm{cm}^{2}$ spätapoptotische Werte von $43,7 \%$ mit einer STABW von 12,6\% gemessen. Nach Steigerung der Dosis auf $6 \mathrm{~J} / \mathrm{cm}^{2}$ waren es am dritten Tag 45,1\% mit einer STABW von $9 \%$. Die unbehandelte Kontrollgruppe wies an Tag drei einen spätapoptotischen Mittelwert von $17 \%$ auf.

Der Globalvergleich ANOVA war an Tag eins, zwei und drei signifikant mit $p<0,0001$. Insgesamt zeigte sich unter beiden untersuchten Strahlenarten ein ähnliches Apoptoseprofil, das im Vergleich zwischen 8-MOP / UVA $2 \mathrm{~J} / \mathrm{cm}^{2}$ und UVC $6 \mathrm{~J} / \mathrm{cm}^{2}$ an keiner Stelle einen signifikanten Unterschied aufwies.

Im Anhang sind aus Übersichtstabellen Mittelwerte \pm STABW und p-Werte zu oben beschriebenen Vergleichen ersichtlich.

Tabelle 12 beinhaltet Daten zum Vergleich von UVC $2 \mathrm{~J} / \mathrm{cm}^{2}$ und UVC $6 \mathrm{~J} / \mathrm{cm}^{2}$.

Tabelle 13 beinhaltet Daten zum Vergleich von 8-MOP / UVA $2 \mathrm{~J} / \mathrm{cm}^{2}$ und UVC $6 \mathrm{~J} / \mathrm{cm}^{2}$. 
Auf Grundlage der erhobenen Daten konnte ein konstanter Anstieg spätapoptotischer Zellen festgestellt werden.

\subsection{Mixed Lymphocyte Reaction}

Im Anschluss an oben beschriebene Versuche wurde im Rahmen des vorliegenden Projekts in drei aufeinanderfolgenden Durchläufen begonnen, die Anwendbarkeit der gewonnenen Erkenntnisse in einer Mixed Lymphocyte Reaction (MLR) zu testen. Ziel dieser etablierten Methode zur Prüfung des Sicherheitsprofils einer neuen Therapie war es, nach Konstruktion einer ex-vivo GVHD, unter Verwendung von Aktivitätsmarkern wie CD69, CD154 und CD137 eine Bestätigung der ECP-Wirkung zu erlangen. Aktivitätsmarker korrelieren mit der Zellproliferationsrate. Hohe Wachstums- und Teilungsraten wiederum implizieren Reaktivität. Je höher die Reaktivität der Donor-Zellen, desto größer wiederum die Wahrscheinlichkeit, dass es zu einer Transplantatabstoßung kommt. Ziel der ECP-Therapie ist es demnach, die Reaktivität der Zellen zu senken um ein erfolgreiches Engraftment zu ermöglichen.

In der vorliegenden Arbeit wurden CD4+ T-Helferzellen, CD8+ zytotoxische T-Zellen und natürliche Killerzellen in ihrer Expression von Aktivitätsmarkern nach ECP-Behandlung untersucht und mit einer unbehandelten Kontrollgruppe verglichen. Hierbei wurden zwei Buffy-Coats miteinander ko-kultiviert, nachdem einer davon zuvor mit 20 Gy $\gamma$-Strahlung behandelt wurde, was die erforderliche Hochdosis-Chemotherapie der Patienten vor aHSCT imitiert. Bestrahlte antigenpräsentierende Zellen, wie z. B. reife dendritische Zellen (DC), die als Stimulatoren agieren können, treffen hierbei auf allogene T-Lymphozyten des zweiten, unbehandelten Buffy-Coats. Nach 24 Stunden wurden $10 \%$ der Zellen einer inkubierten Zellkultur unter sterilen Bedingungen der standardisierten 8-MOP/ UVABehandlung unterzogen. Nach 72 Stunden wurde die therapierte Zellpopulation mit der unbehandelten Kontrollpopulation mittels Durchflusszytometrie anhand der Färbung in ihrer Aktivitätsausprägung verglichen.

Die folgenden Abbildungen zeigen die graphische Zusammenfassung der drei Versuchsdurchgänge.

Die prozentualen Anteile der Zellen mit den Aktivierungsmarkern beziehen sich jeweils auf alle MNZ. 
3.3.1 MLR und Aktivitätsmessung bei CD4+ T-Helferzellen

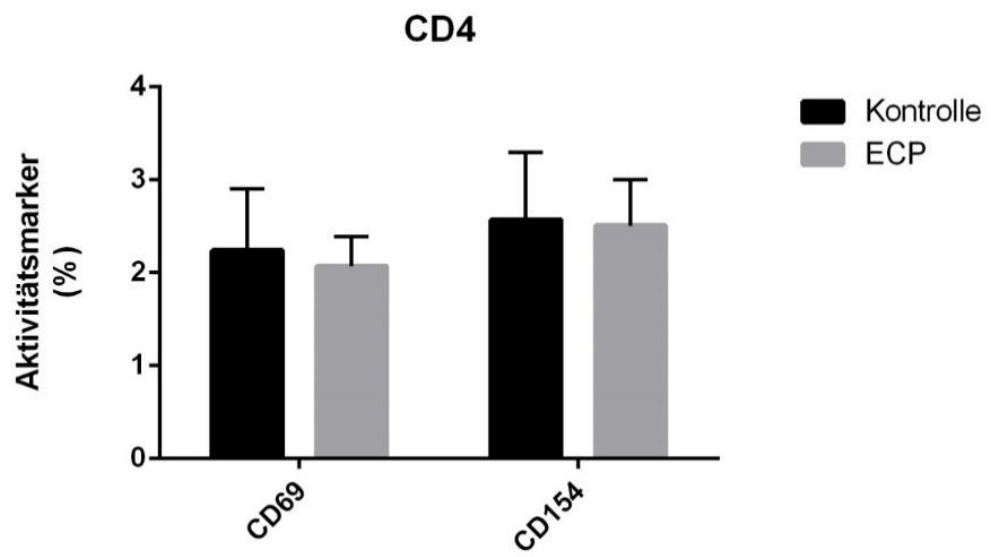

Abbildung 21: MLR: Anteil der CD4 CD69 bzw. CD4 CD154 doppelt-positiven Zellen an allen MNZ der Probe Kontrolle $n=3 \quad E C P n=3$

In der unbehandelten Kontrollgruppe betrug der Mittelwert von CD69 positiven Zellen 72 Stunden nach Beginn des Versuches 2,23\%. In der mit 8-MOP / UVA $2 \mathrm{~J} / \mathrm{cm}^{2}$ behandelten Gruppe wurden 72 Stunden nach ECP-Therapie 2,07 \% gemessen. Der Aktivitätsmarker CD154 wies bei der unbehandelten Kontrollgruppe nach 72 Stunden einen Wert von 2,56 \% auf. Bei der mit ECP behandelten Gruppe waren es 2,5\%.

3.3.2 MLR und Aktivitätsmessung bei CD8+ zytotoxischen T-Zellen

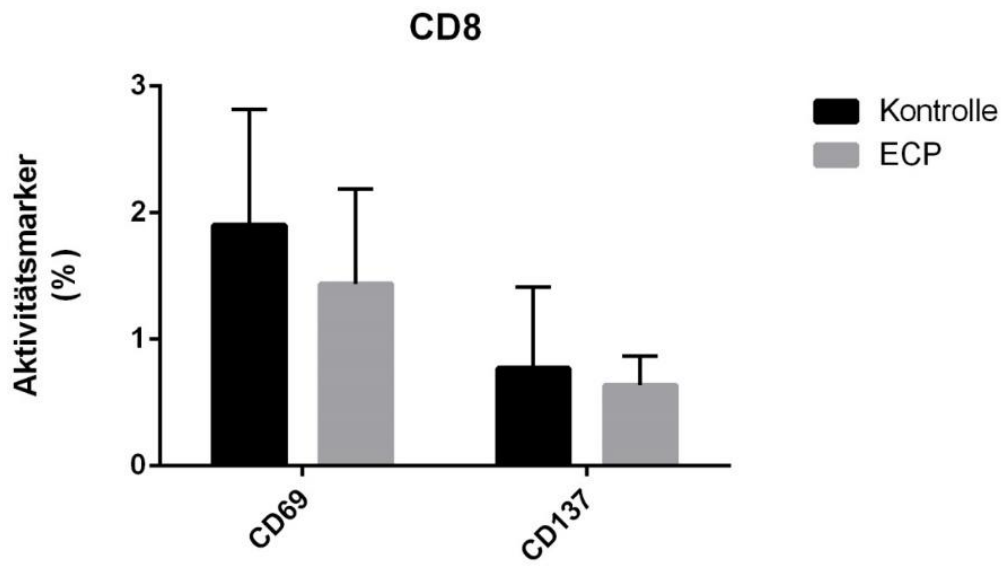

Abbildung 22: MLR: Anteil der CD8 CD69 bzw. CD8 CD137 doppelt-positiven Zellen an allen MNZ der Probe Kontrolle $n=3 \quad$ ECP $n=3$

Bei CD8+ zytotoxischen T-Zellen betrug der Aktivitätsmarker CD69 72 Stunden nach Versuchsbeginn in der unbehandelten Kontrollgruppe 1,9\% und in der mit 8-MOP / UVA 
$2 \mathrm{~J} / \mathrm{cm}^{2}$ behandelten Gruppe 1,43\%. Der Aktivitätsmarker CD137 zeigte in der unbehandelten Kontrollgruppe 72 Stunden nach Versuchsbeginn einen Mittelwert von 0,77\% und in der ECP-behandelten Gruppe 0,63\%.

\subsubsection{MLR und Aktivitätsmessung bei CD3- CD56+ NK-Zellen}

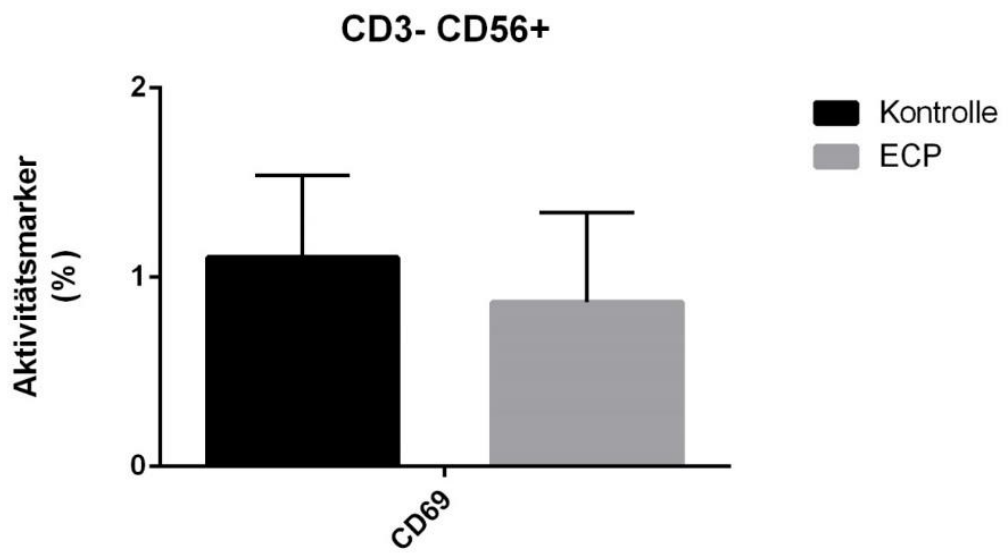

Abbildung 23: MLR: Anteil CD3-CD56+CD69+ Zellen an allen MNZ der Probe

Kontrolle $n=3 \quad$ ECP $n=3$

Natürliche Killerzellen wurden ausschließlich auf den Aktivitätsmarker CD69 getestet. Dieser betrug bei der unbehandelten Kontrollgruppe 72 Stunden nach Versuchsbeginn $1,1 \%$. Bei der mit 8-MOP / UVA $2 \mathrm{~J} / \mathrm{cm}^{2}$ behandelten Gruppe betrug der Aktivitätswert 72 Stunden nach ECP-Therapie 0,87\%. 


\section{Diskussion}

Die ECP-Therapie ist ein sich seit rund drei Jahrzehnten weltweit etablierender Therapieansatz für verschiedene maligne und nicht maligne Erkrankungen. Neben dermatologischen und hämatologischen Krankheitsbildern werden inzwischen auch Abstoßungsreaktionen nach soliden Organtransplantationen als Indikation begriffen (Durazzo et al. 2014), wobei die Therapie hier in den meisten Fällen noch als Zweitlinientherapie angewandt wird (Cho et al. 2018; Sanford und Balogun 2012). Die Therapie bekommt zunehmend mehr Beachtung und Aufmerksamkeit und ist sowohl wegen ihrer wenig-invasiven, nebenwirkungsarmen Methode und ihren erfolgreichen Ergebnissen als auch aufgrund ihres noch nicht vollends geklärten Wirkmechanismus Gegenstand aktueller Forschungen (Marques und Adamski 2014; Durazzo et al. 2014).

Die Einrichtung und das Betreiben einer ECP-Behandlungseinheit erfordert jedoch besondere räumliche Ausstattungen, ein hohes Maß an Spezialequipment und explizit ausgebildetes pflegerisches- und ärztliches Personal. Im Zuge der Modernisierung und Digitalisierung steigen Hygiene- und Sicherheitsstandards an, und auch die Sicherheitsvorkehrungen und Kontrollen von Seiten des Qualitätsmanagements werden streng überprüft. Es ist anzunehmen, dass zukünftig ECP-praktizierende Häuser verpflichtet werden, die Therapie in sterile GMP-Bereiche zu verlagern, da ein Kontaminationsrisiko durch die Öffnung des geschlossenen Systems durch die Zugabe von 8-MOP potenziell gegeben ist und auch dieses Risiko nach heutigen Standards beseitigt werden will. Diese Sicherheitsauflage wäre verbunden mit kaum realisierbaren logistischen Umstrukturierungen der Fachkliniken, die sich, wenn überhaupt, nur die finanziell stärksten Maximalversorger leisten könnten.

Dem könnte mit der Hypothese, dass die alleinige Wirkung von UVC gleiche Ergebnisse hervorbringt wie UVA / 8-MOP, begegnet werden.

Standardmäßig wird für die extrakorporale Photopherese-Therapie, die durch Immunmodulation vor allem in der Behandlung T-Zell-vermittelter Erkrankungen Verwendung findet, UVA-Licht in einer Dosis von $2 \mathrm{~J} / \mathrm{cm}^{2}$ in fixer Kombination mit dem DNAInterkalator 8-MOP verwendet. UVA-Strahlung allein ist energetisch nicht ausreichend stark, wodurch die photobiologischen Auswirkungen vorwiegend auf indirekten Effekten beruhen und auf von außen zugeführte Verstärkung, wie durch Psoralene, angewiesen sind 
(Singer und Berneburg 2018; Cho et al. 2018). Da die Induktion der Apoptose in den bestrahlten MNZ und deren Phagozytose nach Reinfusion jedoch allgemein als wesentlich für die Wirkung der ECP-Therapie verstanden wird (Chen et al. 2015; Heshmati 2014), wird das chemisch hergestellte 8-MOP als Interkalator zu Hilfe genommen. Es dient der Photosensibilisierung, führt unter dem Einfluss von UVA-Licht zu einer Photoaktivierung und induziert die therapeutisch notwendige Apoptose. Da durch das manuelle Injizieren von 8-MOP in den Behandlungsbeutel ein in sich geschlossenes System geöffnet wird und Kontakt zur Umgebungsluft entsteht, steigt in der Konsequenz das bakterielle Kontaminationsrisiko.

Diese Tatsache führte zu der dieser Arbeit zugrunde liegenden Überlegung, durch die Verwendung einer energetisch stärkeren UV-Strahlenart zukünftig auf 8-MOP verzichten zu können und somit ein geschlossenes Therapiesystem zu gewährleisten, das theoretisch weniger anfällig für Kontaminationen ist. Da UVA-Strahlung mit einer Wellenlänge von 315-380 nm zwar eine verhältnismäßig große Eindringtiefe in die Zellsuspension aufweist, aber energetisch für den erforderlichen Zweck der Apoptoseinduktion nicht stark genug ist, wurde in dieser Arbeit die energetisch überlegene UVC-Strahlung mit einer Wellenlänge von $254 \mathrm{~nm}$ als Alternative experimentell untersucht. Während UVA-Strahlen bekanntermaßen in vivo bis in dermale Strukturen und zu Blutgefäßen vordringen und auch die Eindringtiefe der UVB-Strahlen bis zur dermo-epidermalen Junktionszone bekannt ist, bleibt der Effekt von UVC-Strahlung, abgesehen von beschriebenen DNA-Läsionen, Bildung von Photodimeren und bekanntem kanzerogenem Potenzial, hinsichtlich der Verwendung im phototherapeutischem Therapieansatz weitgehend unklar (Situm et al. 2014; Narita et al. 2018).

In mehreren Versuchsdurchläufen wurden die Wirkweisen der beiden Strahlenarten auf aus Buffy-Coats extrahierten MNZ ex vivo untersucht und anschließend die induzierten Apoptoseraten, unter 8-MOP / UVA $2 \mathrm{~J} / \mathrm{cm}^{2}$, UVC $2 \mathrm{~J} / \mathrm{cm}^{2}$ und UVC $6 \mathrm{~J} / \mathrm{cm}^{2}$ statistisch miteinander verglichen. Die Buffy-Coats wurden von gesunden, freiwilligen Blutspendern nach deren Einwilligung als Restmaterial aus Vollblutspenden gewonnen.

In Übereinstimmung mit Ergebnissen anderer Studien konnten die Versuchsergebnisse der vorliegenden Arbeit einerseits die bereits erlangte Erkenntnis der nahezu vollständigen Apoptose der meisten MNZ im Rahmen der ECP-Behandlung reproduzieren (Durazzo et al. 2014). Andererseits zeigten sich erfolgversprechende neue Tendenzen bzgl. der apoptoseinduzierenden Wirkung von UVC-Strahlung. In Anlehnung an weitere Studien 
wurde sowohl der in der Arbeitsgruppe bereits etablierte Zelltodmarker Annexin V (Budde et al. 2017), als auch der Avitalfarbstoff 7-AAD zur Objektivierung der Apoptose in paralleler Durchführung verwendet, um zwischen Früh- und Spätapoptose differenzieren zu können. Es ist wahrscheinlich, dass ein konstant aufrechterhaltenes Apoptoselevel nach Reinfusion zu einer beständigen Immunmodulation führt (Birge und Ucker 2008). Sowohl ein zu rascher als auch ein sehr zögerlicher Apoptoseanstieg könnte im Rahmen der ECPTherapie unerwünschte Auswirkungen auf das therapeutische Endergebnis haben. Der konsekutive, stete Anstieg der Apoptose im Verlauf mehrerer Tage ist somit von ausschlaggebender Bedeutung und ein Grund für die stärker frequentierten Therapiesitzungen zu Beginn der Behandlung, die zwei Mal wöchentlich stattfinden und einen regelmäßigen Apoptoseanstieg in der Peripherie des Patienten gewährleisten.

Insgesamt konnte festgestellt werden, dass die verschiedenen Leukozytensubpopulationen unter dem Einfluss von UVC-Strahlung ähnliche Apoptosemuster aufwiesen wie unter dem Einfluss von 8-MOP / UVA, auch wenn sie im Schnitt unter den in unseren Versuchsreihen eingesetzten UVC-Dosen eine geringfügig langsamere Kinetik zeigten.

In Erwägung der Möglichkeit einer rein zufälligen Apoptosekinetik nach UVC-Bestrahlung durch eine tendenziell vulnerable Prädisposition einer Versuchspopulation, wurden in drei Versuchen aus je einem BC zwei Versuchsreihen gestartet. Die Versuchsreihen unterlagen stets exakt den gleichen äußeren Umständen, mit der Ausnahme, dass in einem der beiden Experimente die MNZ mit UVC bestrahlt wurden. Im direkten Vergleich konnte nach Beendigung dieser parallelen Versuchsdurchläufe die angenommene apoptoseinduzierende Wirkung von UVC-Strahlung eindeutig gezeigt werden.

Obwohl die Apoptoseraten nach Angleichung der UVC-Strahlungsdosis auf $6 \mathrm{~J} / \mathrm{cm}^{2}$ noch nicht exakt äquivalent hohe Werte wie die herkömmliche ECP-Therapie mit 8-MOP / UVA $2 \mathrm{~J} / \mathrm{cm}^{2}$ ergaben, wurden im Durchschnitt, bezogen auf in dieser Arbeit erhobene Daten, in den meisten Fällen keine signifikanten Unterschiede $(\mathrm{p}>0,05)$ in der Wirkung der beiden untersuchten Strahlenarten bzgl. ihrer absoluten Apoptosewerte festgestellt. Die Anpassung der UVC-Dosisleistung erfolgte, nachdem ein Verlust der Strahlungswirkung durch Absorption an der Plastikoberfläche der Kulturflaschen festgestellt wurde. Mittels Messsonde wurden die Wirkungsverluste unter UVA und UVC an der Plastikoberfläche ermittelt, anhand derer die UVC-Bestrahlungsdosis so erhöht wurde, dass rechnerisch äquivalente Dosisleistungen unter beiden Strahlenarten in den Zellen erreicht werden konnten. Es wurde durchgehend in allen untersuchten Zellpopulationen eine Zunahme der 
Apoptoserate nach Dosissteigerung der UVC-Strahlung beobachtet. Dies legt die Annahme nahe, dass ein weiterer Anstieg der Apoptoserate nach erneuter Dosissteigerung auf z. B. $8 \mathrm{~J} / \mathrm{cm}^{2} \mathrm{zu}$ erwarten ist. Es scheint daher realistisch, dass zunächst im in vitro Modell mit UVC-Strahlung Apoptosewerte erzielt werden können, die exakt so hoch sind wie unter dem Einsatz von 8-MOP / UVA.

Die GVHD ist nach einer aHSCT mit einer Auftrittswahrscheinlichkeit von rund $50 \%$ nach wie vor die Hauptkomplikation des in vielen Fällen letzten kurativen Therapieversuchs der HSCT und wird mit einer signifikant erhöhten therapiebedingten Mortalität assoziiert (Martínez-Laperche et al. 2018). Da die GVHD in Deutschland außerdem eine Hauptindikation für die ECP-Behandlung darstellt und diese Systemerkrankung durch eine T-Zell vermittelte Entzündungsreaktion hervorgerufen wird, die durch alloreaktive T-Zellen des Donors ausgelöst wird (Welniak et al. 2007; Ferrara et al. 2009), ist ein Focus auf die UV-Licht-Reaktion dieser Subpopulation von besonderer Wichtigkeit.

Es konnte gezeigt werden, dass CD3+ T-Zellen insgesamt, und CD4+ CD8+ im Besonderen, sowohl unter dem Einfluss von UVA als auch unter UVC hohe Apoptosewerte im In-vitroModell erreichten. Die Ergebnisse unter UVA korrelieren mit erhobenen Daten anderer Arbeitsgruppen wie der von Schmid et al., die ebenfalls nach rund 70 Stunden hohe Apoptoseraten in CD3+ Zellen nach einer Ex-vivo-ECP beschrieben haben (Schmid et al. 2015).

CD3+ CD4+ T-Helferzellen lassen sich abhängig von ihrem Zytokinprofil in TH1, TH2 und TH17-Zellen unterteilen und kontrollieren sich untereinander über Feedback-Mechanismen. Dementsprechend übernehmen sie unterschiedliche, aber entscheidende Rollen in der Entstehung einer GVHD (Blazar et al. 2012) und zeigten in allen Versuchsdurchläufen dieses Projekts einen steigenden Apoptoseanstieg. Sie gingen sowohl unter 8-MOP / UVA $2 \mathrm{~J} / \mathrm{cm}^{2}$ als auch unter UVC $6 \mathrm{~J} / \mathrm{cm}^{2}$ bis zum zweiten Tag mit nicht signifikant unterschiedlicher Kinetik in Apoptose. Lediglich am letzten Tag wurden unter der herkömmlichen Bestrahlungsmethode mit 8-MOP / UVA signifikant höhere Apoptosewerte mit $\mathrm{p}>0,05$ erreicht. Mit großer Wahrscheinlichkeit ließe sich diese verbleibende Differenz jedoch mit einer Dosissteigerung der UVC-Leistung ausgleichen.

Zytotoxische CD3+CD8+ Zellen sind einerseits durch eine anfängliche Gewebedestruktion nach aHSCT mitverantwortlich für die Entstehung einer GVHD und andererseits die Hauptakteure im erwünschten GVL-Effekt (Blazar et al. 2012). In den durchgeführten Versuchen zeigten sie nach anfänglicher Startgleichheit, 24 Stunden nach Beginn der 
Therapie an Tag eins, einen signifikanten Unterschied in den durch die beiden untersuchten Strahlenarten erreichten Apoptosewerten. Am zweiten Tag erzielten beide Strahlenarten wieder nahezu identische Werte mit $82 \%$ unter UVA und $81 \%$ unter UVC, wohingegen am dritten Tag erneut signifikante Unterschiede auftraten. Unter UVA wurden über $90 \%$ erreicht, unter UVC waren es rund 20 Prozentpunkte weniger. Da Apoptose kein reversibles Geschehen ist, stellt sich hier die Frage, wie eine Abnahme des Mittelwerts der Apoptoseraten zustande kommen kann. Nachdem jedoch kein signifikanter Unterschied zwischen den Apoptosewerten an Tag zwei und an Tag drei bestand und eine ähnlich leichte Apoptosereduktion auch in einer Kontrollgruppe zu erkennen war, liegt die Annahme nahe, dass leichte Abweichungen der Apoptoseraten womöglich dadurch entstehen, dass apoptotische Zellen in winzige apoptotische Körper zerfallen, die durch ihre geringen Durchmesser nicht mehr von den eingestellten Aufnahmebereichen des Durchflusszytometers erfasst werden. Ebenfalls können die Abnahme der gesamten Zellzahl im Verlauf der Tage und natürliche Schwankungen in der Erhebung der Messwerte einen Grund für die leichte, gemessene Apoptosereduktion darstellen.

Insgesamt sind demnach unter der alternativen Strahlenart UVC bei zytotoxischen CD3+ CD8+ T-Zellen deutlich erkennbare, steigende Apoptosekinetiken zu beobachten, die sich jedoch nicht zu allen Messzeitpunkten mit den Apoptosekinetiken unter 8-MOP / UVA decken.

Monozyten machen rund $30 \%$ der im Rahmen der ECP-Therapie bestrahlten MNZ aus und spielen eine wichtige Rolle im Prozess der adaptiven Immunantwort. Über ihre Bedeutung im Rahmen der ECP-Behandlung wird seit der Zulassung durch die FDA im Jahr 1988 kontrovers diskutiert. Edelson et al. vertreten die Hypothese, ein wesentlicher Wirkmechanismus der ECP-Therpie läge in der Induktion des Differenzierungsprozesses der Monozyten hin zu plasmazytoiden dendritischen Zellen und sind der Meinung, Monozyten gingen unter dem Einfluss von 8-MOP/ UVA im Gegensatz zu anderen Leukozytensubpopulationen nicht in Apoptose (Edelson 2014; Durazzo et al. 2014). Aktuell ist dies die in der Literatur vorherrschende Annahme, wohingegen es inzwischen auch konträre Meinungen von Arbeitsgruppen gibt, die entweder Gegenteiliges feststellen konnten (Budde et al. 2017) oder der Auffassung sind, Monozyten gingen im Vergleich zu anderen Leukozytensubpopulationen lediglich zeitlich verspätet in Apoptose (Heshmati 2014). Auch Hannani et al. konnten zeigen, dass Monozyten unter der ECP-Behandlung zwar in Apoptose gingen, jedoch in einer weitaus langsameren Kinetik. Dies führe dazu, dass es auch nach Tagen noch überlebende Zellen gäbe, die in ihrer immunmodulierenden Funktion 
weitgehend unbeeinträchtigt blieben. Sowohl die Sekretion antiinflammatorischer Zytokine wie IL-10 als auch die Differenzierung hin zu dendritischen Zellen sei weiterhin möglich (Hannani et al. 2010). In der hier vorliegenden Arbeit wurde unter dem Einfluss der untersuchten Strahlenarten und mittels Apoptosemarker Annexin V eine stetig ansteigende Apoptosekinetik bei CD14+ Monozyten beobachtet, die an Tag drei unter beiden Strahlenarten Werte von rund $80 \%$ erreichte. Hier zeigte sich mit $\mathrm{p}=0,21$ kein signifikanter Unterschied zwischen UVA und UVC. Interessanterweise wurde jedoch gleichzeitig eine im Vergleich mit anderen Leukozytensubpopulationen auffällig und eindeutig schwächere Spätapoptose mit dem Avitalfarbstoff 7-AAD gemessen. Heshmati F. diskutierte bereits 2014 in einem Übersichtsartikel über die ECP-Wirkmechanismen und machte den unterschiedlichen Effekt, den früh- oder spätapoptotische Zellen nach Reinfusion auf das Immunsystem hätten, deutlich. Ihm zufolge führten frühapoptotische Zellen tendenziell zu einer Immuntoleranz, während spätapoptotische oder bereits nekrotische Zellen zusammen mit proinflammatorischen Zytokinen die Immunantwort nach Reinfusion steigern würden (Heshmati 2014). Dies ist eine interessante Erkenntnis, die die selbst erhobenen Daten einfacher einordnen lässt. Obwohl die Meinungen bzgl. des Verhaltens der Monozyten noch stark heterogen sind und die genauen Wirkmechanismen der ECP-Behandlung nach wie vor nicht vollends geklärt sind, scheint die Apoptoseinduktion und die Differenzierung zwischen Früh- und Spätapoptose hinsichtlich Herauf- oder Herunterregulierung des Immunsystems nach Reinfusion ein vielfach bestätigter, aber noch nicht vollends verstandener Schlüsselmechanismus zu sein.

In der komplexen Entstehungspathologie der GVHD gibt es laufend neue Erkenntnisse, die belegen, dass neben T-Zellen auch B-Zellen und APCs maßgeblich am Krankheitsmechanismus beteiligt sind. Auch ein erhöhter B-Zell-Aktivierungsmarker (BAFF) und erhöhte Subpopulationen an B-Zellen vor und während einer cGVHD konnten festgestellt werden, die evtl. als Indikatoren für eine Krankheitsentwicklung dienen können (Socié und Ritz 2014).

CD19+ B-Zellen erreichten in dieser Arbeit unter dem Einfluss beider untersuchter Strahlenarten nach drei Tagen mit $95 \%$ unter 8-MOP / UVA und $91 \%$ unter UVC nahezu äquivalente, nicht signifikant unterschiedliche Apoptoseraten. B-Zellen können im Rahmen von ECP-Therapie und GVHD unterschiedliche Funktionen übernehmen. Einerseits kann anhand von CD19+ CD21- B-Zellen ein früher Erfolg und das Ansprechen der ECPTherapie bei einer cGVHD gemessen und beurteilt werden (Chen et al. 2015). Dabei weist hier ein niedriger Prozentsatz an unreifen CD19+ CD21- B-Zellen auf ein im Vergleich zu 
prätherapeutischen Werten gutes Ansprechen der Behandlung hin (Kuzmina et al. 2009). Andererseits wurde auch gezeigt, dass der Abbau von B-Zellen durch das Biological Rituximab nach aHSCT einen präventiven Charakter in der Entwicklung einer cGVHD darstellt (Cutler et al. 2013; Alousi et al. 2010). Während genaue Funktion und Aufgabe der B-Zellen im Rahmen von aHSCT und GVHD folglich noch einen aktuellen Forschungsgegenstand darstellen, konnte in dieser Arbeit deutlich gezeigt werden, dass die Vulnerabilität der untersuchten CD19+ B-Zellen unter dem Einfluss beider Strahlenarten nicht signifikant unterschiedlich ist.

Auch regulatorische T-Zellen sind seit Jahrzehnten verstärkt Gegenstand der Forschung. Besonders interessant macht sie ihre immunsuppressive Funktion, u. a. auch durch ein entsprechendes Zytokinprofil, und ihr Potenzial zur Aufrechterhaltung immunologischer Selbsttoleranz (Abdel-Gadir et al. 2018; Ebrahimi et al. 2014; Kitagawa und Sakaguchi 2017; Sakaguchi et al. 2008). In der Regel werden regulatorische T-Zellen in der Immunphänotypisierung neben CD4+ und CD25+ auch mit dem Transkriptionsfaktor Foxp3+ identifiziert. Da dieser jedoch im Zellkern liegt und eine intrazelluläre Färbung eine Permeabilisation der Zellmembran voraussetzt, die wiederum mit einer positiven Annexin V Färbung einherginge, wurde in dieser Arbeit CD39 als Zellmarker verwendet. CD39 wird an der Zelloberfläche exprimiert und ist somit leichter nachzuweisen. Die ATPase CD39, die koexprimiert mit CD73 die immunsuppressive Aktivität der Tregs unterstützt, könnte ein interessantes pharmakologisches Target für die Zukunft sein, um Adenosin getriggerte immunsuppressive Effekte zu verhindern (Zhao et al. 2017). In der vorliegenden Arbeit zeigten Tregs sowohl unter dem Einfluss von 8-MOP / UVA als auch nach Behandlung mit UVC eine regelmäßig zunehmende Apoptosekinetik. An keiner Stelle zeigten sich signifikante Unterschiede zwischen den zwei Strahlenarten und den hervorgerufenen Apoptosewerten $(\mathrm{p}>0,05)$. Es wird stark angenommen, dass die steigende Produktion antigen-spezifischer Tregs einen wichtigen Beitrag in der immunmodulatorischen Wirkung der ECP-Therapie leistet (Ward 2011). Interessanterweise gibt es allerdings auch bzgl. dieser Zellpopulation Stimmen, die die bisher angenommene Schlüsselrolle der Tregs im Rahmen des ECP-Wirkmechanismus hinterfragen und der Ansicht sind, dass vor und nach Beginn der Therapie keine signifikanten Veränderungen in der Anzahl der Tregs im peripheren Blut zu finden seien (Gandelman et al. 2018).

NKT-Zellen reagierten auf beide Strahlenarten mit einer ähnlichen Apoptosekinetik. Lediglich am dritten Tag gab es einen signifikanten Unterschied in den Apoptosewerten, in denen die UVC-Behandlung der herkömmlichen Therapie mit 8-MOP / UVA um rund zehn 
Prozentpunkte unterlag. Auch hier ist nach einer Steigerung der UVC-Dosis auf z. B. $8 \mathrm{~J} / \mathrm{cm}^{2}$ von einer weiteren Annäherung der Werte auszugehen.

Während natürliche Killer-T-Zellen zunächst keine bekannte Schlüsselrolle im Rahmen der ECP-Effekte einzunehmen scheinen, sieht das bei NK-Zellen anders aus. Natürliche Killerzellen scheinen einige bekannte positive Effekte im Rahmen einer aHSCT zu haben. Sie sind laut Palmer et al. eine der Zellgruppen, die sich nach einer HSCT am schnellsten erholt und sowohl einen risikoreduktiven Effekt auf die Entwicklung einer GVHD zu haben scheint als auch im HLA-haploidenten HSCT-Setting den GVL-Effekt verstärkt (Palmer et al. 2013). Außerdem ist ihr antiinfektiöses Potenzial im post-Transplantationssetting von wichtiger Bedeutung. Becherucci et al. zeigten außerdem die inhibitorische Wirkung der ECP-Therapie auf die zytotoxische Eigenschaft der NK-Zellen, die mit einem niedrigem Hämatokrit positiv zu korrelieren schien (Becherucci et al. 2017). Im direkten Zusammenhang mit der ECP-Therapie hat die Zellgruppe der NK-Zellen aber somit im Vergleich zu anderen Subpopulationen eher nur Nebeneffekte. NK-Zellen gingen in der vorliegenden Arbeit unter dem Einfluss beider untersuchter Strahlenarten kontinuierlich in Apoptose, zeigten jedoch an Tag zwei und drei noch signifikant unterschiedliche Apoptosewerte.

Parallel zu den oben diskutierten Apoptosemustern, die mithilfe des Markers Annexin V erhoben wurden, ist jeweils stets auch der Anteil der Spätapoptoserate an den bereits Annexin V positiven Zellen mit dem Avitalfarbstoff 7-AAD ermittelt worden. Reagieren Zellen auf beide Apoptosemarker positiv, befinden sich die Zellen entweder in einem spätapoptotischem Stadium oder in Nekrose. In den untersuchten Leukozytensubpopulationen konnten von Beginn an, sowohl unter dem Einfluss von UVA als auch nach Behandlung mit UVC-Strahlung, spätapoptotische Werte gemessen werden, die nahezu durchgehend mit einem Anteil von ca. 50\% an den bereits Annexin V positiven Zellen korrelierten, was im Laufe der untersuchten Zeit von vier Tagen zu einem kontinuierlichen Anstieg der Spätapoptosewerte führte. Interessanterweise stellte hierbei die bereits oben diskutierte Gruppe der CD14+ Monozyten eine Ausnahme dar, da sie im Vergleich eine im Durchschnitt eindeutig geringere spätapoptotische Rate aufwies. Im Kontext der bereits oben diskutierten heterogenen Meinungen hinsichtlich der Veränderung der Monozyten unter dem Einfluss der ECP-Behandlung ist dies eine Erkenntnis, die weiter untersucht und beobachtet werden sollte.

Da proinflammatorische Reaktionen bei einem Überangebot an apoptotischem, wenn nicht sogar nekrotischem Material entstehen können, ist es im Rahmen der ECP-Therapie von 
entscheidender Bedeutung, dass die durch Bestrahlung verursachte Apoptose eine schrittweise ansteigende Kinetik zeigt, um Entzündungsreaktionen nach Reinfusion bei den Patienten zu vermeiden.

Die Ergebnisse dieser Arbeit sind hinsichtlich einer realistischen und praktikablen Weiterentwicklung der ECP-Therapie insgesamt erfolgversprechend. Ein hochgestecktes, ambitioniertes Ziel für die Zukunft wäre die Weiterentwicklung eben solcher immunmodulatorischer Therapieansätze, um eine Immunsuppression mit ihren vielen unerwünschten Nebenwirkungen künftig weniger häufig notwendig zu machen. Nicht außer Acht zu lassen sind in diesem Prozess jedoch auch kritische Stimmen aus jüngster Zeit, die über eventuelle Risiken und Nebenwirkungen der ECP-Therapie berichten. Im Februar 2018 veröffentlichte die U.S. Food and Drug Administration einen Brief mit dem Appell an ECPpraktizierendes Personal, ein besonderes Augenmerk auf eine Thromboseentwicklung im direkten zeitlichen Zusammenhang mit der ECP-Behandlung zu richten, da es einzelne Erfahrungsberichte von tiefen Beinvenenthrombosen oder Lungenembolien gäbe. Dies seien bis dato nur Einzelfälle, trotzdem müsse weiterhin mit Nachdruck auf einen Zusammenhang geachtet werden (U.S. Food and Drug Administration (FDA) 2018).

Des Weiteren gibt es einen Bericht, der das Auftreten einer Eisenmangelanämie bei CTCL Patienten im Rahmen einer ECP-Therapie in einer retrospektiven Studie beobachtet (Sanford et al. 2018).

Direkte Zusammenhänge zwischen Sekundärerkrankung und ECP-Therapie konnten in beiden Fällen nicht belegt werden, Eine differenzierte Betrachtung dieser Berichterstattung ist dennoch von Wichtigkeit.

\subsection{Stärken und Schwächen der Arbeit}

Die Fragestellung dieser Dissertation, ob eine Bestrahlung der Leukapheresate mit UVC die bisherige Behandlung mit 8-MOP / UVA im Rahmen der ECP zukünftig ersetzen kann, ließ sich nur in Teilen beantworten. Die ersten in vitro Untersuchungen mit $2 \mathrm{~J} / \mathrm{cm}^{2} \mathrm{UVC}$ machten deutlich, dass vor der Durchführung komplexerer Experimente zunächst die optimale Bestrahlungsdosis ermittelt werden muss. Der hier gewählte Ansatz der Messung der Strahlung hinter der verwendeten Plastikoberfläche wies in die richtige Richtung, wobei sich bei der statistischen Auswertung der Daten zeigte, dass in einigen Fällen immer noch signifikante Unterschiede zwischen 8-MOP / UVA $2 \mathrm{~J} / \mathrm{cm}^{2}$ und UVC $6 \mathrm{~J} / \mathrm{cm}^{2}$ gemessen 
wurden. Zusätzliche Untersuchungen mit UVC $8 \mathrm{~J} / \mathrm{cm} 2$ und $10 \mathrm{~J} / \mathrm{cm}^{2}$ wurden als alternativer experimenteller Ansatz in Betracht gezogen, wegen der nur limitiert zur Verfügung stehenden Ressourcen jedoch nicht weiter verfolgt. Die detaillierte Untersuchung der UVCStrahlendosen $2 \mathrm{~J} / \mathrm{cm}^{2}$ und $6 \mathrm{~J} / \mathrm{cm}^{2}$ erlaubte eine robuste und statistisch abgesicherte Auswertung der Ergebnisse, worauf die Stärke der vorliegenden Arbeit beruht. Es fehlen allerdings Untersuchungen zu alternativen Bestrahlungsintensitäten.

Da die Untersuchung ausschließlich auf die Messung der Apoptosemarker konzentriert war, ist die Aussagekraft beschränkt. Die Auswirkungen der unterschiedlich behandelten Lymphozyten auf ein Spender/ Empfänger in vitro Modell sollten weitere Ergebnisse liefern. Im Anschluss an die Untersuchung der apoptoseinduzierenden Wirkung der Alternativstrahlung UVC wurden in einer kleinen Versuchsreihe $(\mathrm{n}=3)$ Mixed Lymphocyte Reactions durchgeführt mit dem Ziel, die Wirkung der ECP-Behandlung und die erlangten theoretischen Erkenntnisse auch in einem in vitro Modell der Gewebeabstoßung zu zeigen. Nach Beendigung der Versuche mit der etablierten Therapie 8-MOP / UVA $2 \mathrm{~J} / \mathrm{cm}^{2}$ zeigten sich die Ergebnisse allerdings noch nicht aussagekräftig, da die erwartete Reaktivitätsreduktion nach ECP-Behandlung nicht signifikant war. Bevor demnach eine Wirkungsüberprüfung der Alternativstrahlung UVC stattfinden kann, legen die erhobenen Daten zunächst eine weitere Untersuchung des MLR-Settings unter der Therapie mit 8-MOP / UVA $2 \mathrm{~J} / \mathrm{cm}^{2}$ nahe.

\subsection{Ausblick}

Die in dieser Arbeit erlangten Erkenntnisse sind hinsichtlich der Alternativstrahlung UVC insgesamt vielversprechend. Nach Berücksichtigung des Dosisleistungsverlusts durch die Absorption an der Plastikoberfläche der Kulturflaschen und dem Ausgleich des Verlusts durch kalkulierte Dosiserhöhung wurden im Vergleich zu der etablierten ECP-Therapie mit 8-MOP / UVA in allen untersuchten Zellpopulationen vergleichbar hohe Apoptosewerte mit alleiniger UVC-Strahlung erreicht. Um das Ziel einer klinischen Studie mit UVC behandelten Leukapheresaten erreichen zu können, sind präklinisch eine ausgedehntere in vitro Dosisfindungsstudie und die Überprüfung der therapeutischen Wirkung in einer optimierten Mixed Lymphocyte Reaction sowie im Tiermodell vielversprechende Ansätze für zukünftige Forschungsarbeiten. 


\section{Zusammenfassung}

Trotz bemerkenswerter Errungenschaften in der Therapieforschung der letzten Jahrzehnte besteht sowohl im Bereich der malignen, hämatologischen Erkrankungen als auch in der Behandlung pathologischer immunologischer Prozesse noch großer Bedarf an Verbesserung.

Während versucht wird, das Gros der Autoimmunerkrankungen mit Immunsuppressiva unter Kontrolle zu halten, muss dabei die steigende Rate an opportunistischen Infektionen in Kauf genommen werden. Gleiches gilt für die Behandlung der GVHD oder einer Abstoßungsreaktion nach Transplantation solider Organe. Die etablierte ECP-Therapie mit 8-MOP / UVA bildet hier, vor allem in Anbetracht der drastisch zunehmenden Antibiotikaresistenzen, die die Behandlung von Infektionen erheblich erschweren, eine außerordentlich wichtige Therapiealternative. Durch die wenig-invasive Vorgehensweise, die gute Verträglichkeit und die Möglichkeit der Reduktion der Immunsuppression, hat sie bei sehr erfolgreichen Therapieergebnissen in den letzten 30 Jahren immer mehr an Bedeutung gewonnen.

Die praktische Durchführung der Therapie durch die manuelle Injektion des erforderlichen 8-MOP weist allerdings eine theoretische Schwachstelle auf. Ein bis dahin geschlossenes Zellentnahmesystem wird eröffnet, gelangt in direkten Kontakt mit der Umgebung und wird somit anfällig für potenzielle bakterielle Kontaminationen. Um die Sicherheit der Patientenbehandlung weiter $\mathrm{zu}$ erhöhen, wurde in der vorliegenden Arbeit eine Alternativstrahlung untersucht, die das Problem der Öffnung des Systems beheben könnte.

Wegen ihrer starken energetischen Eigenschaften wurde in dieser Arbeit die UVC-Strahlung als Forschungsgegenstand gewählt und in ihrer apoptoseinduzierenden Wirkung im direkten Vergleich mit 8-MOP / UVA untersucht. Hierfür wurden MNZ aus Buffy-Coats freiwilliger Spender isoliert und nach verschiedenen Bestrahlungsprotokollen behandelt. Nach einer Anpassung der Dosisleistung, die die Lichtabsorption durch das Plastikmaterial der Zellkulturflasche berücksichtigt, konnte in allen untersuchten Leukozytensubpopulationen eine zur 8-MOP / UVA-Bestrahlung nahezu äquivalente apoptoseinduzierende Wirkung der UVC-Strahlung gezeigt werden.

In einer Subgruppenanalyse von Apoptoseraten der verschiedenen Leukozytensubpopulationen gab es an einzelnen Versuchstagen noch signifikante Unterschiede, die jedoch 
vermutlich mit einer weiteren Dosissteigerung der UVC-Strahlung beseitigt werden könnten, da bereits die Erhöhung der Bestrahlungsdosis von $2 \mathrm{~J} / \mathrm{cm}^{2}$ auf $6 \mathrm{~J} / \mathrm{cm}^{2}$ eine signifikante Steigerung der Apoptoserate zur Folge hatte.

Durch die objektiv gemessenen Ergebnisse der vergleichenden Bestrahlungsversuche von 8-MOP / UVA und UVC, die eindeutig eine ähnliche Wirkung auf die therapeutisch notwenige Apoptose zeigten, ist das Fazit dieser Arbeit ein Erfolg versprechendes.

Mit einer kleinen Versuchsreihe $(n=3)$ wurde in der vorliegenden Arbeit außerdem begonnen, die gewonnenen Erkenntnisse in einer MLR zu testen, wobei festgestellt werden musste, dass in keiner der drei untersuchten Zellgruppen eindeutige Aktivierungsreduktionen nach Anwendung der ECP-Therapie zu erkennen waren. Da sich die Ergebnisse der MLR nach der Behandlung mit 8-MOP / UVA $2 \mathrm{~J} / \mathrm{cm}^{2}$ nicht im signifikanten Bereich befanden, wurde der experimentelle Versuch mit der Alternativstrahlung UVC zunächst nicht durchgeführt, wobei zu untersuchen bliebe, ob Aktivatorsubstanzen wie Anti-CD28 oder Ionomycin evtl. eine gesteigerte Reaktion hervorrufen würden. Die in dieser Arbeit durchgeführte MLR kann, nicht zuletzt auch wegen der geringen Versuchsanzahl und der ausschließlichen Verwendung von 8-MOP / UVA $2 \mathrm{~J} / \mathrm{cm}^{2}$, lediglich als Anstoß für weitere Projekte verstanden werden. Bevor die Wirkung von mit UVC behandelten Zellen im MLRModell in vitro untersucht werden kann, muss zunächst unter abgeänderten Zellkulturbedingungen, wie durch Zugabe von Aktivatorsubstanzen, die Wirkung von 8-MOP / UVA weitergehend überprüft werden.

Bisher beruhen die beschriebenen und vielversprechenden neuen Erkenntnisse über die Alternativstrahlung UVC auf In-vitro-Versuchen, die in Zukunft im In-vivo-Modell auf ihre therapeutische Wirksamkeit und ihre realistische Verwendbarkeit in der ECP-Therapie überprüft werden müssen. 


\section{Anhang}

Tabelle 10: UVC $2 \mathrm{~J} / \mathrm{cm}^{2}$ und UVC $6 \mathrm{~J} / \mathrm{cm}^{2}$, Mittelwerte \pm STABW und p-Werte

Tabelle 11: UVA $2 \mathrm{~J} / \mathrm{cm}^{2}$ und UVC $6 \mathrm{~J} / \mathrm{cm}^{2}$, Mittelwerte \pm STABW und p-Werte

Tabelle 12: Spätapoptose - UVC $2 \mathrm{~J} / \mathrm{cm}^{2}$ und UVC $6 \mathrm{~J} / \mathrm{cm}^{2}$, Mittelwerte \pm STABW und $\mathrm{p}$-Werte

Tabelle 13: Spätapoptose - UVA $2 \mathrm{~J} / \mathrm{cm}^{2}$ und UVC $6 \mathrm{~J} / \mathrm{cm}^{2}$, Mittelwerte \pm STABW und $\mathrm{p}$-Werte 


\begin{tabular}{|c|c|c|c|c|c|c|c|c|c|c|c|c|c|}
\hline & $\begin{array}{ll}5 & \overline{0} \\
0 & 8 \\
1 & 0 \\
1 & 0\end{array}$ & & $\begin{array}{cc} & 0 \\
& 0 \\
0 & \infty \\
3 & 0 \\
1 & 0 \\
2 & 0\end{array}$ & & $\mid \begin{array}{ll}5 & \\
0 & 0 \\
3 & 0 \\
0 & 0 \\
2 & 0\end{array}$ & & $\begin{array}{ll} & \overline{8} \\
0 & 0 \\
0 & 0 \\
1 & 0 \\
0 & 0 \\
2 & 0\end{array}$ & & $\left|\begin{array}{ll}5 & 0 \\
0 & 0 \\
2 & 0 \\
\vdots & 0 \\
2 & 0\end{array}\right|$ & & $\begin{array}{ll}\frac{1}{0} & - \\
\sum_{0}^{2} & \infty \\
1 & 0 \\
0\end{array}$ & & 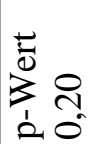 \\
\hline 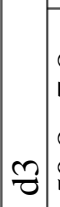 & 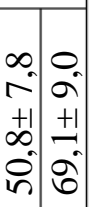 & $\eta$ & 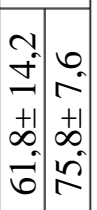 & $\eta$ & 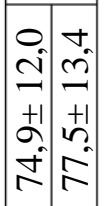 & 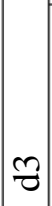 & 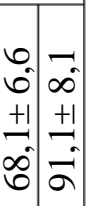 & $\eta$ & 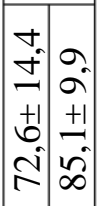 & 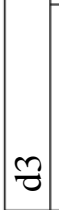 & 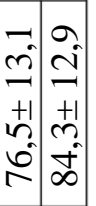 & 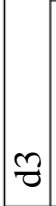 & 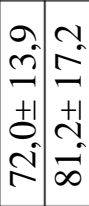 \\
\hline & $\begin{array}{ll}\frac{1}{0} & + \\
0 \\
3 & 8 \\
1 & 8 \\
2 & 0\end{array}$ & & $\begin{array}{ll} & 0 \\
5 & 0 \\
0 & 8 \\
3 & 8 \\
1 & 0 \\
1 & 0\end{array}$ & & $\mid \begin{array}{ll} & \\
0 & 0 \\
3 & 0 \\
1 & 0 \\
2 & 0 \\
0\end{array}$ & & $\begin{array}{ll} & 0 \\
0 & 8 \\
0 & 8 \\
3 & 8 \\
1 & 8 \\
1 & 0\end{array}$ & & 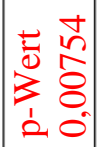 & & $\begin{array}{ll}\frac{1}{0} & m \\
3 & 0 \\
1 & 0 \\
0 & 0\end{array}$ & & 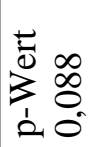 \\
\hline 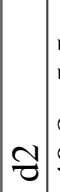 & 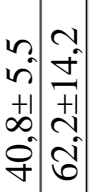 & フै & 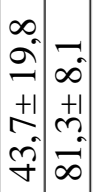 & ชี & 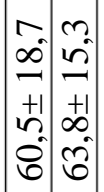 & ชี & 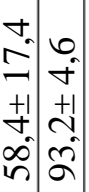 & $\mathcal{\gamma}$ & 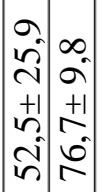 & ชี & 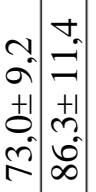 & ชี & 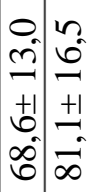 \\
\hline & 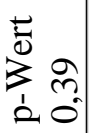 & & $\begin{array}{ll}\overline{0} & \\
3 & 0 \\
1 & 0 \\
0 & 0\end{array}$ & & $\begin{array}{ll}5 & \\
3 & 0 \\
1 & 0 \\
2 & 0\end{array}$ & & $\begin{array}{ll}5 & 0 \\
0 & 8 \\
3 & 8 \\
1 & 0 \\
2 & 0\end{array}$ & & $\mid \begin{array}{cc}5 & t \\
0 & 0 \\
3 & 0 \\
\vdots & 0 \\
2 & 0 \\
0\end{array}$ & & $\begin{array}{ll} & \\
0 & \\
3 & 0 \\
1 & + \\
1 & 0 \\
0 & 0\end{array}$ & & $\begin{array}{l}\frac{1}{0} \\
\sum_{1} \\
\vdots \\
0 \\
0\end{array}$ \\
\hline 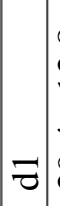 & 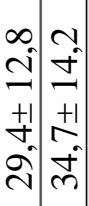 & $\nabla$ & 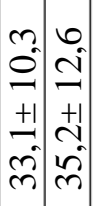 & $\bar{z}$ & 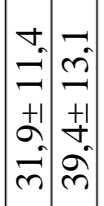 & 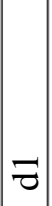 & 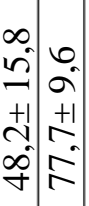 & $\bar{z}$ & 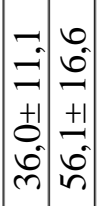 & $\nabla$ & 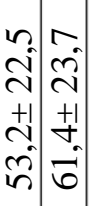 & $\nabla$ & 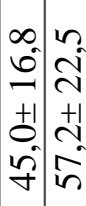 \\
\hline & 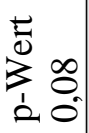 & & $\begin{array}{ll}\overline{0} & \\
3 & \infty \\
1 & 0 \\
2 & 0\end{array}$ & & $\mid \begin{array}{ll}5 & 0 \\
0 & 0 \\
3 & 0 \\
1 & 0 \\
0 & 0\end{array}$ & & 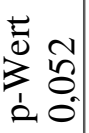 & & 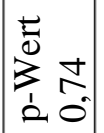 & & $\begin{array}{ll} & \\
0 & \\
3 & n \\
1 & n \\
c & 0\end{array}$ & & $\begin{array}{l}\frac{1}{0} \\
\frac{1}{2} \\
\frac{1}{0}\end{array}$ \\
\hline 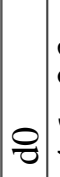 & $\begin{array}{lll}2 & 0 \\
& - \\
+1 & +1 \\
0 & + \\
+ & 0\end{array}$ & 잉 & \begin{tabular}{c|c}
0 & $m$ \\
$i$ & $i$ \\
+1 & +1 \\
$\infty$ & +1 \\
$c$ & $m$
\end{tabular} & 잉 & 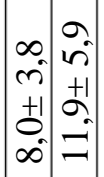 & 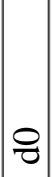 & 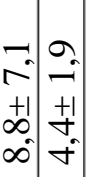 & $\varnothing$ & 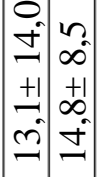 & 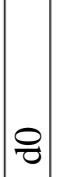 & 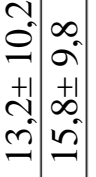 & 잉 & 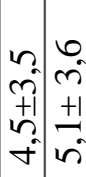 \\
\hline \begin{tabular}{|l} 
\\
0 \\
0 \\
0 \\
0 \\
0
\end{tabular} & 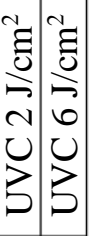 & $\begin{array}{l}\infty \\
\text { 己ิ } \\
\text { 己ิ }\end{array}$ & 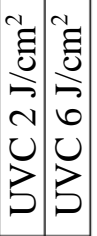 & & 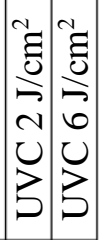 & $\vec{a}$ & 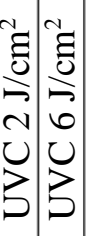 & 气ิ & 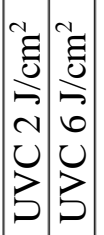 & 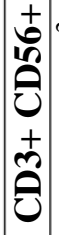 & 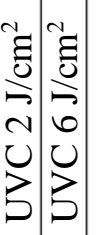 & 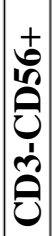 & 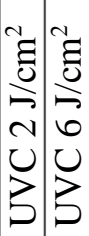 \\
\hline
\end{tabular}




\begin{tabular}{|c|c|c|c|c|c|c|c|c|c|c|c|c|c|}
\hline & $\begin{array}{ll}5 & n \\
0 & 0 \\
3 & 8 \\
1 & 0 \\
2 & 0\end{array}$ & & 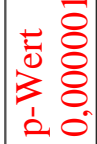 & & $\mid \begin{array}{ll}5 & 2 \\
0 & 0 \\
1 & 0 \\
0 & 0\end{array}$ & & $\begin{array}{ll} & 0 \\
0 & 0 \\
3 & 0 \\
1 & 0 \\
1 & 0\end{array}$ & & $\begin{array}{ll} & 0 \\
3 & 0 \\
1 & 0 \\
0 & 0 \\
0 & 0\end{array}$ & & $\left|\begin{array}{cc}1 & 0 \\
0 & 0 \\
1 & 0 \\
2 & 0 \\
2 & 0\end{array}\right|$ & & 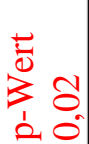 \\
\hline$\eta$ & $\begin{array}{ll}n & 0 \\
0 & 0 \\
+1 & 1 \\
\infty & 1 \\
n & 0 \\
\infty & 0\end{array}$ & $\theta$ & 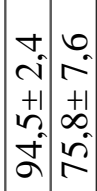 & 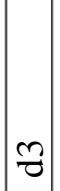 & 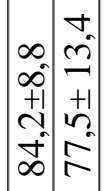 & $\theta$ & 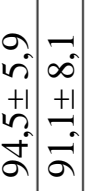 & 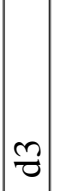 & 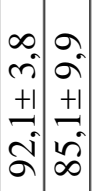 & $\ddot{z}$ & 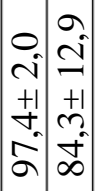 & $\approx$ & 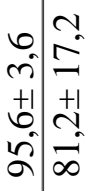 \\
\hline & 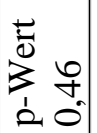 & & $\begin{array}{ll}5 & \\
0 & 0 \\
1 & 0 \\
1 & 0 \\
0 & 0\end{array}$ & & $\begin{array}{ll} & \\
0 & \\
3 & \infty \\
1 & 0 \\
2 & 0\end{array}$ & & 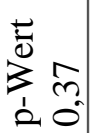 & & 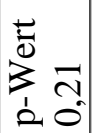 & & 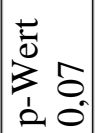 & & $\begin{array}{ll}\frac{1}{0} & m \\
\sum_{1}^{2} & 0 \\
0 & 0\end{array}$ \\
\hline 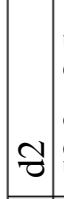 & 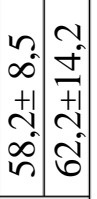 & ชै & \begin{tabular}{c|c}
$m$ & - \\
$\infty$ & $\infty$ \\
+1 & +1 \\
0 & $m$ \\
$\infty$ & $\infty$ \\
$\infty$ & $\infty$ \\
\end{tabular} & ขै & 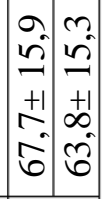 & ขิ & 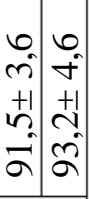 & 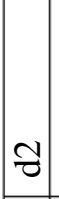 & \begin{tabular}{cc|c}
$n$ & $\infty$ \\
$r$ & 0 \\
+1 & +1 \\
1 & +1 \\
$-\infty$ & 0 \\
$\infty$ & 0
\end{tabular} & శี & 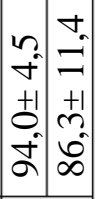 & $\approx$ & 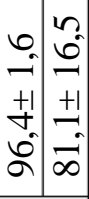 \\
\hline & $\begin{array}{ll}\frac{1}{0} & \\
\sum_{0}^{2} & \infty \\
0 & 0\end{array}$ & & $\begin{array}{ll} & \\
0 & \\
0 & 0 \\
3 & 0 \\
1 & 0 \\
2 & 0\end{array}$ & & $\mid \begin{array}{ll} & 0 \\
& 0 \\
0 & 0 \\
0 & 1 \\
3 & 0 \\
1 & 0 \\
2 & 0\end{array}$ & & $\begin{array}{ll} & \overline{0} \\
5 & 0 \\
0 & 0 \\
3 & 8 \\
1 & 0 \\
2 & 0\end{array}$ & & \begin{tabular}{ll} 
& \multicolumn{1}{c}{} \\
0 & 0 \\
3 & 0 \\
1 & 0 \\
0 & 0
\end{tabular} & & $\mid \begin{array}{cc}\overline{0} & r \\
3 & 0 \\
1 & 0 \\
2 & 0\end{array}$ & & $\frac{L_{0}^{0}}{\sum_{1}^{0}} \frac{\infty}{0}$ \\
\hline $\bar{\sigma}$ & 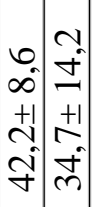 & $\nabla$ & \begin{tabular}{c|c}
$n$ & 0 \\
0 & 0 \\
0 & 1 \\
+1 & +1 \\
0 & 1 \\
$n$ & $n$ \\
$n$ & $n$
\end{tabular} & $\nabla$ & 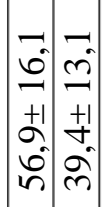 & $\bar{\sigma}$ & 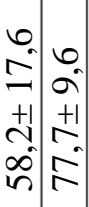 & 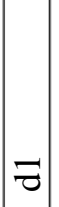 & 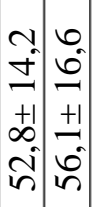 & 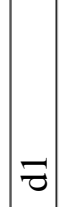 & 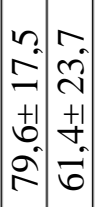 & $\exists$ & 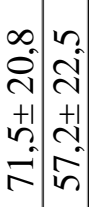 \\
\hline & 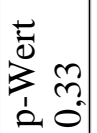 & & $\begin{array}{ll} & \\
0 & 0 \\
1 & 2 \\
\vdots & 0 \\
0 & 0\end{array}$ & & $\begin{array}{ll}\frac{1}{0} & \\
\sum_{1}^{0} & f \\
1 & 0 \\
2 & 0\end{array}$ & & 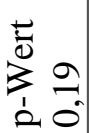 & & 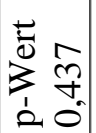 & & $\begin{array}{l}\frac{1}{0} \\
\sum_{1}^{2} \\
\vdots \\
0\end{array}$ & & $\sum_{i}^{\frac{\pi}{0}} \frac{\infty}{0}$ \\
\hline 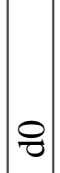 & 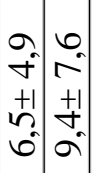 & 유 & 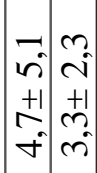 & $\%$ & 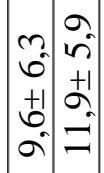 & ㅇ & 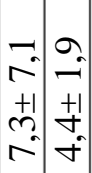 & 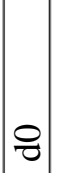 & 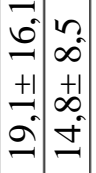 & 8 & 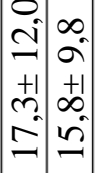 & \% & \begin{tabular}{c|c}
+ & 0 \\
0 & \multicolumn{1}{c}{} \\
+1 & +1 \\
$\infty$ & $=$ \\
$\infty$
\end{tabular} \\
\hline 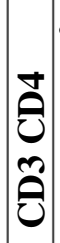 & 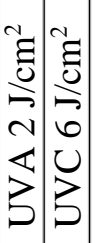 & $\begin{array}{l}\infty \\
\tilde{\theta} \\
\tilde{\theta} \\
\tilde{\theta}\end{array}$ & 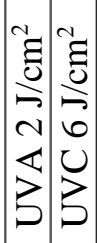 & తి & 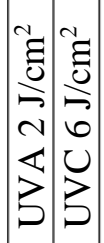 & 宅 & 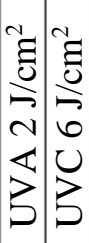 & 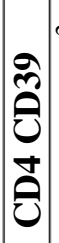 & 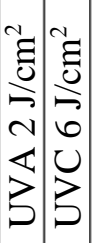 & 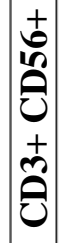 & 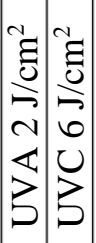 & 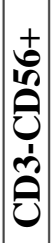 & 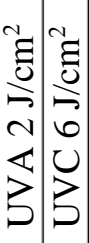 \\
\hline
\end{tabular}




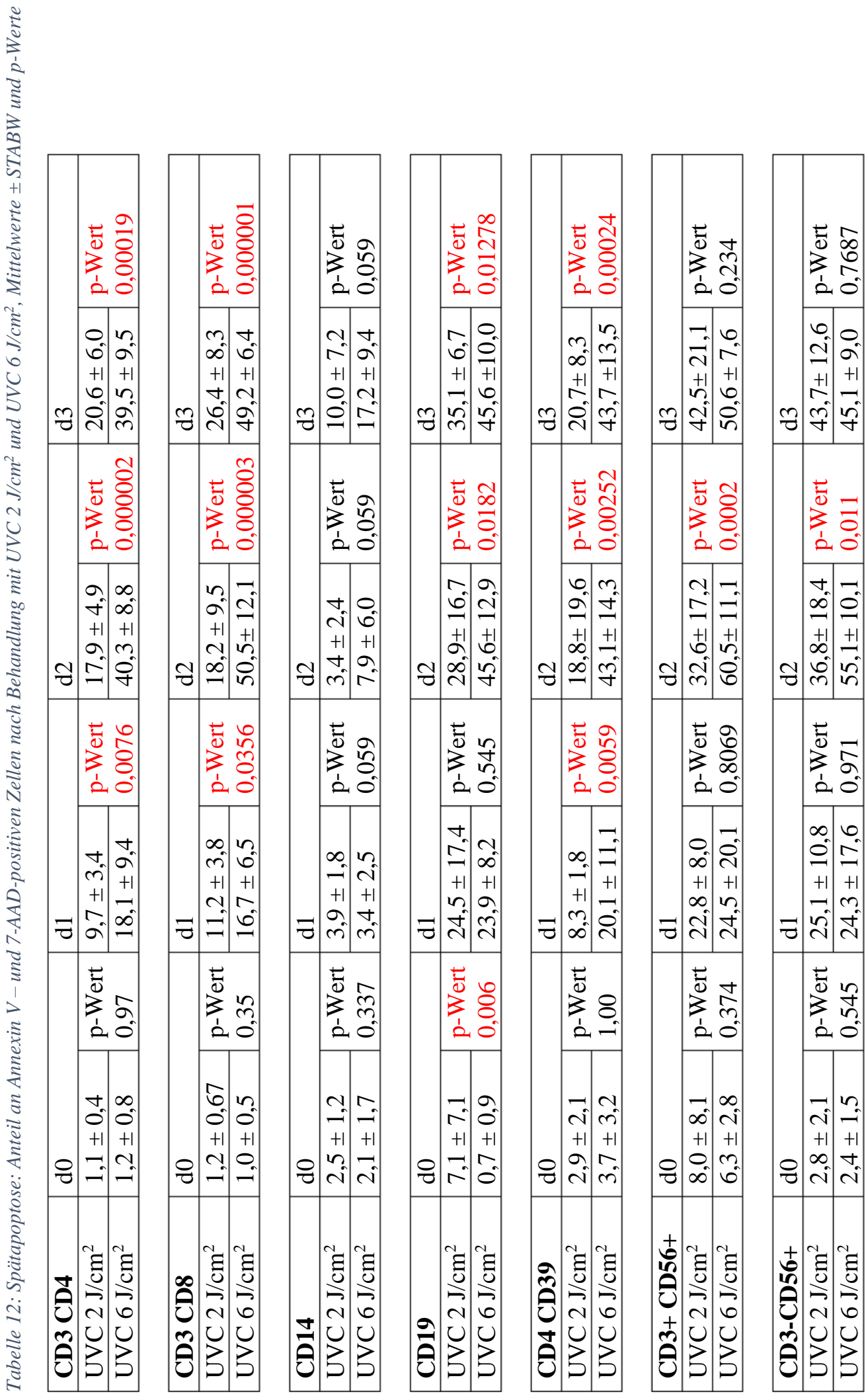




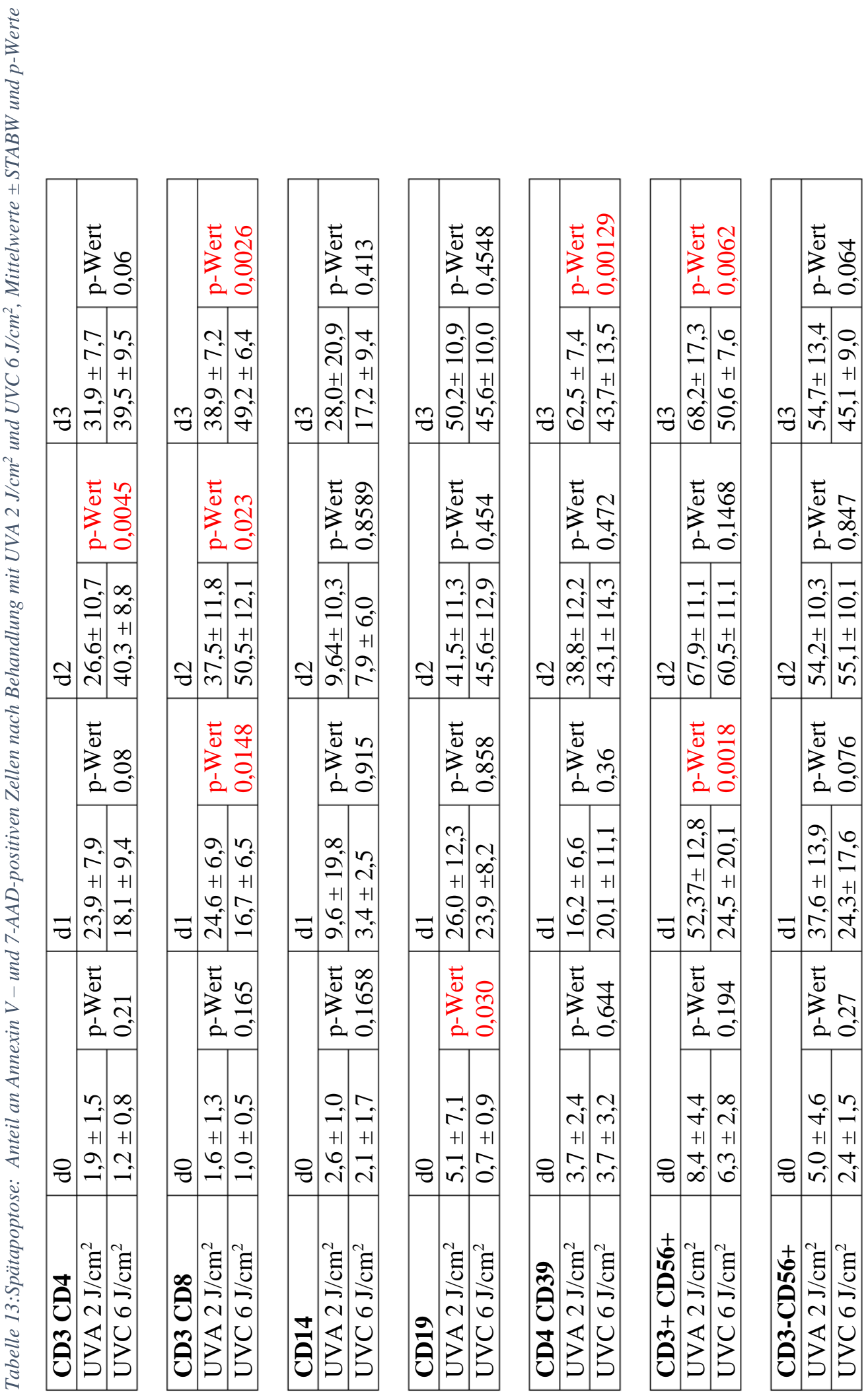




\section{Literaturverzeichnis}

Abdel-Gadir A, Massoud AH, Chatila TA (2018): Antigen-specific Treg cells in immunological tolerance: implications for allergic diseases. F1000Res $\underline{7,38}$

Alousi AM, Uberti J, Ratanatharathorn V (2010): The role of B cell depleting therapy in graft versus host disease after allogeneic hematopoietic cell transplant. Leuk Lymphoma $\underline{51}$, 376-389

Becherucci V, Allegro E, Brugnolo F, Piccini L, Gori V, Bisin S, Bindi B, Ceccantini R, Pavan P, Cunial V et al. (2017): Extracorporeal photopheresis as an immunomodulatory agent: Haematocrit-dependent effects on natural killer cells. J Clin Apher 32, 257-265

Birge RB, Ucker DS (2008): Innate apoptotic immunity: the calming touch of death. Cell Death Differ $\underline{15}, 1096-1102$

Blazar BR, Murphy WJ, Abedi M (2012): Advances in graft-versus-host disease biology and therapy. Nat Rev Immunol $\underline{12}, 443-458$

Budde H, Berntsch U, Riggert J, Legler TJ (2017): In vitro effects of different 8-methoxypsoralen treatment protocols for extracorporeal photopheresis on mononuclear cells. Cent Eur $\mathbf{J}$ Immunol $\underline{42}, 1-9$

Bush K, Courvalin P, Dantas G, Davies J, Eisenstein B, Huovinen P, Jacoby GA, Kishony R, Kreiswirth BN, Kutter E et al. (2011): Tackling antibiotic resistance. Nat Rev Microbiol 9 , 894-896

Chen R-Z, Chen B-A, Cheng J (2015): [Advances on Extrocorporeal Photochemotherapy in the Treatment of Chronic Graft-Versus-Host Disease.] Zhongguo Shi Yan Xue Ye Xue Za Zhi $\underline{23}, 1203-1207$

Cho A, Jantschitsch C, Knobler R (2018): Extracorporeal Photopheresis-An Overview. Front Med (Lausanne) $\underline{5}, 236$

Choi S, Reddy P (2010): Graft-versus-host disease. Panminerva Med 52, 111-124

Christensen I, Heald P (1991): Photopheresis in the 1990s. J Clin Apher 6, 216-220

Coghill JM, Sarantopoulos S, Moran TP, Murphy WJ, Blazar BR, Serody JS (2011): Effector CD4+ T cells, the cytokines they generate, and GVHD: something old and something new. Blood 117, 3268-3276

Cutler C, Kim HT, Bindra B, Sarantopoulos S, Ho VT, Chen Y-B, Rosenblatt J, McDonough S, Watanaboonyongcharoen P, Armand P et al. (2013): Rituximab prophylaxis prevents corticosteroid-requiring chronic GVHD after allogeneic peripheral blood stem cell transplantation: results of a phase 2 trial. Blood 122, 1510-1517

Durazzo TS, Tigelaar RE, Filler R, Hayday A, Girardi M, Edelson RL (2014): Induction of monocyte-to-dendritic cell maturation by extracorporeal photochemotherapy: initiation via direct platelet signaling. Transfus Apher Sci 50, 370-378

Ebrahimi A, Hosseini SA, Rahim F (2014): Immunosuppressive therapy in allograft transplantation: from novel insights and strategies to tolerance and challenges. Cent Eur J Immunol 39, 400-409

Edelson RL (1989): Photopheresis: a new therapeutic concept. Yale J Biol Med $\underline{62}, 565-577$ 
Edelson RL (2014): Mechanistic insights into extracorporeal photochemotherapy: efficient induction of monocyte-to-dendritic cell maturation. Transfus Apher Sci 50, 322-329

Ferrara JLM, Levine JE, Reddy P, Holler E (2009): Graft-versus-host disease. Lancet 373, 15501561

Filipovich AH, Weisdorf D, Pavletic S, Socie G, Wingard JR, Lee SJ, Martin P, Chien J, Przepiorka D, Couriel D et al. (2005): National Institutes of Health consensus development project on criteria for clinical trials in chronic graft-versus-host disease: I. Diagnosis and staging working group report. Biol Blood Marrow Transplant 11, 945-956

Gandelman JS, Song DJ, Chen H, Engelhardt BG, Chen Y-B, Clark WB, Giver CR, Waller EK, Jung DK, Jagasia M (2018): A Prospective Trial of Extracorporeal Photopheresis for Chronic Graft-versus-Host Disease Reveals Significant Disease Response and No Association with Frequency of Regulatory T Cells. Biol Blood Marrow Transplant 24, 2373-2380

Garnett C, Apperley JF, Pavlů J (2013): Treatment and management of graft-versus-host disease: improving response and survival. Ther Adv Hematol 4, 366-378

Girardi M, Berger CL, Wilson LD, Christensen IR, Thompson KR, Glusac EJ, Edelson RL (2006): Transimmunization for cutaneous T cell lymphoma: a Phase I study. Leuk Lymphoma 47 , $1495-1503$

Gorgun G, Miller KB, Foss FM (2002): Immunologic mechanisms of extracorporeal photochemotherapy in chronic graft-versus-host disease. Blood 100, 941-947

Hannani D, Gabert F, Laurin D, Sall M, Molens J-P, Hequet O, Chaperot L, Plumas J (2010): Photochemotherapy induces the apoptosis of monocytes without impairing their function. Transplantation $\underline{89}, 492-499$

Harrison MR, Paul WE (1973): Stimulus-response in the mixed lymphocyte reaction. J Exp Med $\underline{138}, 1602-1607$

Heshmati F (2003): Mechanisms of action of extracorporeal photochemotherapy. Transfus Apher Sci $\underline{29}, 61-70$

Heshmati F (2014): Updating ECP action mechanisms. Transfus Apher Sci 50, 330-339

Huang W, Chao NJ (2017): Memory T cells: A helpful guard for allogeneic hematopoietic stem cell transplantation without causing graft-versus-host disease. Hematol Oncol Stem Cell Ther $\underline{10}, 211-219$

Jagasia MH, Greinix HT, Arora M, Williams KM, Wolff D, Cowen EW, Palmer J, Weisdorf D, Treister NS, Cheng G-S et al. (2015): National Institutes of Health Consensus Development Project on Criteria for Clinical Trials in Chronic Graft-versus-Host Disease: I. The 2014 Diagnosis and Staging Working Group report. Biol Blood Marrow Transplant 21, 389-401.e1

Kitagawa Y, Sakaguchi S (2017): Molecular control of regulatory T cell development and function. Curr Opin Immunol $\underline{49}, 64-70$

Kitko CL, Levine JE (2015): Extracorporeal photopheresis in prevention and treatment of acute GVHD. Transfus Apher Sci 52, 151-156

Kuzmina Z, Greinix HT, Knobler R, Worel N, Kouba M, Weigl R, Körmöczi U, Rottal A, Pohlreich D, Zielinski C et al. (2009): Proportions of immature CD19+CD21- B lymphocytes predict the response to extracorporeal photopheresis in patients with chronic graft-versus-host disease. Blood $\underline{114}, 744-746$ 
Kuzmina Z, Stroncek D, Pavletic SZ (2015): Extracorporeal photopheresis as a therapy for autoimmune diseases. J Clin Apher 30, 224-237

Lorenz K, Rommel K, Mani J, Jin N, Hilgendorf I, Ho AD, Freund M, Schmitt M, Schmitt A (2015): Modulation of lymphocyte subpopulations by extracorporeal photopheresis in patients with acute graft-versus-host disease or graft rejection. Leuk Lymphoma 56, 671675

Mangi RJ, Kantor FS (1975): The multiple mixed lymphocyte reaction: variables important in the test as a measure of lymphocyte competence in man. Yale J Biol Med 48, 217-228

Marques MB, Adamski J (2014): Extracorporeal photopheresis: technique, established and novel indications. J Clin Apher 29, 228-234

Marshall SR (2006): Technology Insight: ECP for the treatment of GvHD — can we offer selective immune control without generalized immunosuppression? Nat Clin Pract Oncol $\underline{3}$, 302-314

Martínez-Laperche C, Buces E, Aguilera-Morillo MC, Picornell A, González-Rivera M, Lillo R, Santos N, Martín-Antonio B, Guillem V, Nieto JB et al. (2018): A novel predictive approach for GVHD after allogeneic SCT based on clinical variables and cytokine gene polymorphisms. Blood Adv $\underline{2}, 1719-1737$

Murphy KM, Weaver C (Hrsg.): Janeway Immunologie. 9. Auflage; Springer, Berlin 2018

Narita K, Asano K, Morimoto Y, Igarashi T, Hamblin MR, Dai T, Nakane A (2018): Disinfection and healing effects of 222-nm UVC light on methicillin-resistant Staphylococcus aureus infection in mouse wounds. J Photochem Photobiol B 178, 10-18

Oliven A, Shechter Y (2001): Extracorporeal photopheresis: a review. Blood Rev 15, 103-108

Palmer JM, Rajasekaran K, Thakar MS, Malarkannan S (2013): Clinical relevance of natural killer cells following hematopoietic stem cell transplantation. J Cancer $\underline{4}, 25-35$

Rezvani K, Mielke S, Ahmadzadeh M, Kilical Y, Savani BN, Zeilah J, Keyvanfar K, Montero A, Hensel N, Kurlander R et al. (2006): High donor FOXP3-positive regulatory T-cell (Treg) content is associated with a low risk of GVHD following HLA-matched allogeneic SCT. Blood 108, 1291-1297

Richet C, Huynh A, Dimeglio C, Borel C, Lepage B, Boulinguez S, Marguery MC, Paul C, Bulai Livideanu C (2018): Extracorporeal Photopheresis: An Efficacious and Well-Tolerated Treatment for Cutaneous and Oral Mucosal Chronic Graft-versus-Host Disease. Dermatology 234, 23-30

Sakaguchi S, Yamaguchi T, Nomura T, Ono M (2008): Regulatory T cells and immune tolerance. Cell $\underline{133}, 775-787$

Sanford KW, Balogun RA (2012): Extracorporeal photopheresis: clinical use so far. J Clin Apher 27, 126-131

Sanford KW, Anderson J, Roseff S, McPherson RA (2019): Iron Deficiency Anemia in Patients Undergoing Extracorporeal Photopheresis for Cutaneous T-Cell Lymphoma. Lab Med $\underline{50}$, 29-33

Schiller M, Klemke CD, Arnold A, Booken N, Hanneken S, Hölzle E, Kaatz M, Schwarz T, Weichenthal M, Hillen U (2011): Leitlinie - extrakorporale Photopherese.

Leitlinie im Auftrag der Arbeitsgemeinschaft Dermatologische Onkologie (ADO) der Deutschen Krebsgesellschaft und der Deutschen Dermatologischen Gesellschaft https://www.awmf.org/uploads/tx_szleitlinien/0130721_S1_ECP_Extrakorporale_Photopherese_2011_abgelaufen.pdf 2011 
Schmid D, Grabmer C, Streif D, Lener T, Schallmoser K, Rohde E (2015): T-cell death, phosphatidylserine exposure and reduced proliferation rate to validate extracorporeal photochemotherapy. Vox Sang $\underline{108}, 82-88$

Singer S, Berneburg M (2018): Phototherapy. J Dtsch Dermatol Ges $\underline{16}$, 1120-1129

Situm M, Bulat V, Majcen K, Dzapo A, Jezovita J (2014): Benefits of controlled ultraviolet radiation in the treatment of dermatological diseases. Coll Antropol 38, 1249-1253

Socié G, Ritz J (2014): Current issues in chronic graft-versus-host disease. Blood 124, 374-384

Sung AD, Chao NJ (2013): Concise review: acute graft-versus-host disease: immunobiology, prevention, and treatment. Stem Cells Transl Med 2, 25-32

Taverna F, Coluccia P, Arienti F, Birolini A, Terranova L, Mazzocchi A, Rini F, Mariani L, Melani C, Ravagnani F (2015): Biological quality control for extracorporeal photochemotherapy: Assessing mononuclear cell apoptosis levels in ECP bags of chronic GvHD patients. J Clin Apher $\underline{30}, 162-170$

Thomas ED, Storb R, Clift RA, Fefer A, Johnson L, Neiman PE, Lerner KG, Glucksberg H, Buckner CD (1975): Bone-marrow transplantation (second of two parts). N Engl J Med 292, 895-902

Ventura A, Vassall A, Robinson E, Filler R, Hanlon D, Meeth K, Ezaldein H, Girardi M, Sobolev O, Bosenberg MW et al. (2018): Extracorporeal Photochemotherapy Drives Monocyte-toDendritic Cell Maturation to Induce Anticancer Immunity. Cancer Res $\underline{78}$, 4045-4058

Ward DM (2011): Extracorporeal photopheresis: how, when, and why. J Clin Apher 26, 276-285

Welniak LA, Blazar BR, Murphy WJ (2007): Immunobiology of allogeneic hematopoietic stem cell transplantation. Annu Rev Immunol 25, 139-170

Wu X, Hu X, Hamblin MR (2016): Ultraviolet blood irradiation: Is it time to remember "the cure that time forgot"? J Photochem Photobiol B 157, 89-96

Yin R, Dai T, Avci P, Jorge AES, Melo WCMA de, Vecchio D, Huang Y-Y, Gupta A, Hamblin MR (2013): Light based anti-infectives: ultraviolet C irradiation, photodynamic therapy, blue light, and beyond. Curr Opin Pharmacol 13, 731-762

Zhao H, Bo C, Kang Y, Li H (2017): What Else Can CD39 Tell Us? Front Immunol $\underline{8}, 727$

U.S. Food \& Drug Administration (FDA) (2018): Death and Pulmonary Embolism Related to Extracorporeal Photopheresis (ECP) Treatment - Letter to Health Care Providers. https://www.fda.gov/MedicalDevices/Safety/LetterstoHealthCareProviders/ucm595147.ht m, abgerufen am: 19.12.2018 
Ein besonderer Dank gilt zunächst der Abteilung Transfusionsmedizin der Universitätsmedizin Göttingen und Herrn Prof. Dr. Riggert, der durch die Bereitstellung von Mitteln und Ressourcen dieses Projekt möglich machte.

Für engagierte Diskussionen, konstruktives Feedback und die Begleitung meiner Arbeit möchte ich meinen Betreuern Herrn Prof. Dr. T. Legler und Herrn. Prof. Dr. I. Bogeski herzlich danken.

Konstruktive und beständige Unterstützung während des gesamten Projektzeitraums erhielt ich außerdem von Herrn Dr. H. Budde. Er gewährte mir einen Einblick in kritische Wissenschaft und gab mir wertvolle Anregungen, wofür ich ihm in besonderer Weise danke. 